Portland State University

PDXScholar

4-2005

\title{
Development and Validation of the Sustainability Climate Survey
}

David Edward Hall

Portland State University

Follow this and additional works at: https://pdxscholar.library.pdx.edu/open_access_etds

Part of the Industrial and Organizational Psychology Commons, and the Social Psychology Commons Let us know how access to this document benefits you.

\section{Recommended Citation}

Hall, David Edward, "Development and Validation of the Sustainability Climate Survey" (2005).

Dissertations and Theses. Paper 2570.

https://doi.org/10.15760/etd.2567

This Thesis is brought to you for free and open access. It has been accepted for inclusion in Dissertations and Theses by an authorized administrator of PDXScholar. Please contact us if we can make this document more accessible: pdxscholar@pdx.edu. 


\begin{abstract}
An abstract of the thesis of David E. Hall for the Master of Science in Psychology presented April 5, 2005.
\end{abstract}

Title: Development and Validation of the Sustainability Climate Survey

Motivated by an assumption of and concern about the unsustainable trajectory of modern human civilization, the purpose of this study was to develop a measurement tool to assist organizations striving to align their operations with principles of sustainability. The relevant context is established with consideration of the dimensions of environment, society and economy, as well as their interconnections, with an eye towards sustainability. Some of the challenges and opportunities presented to organizations by the current unsustainable trajectory are reviewed. The social constructs of culture and climate (organizational and psychological) are discussed as important to understand organizational life. I propose the notion of a sustainability climate to represent factors within the organization that are theorized as important for successfully integrating the principles of sustainability into organizational decision-making and routine behaviors.

Items were developed to tap the theorized constructs and were administered to a population of university employees $(\mathrm{N}=252)$. The study explored construct 
validity of these measures through exploratory factor analysis, assessment of internal consistency, convergent and divergent validity, and criterion validity. Results provide preliminary evidence for the reliability and validity of the sustainability climate factors (perceived top-management support, shared vision, employee involvement, rewards, sustainability norms), and factors of sustainability beliefs (personal understanding, supportive attitude, and positive engagement). These factors' power predicting the criteria, sustainability role expectations, sustainability role behaviors, and environmental stewardship demonstrates the potential to improve upon the instrument. Limitations of the present study are discussed and appropriate application of the Sustainability Climate Survey is explored. 


\title{
DEVELOPMENT AND VALIDATION OF THE SUSTAINABILITY CLIMATE SURVEY
}

\author{
by \\ DAVID E. HALL
}

A thesis submitted in partial fulfillment of the requirements for the degree of

\section{MASTER OF SCIENCE \\ in PSYCHOLOGY}

Portland State University 2005 
Dedicated to the passengers of spaceship Earth 


\section{ACKNOWLEDGEMENTS}

This project would not have been possible without the support and inspiration of Mother Earth, and many people there within.

Much gratitude is felt for all the Shambala Warriors of the global community who recognize the profound injustices humanity is perpetuating against our planet and ourselves. I've been enriched by so many perspectives, and inspired by visions of hope. I look forward to continuing this journey with you.

Thank you to everyone within the Portland State University community who saw value in the idea and helped bring it fruition. Special thanks to Michele Crim, PSU's former Sustainability Coordinator of Operations, for her faith in the idea of this project, and her support along the way. Thanks to the participants of SWARM, especially, Alisa Kane, Janell Jures, Paul DeBlock, and Susan Marcus for their feedback and encouragement. Jay Kenton and Mike Irish for their endorsement, and all the participants who volunteered their time and thoughts that breathed life and meaning into the project.

Appreciation to my committee, Bob Sinclair, Donald Truxillo, Scott Marshall, and Virginia Butler, for humbly fulfilling their duties as guardians of the degree. As well as for their guidance, for challenging me to go further, and for patience throughout the process.

Words cannot say how blessed I feel for being part of such a wonderful family, immediate and extended. Mom and Dad, thank you for instilling in me a set of values that embrace a broader sense of Self, and for the stable foundation that has 
enabled exploration of who I truly am. A special shout out to my brother, Loren, who offers an infectiously provocative view and approach to life. As you always say, I'm glad we're on the same team.

Special acknowledgement goes to my partner, Lisa, for her love, patience, and support. I'm so grateful for all the joy you bring into my life.

Finally, a humble tribute to All That Is, which enables the marvelous gift of Life. May we recognize the value of this gift and be wise enough to treat it with care. 


\section{TABLE OF CONTENTS}

\section{PAGE}

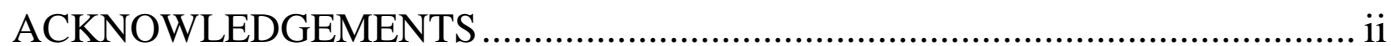

LIST OF TABLES ………………………........................................................ vi

LIST OF FIGURES …….................................................................................. vii

\section{CHAPTER}

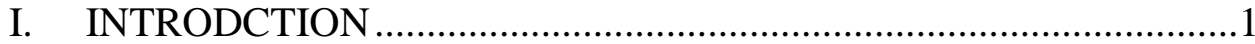

II. REVIEW OF THE LITERATURE....................................................

Environmental Dimension .........................................................

Social and Economic Dimensions ................................................5

Aligning the Spheres .........................................................13

Towards Sustainability at the Organizational level ......................18

Organizational Culture and Climate ..........................................22

III. THE MEASUREMENT NEED ......................................................

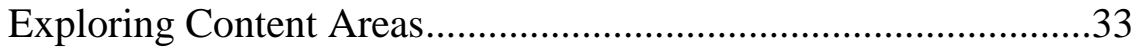

Proposed Content Areas..............................................................37

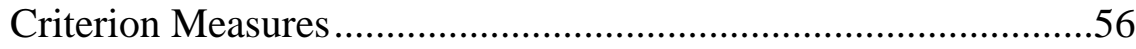

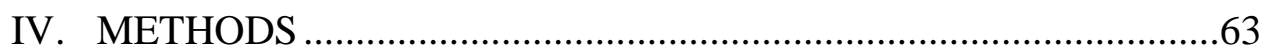

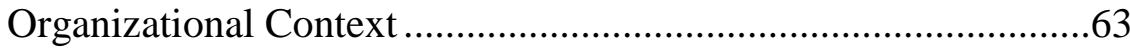

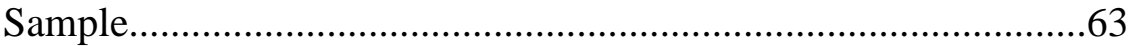

Measurement Process..................................................................64

Sustainability Climate Measures..............................................65

Sustainability Beliefs Measures ...............................................66

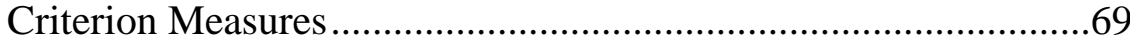

Quality of Work Life Measures ................................................70

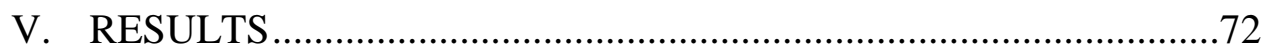

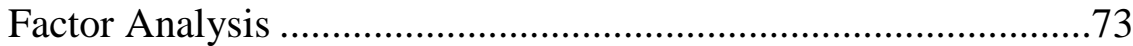

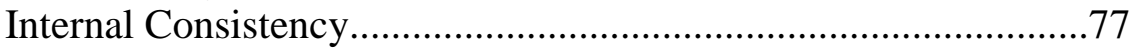

Convergent and Divergent Validity .........................................79 
Criterion Validity ............................................................8

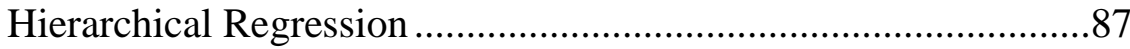

Predicting Environmental Stewardship Items............................90

From Psychological Climate to Organizational Climate ...............91

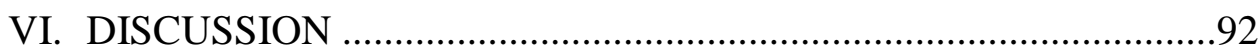

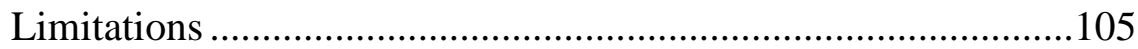

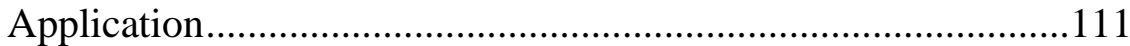

Closing Remarks ............................................................. 115

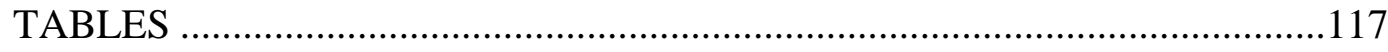

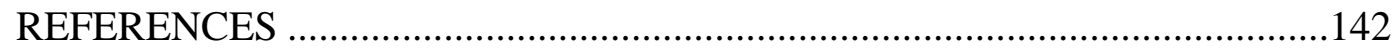

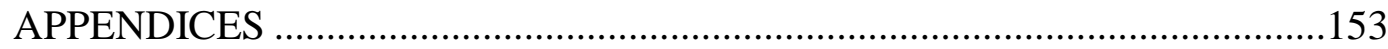

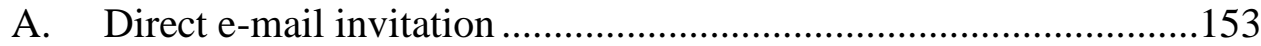

B. Currently posting ................................................................. 154

C. Facilities \& Planning intro letter ............................................. 155

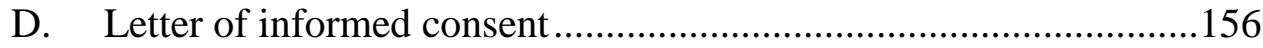

E. The Sustainability Climate Survey ..............................................157 


\section{LIST OF TABLES}

PAGE

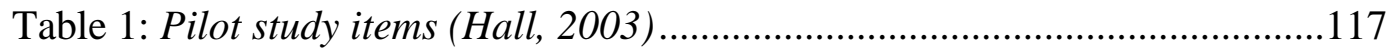

Table 2: Factor loadings for items 8-15 (minus 13) (Hall, 2003) ....................118

Table 3: Factor Loadings for items 24-43 (minus 26, 39, 41) (Hall, 2003) ........119

Table 4: Correlations Matrix and Alphas (Hall, 2003) .....................................120

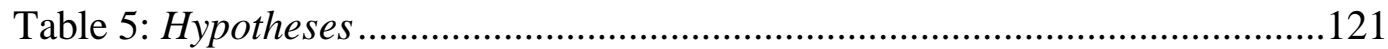

Table 6: Sustainability Climate Survey Item List..............................................122

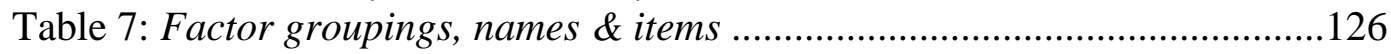

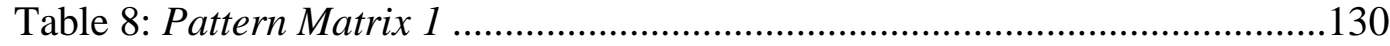

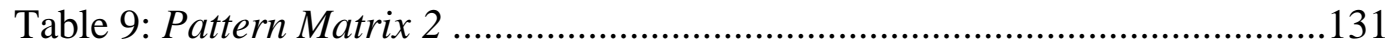

Table 10: Pattern Matrix of higher-order FA.....................................................132

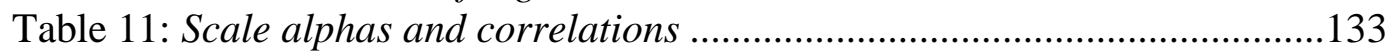

Table 12: Discriminate Validity and Criterion Validity Correlations..................134

Table 13: Organizational profile of SCS measures ...........................................135

Table 14: Correlations between Climate Measures and ES items......................136

Table 15: Hierarchical regression analysis of sustainability climate factors on SRE, controlling for demographics ................................137

Table 16: Hierarchical regression analysis of sustainability climate factors on SRB, controlling for demographics .................................138

Table 17: Hierarchical regression analysis of sustainability beliefs factors on SRB, controlling for demographics....

Table 18: Hierarchical regression analysis of sustainability beliefs factors on ES, controlling for demographics

Table 19: Hierarchical regression analysis of sustainability climate and sustainability beliefs factors on SRB, controlling for demos 


\section{LIST OF FIGURES}

PAGE

Figure 1: Common depiction of the 3 dimensions of sustainability and their overlaps. Operating within the nexus is the goal of the sustainability $(\underline{\mathbf{S}})$ movement ........................................................14

Figure 2: Embeddedness of Economy within Society within the Environment, with Matter, Energy \& Info flows.....................................15

Figure 3: Model of levels relevant to the SCS .....................................................32

Figure 4: Investigation of interaction between Sustainability Norms and Sense of Community on Sustainability Role Behaviors ..................85 


\section{Sustainability Climate Survey 1}

\section{CHAPTER I}

\section{INTRODUCTION}

In fourteenth century England, the general village structure consisted of homes arranged closely together, in proximity to a communal pasture for people to put their livestock out to graze. The communal pasture represents the commons, a resource available to every member of the community to provide for individual need. In these villages, one's livelihood was tied to one's ability to rear livestock. Clever individuals realized they could enhance their wealth by putting out more livestock to graze at a limited personal cost. As more individuals adopted this strategy, the ability of the commons to provide the necessary vegetation to support the livestock became overwhelmed. Without the ability to raise livestock to provide for human sustenance, village after village collapsed. What appeared to be a logical practice from the individual perspective proved to conflict with the interests of the community as a whole, and thus, eventually conflicted with the interests of the individual. The story provides an exemplar case of the tragedy of the commons (Hardin, 1968), illustrating the inter-relationships that exist between the three domains of ecology, society, and economy. Ultimately, when talking about human systems these three domains should be considered as inseparably interconnected.

This study was motivated by an assumption of and concern about the unsustainable trajectory of modern human civilization that could equate to a tragedy of the commons on a global scale. I establish the relevant context by considering the dimensions of environment, society and economy, their interconnections, with 
an eye towards sustainability. Attention of my literature review is focused at the level of organizations that have recognized the challenges and opportunities presented by the present unsustainable trajectory. The social constructs of culture and climate are discussed as important to understand organizational life and its influence on employee behavior. The notion of a sustainability climate is proposed to represent factors within the organization that are theorized as important for successfully integrating the concept of sustainability into organizational decisionmaking and routine behaviors. The Sustainability Climate Survey (SCS) was developed to assess the proposed factors at an individual level, thus measuring psychological climate. To claim the presence of an organizational climate, analysis is then warranted to determine whether there is consistency among the individual responses throughout the participating organization. The SCS is intended as a measurement tool to help organizations strategically guide their internal efforts towards sustainability. To provide evidence for this practical application, this study administered the SCS to a population of university employees and sought evidence of construct validity by analyzing the data through exploratory factor analysis, assessment of internal consistency, assessment of divergent and convergent validity, and assessment of criterion validity. Hierarchical regressions were also conducted to determine the unique variance accounted for by the different factors, and the practice of assessing consistency across individual's responses to establish organizational climate is demonstrated. 


\section{CHAPTER II}

\section{REVIEW OF THE LITERATURE}

\section{Environmental Dimension}

At this present moment there may be a tragedy of the commons occurring on a global scale. The earth's resources vital to sustain life (e.g., clean air, fresh water, and productive topsoil) are in decline under the demands of an increasing world population and mass consumption (Goudie, 1990). Human activity threatens fresh water supplies through over-consumption, and the introduction of sewage, infectious agents, synthetic chemicals, organic chemicals, mineral substances, sediments, radioactive substances, and heat into waterways (Strandberg, 1971, Malmqvist \& Rundle 2002). Significant atmospheric changes have been observed, attributed to gasoline emissions (e.g., $\mathrm{CO}_{2}$, methane, chlorofluorocarbons (CFCs) nitrous oxide and others), aerosol generation, deforestation, over-grazing, and other human activities (Goudie, 1990). One of the major environmental concerns is the observed trend of global warming, widely attributed to the consumption of fossil fuels and subsequent release of $\mathrm{CO}_{2}$ into the atmosphere. While still debated, and difficult to quantify, the potential implications of global warming range from extreme and unusual weather patterns (Intergovernmental Panel on Climate Change [IPCC], 2001) to increased risk of disease migration through insect populations that thrive in conditions of warmer temperatures (Epstein, et al, 1998, Epstein, 1999). Additionally, increases in $\mathrm{CO}_{2}$ and global temperatures appear to threaten the 
survival of coral reefs, which act as important carbon sinks, the loss of which could hasten the global warming problem (Hughes et. al., 2003).

Human activity is also associated with a loss of biodiversity. For example, extinction rates are the highest on record since the Pleistocene Age, a phenomenon that correlates with human expansion and dwindling areas of natural habitat for many species (Goudie, 1990). According to Myers (1979), the rate of species decline due to human activity was 1 every 4 years from 1600-1900, rose to 1 per year after 1900 , to increase to 1 every day at the time of his research. The rate of decline appears to follow an exponential growth curve, as it is estimated that the planet now may lose as many as 30,000 species per year (Eldredge, 1998). It should be acknowledged that estimating the rate of species extinction is difficult to accurately quantify due to limited knowledge of the number of existing species and the challenges of continuously monitoring populations over the vastness of the planet. While these estimates may be conservative or overstated it is widely agreed that biodiversity is declining at alarmingly high rates (World Wildlife Fund, 2004). Further, Travis (2003) draws attention to the coupling of climate change with the reduction of available habitat as having potentially devastating effects on biodiversity as species attempt to adapt to climate changes with reduced availability of habitable area suited for their biological needs.

The concern raised by these documented pressures of human activity and subsequent loss of biodiversity is that they threaten the health of entire ecosystems (tropical/ temperate rainforests, wet lands, grasslands, and oceanic ecosystems) that 
provide essential life support processes (Goudie, 1990). Beattie and Ehrlich (2001)

illustrate human dependence on the processes of nature (e.g., water purification, oxygen production, generation of nutrients) and the complex web of biodiversity required for these processes to function. They call for the preservation of biodiversity in the name of preserving the services of the processes as well as preserving the opportunity to tap newly discovered and yet unknown services nature may be able to provide. Recognizing human dependence on natural systems, Beattie and Ehrlich (2001) state, "Conservation is not just for environmentalists, it is everyone's business." They go on to pose the question, "Who can afford to ignore the natural processes that keep us alive?" (p. 225)

Summarizing the current predicament, the Earth's resources are in decline, and human demand upon those resources is increasing. Already our demand exceeds the Earth's carrying capacity, defined as, "the maximum (load) of a given species that can be supported indefinitely in a defined habitat without permanently impairing the productivity of that habitat" (Rees, 1996, p. 226). Fundamentally, the trend is unsustainable and will be reversed either through conscious human action to reduce demands and restore the natural resource capacity, or through the collapse of human villages that are dependent on the Earth's commons.

\section{Social and Economic Dimensions}

Understanding of the environmental problems we face today and the threats they pose to the future is enhanced by an appreciation of relationships with some social and economic factors. These social and economic factors in themselves 
reflect societal well-being. Subsequently, concerns about the health and stability of society are raised when examining trends of some socio-economic indicators.

Some factors and critical aspects of these trends are discussed below, including the concerns of poverty, interpersonal violence, inequality, the consumptive agenda of the economy, and declines in community engagement. Additionally, and of particular relevance to this study, some aspects bear direct relevance to the work place, such as stress and job satisfaction. One theme that runs through this review is the well-being of humans and human systems.

Poverty. One of the primary rationales for including the social dimension in the conversation on sustainability is recognition that there are intimate links between environmental problems and social issues. As recognized by the United Nations Development Program (UNDP, 1994; UNDP, 1998) people in impoverished conditions will seek to satisfy their basic needs via whatever means are available to them. Often this translates to contributing to rapid deforestation (as witnessed in regions of the world's tropical rainforests), over-fishing, poaching of endangered species, engaging in unsustainable farming practices, manufacturing goods and products without regard for environmental impacts, as well as participating in criminal activities. "Thus, the stocks and flows of natural capital that we all rely on for survival will be threatened if society does not equitably share resources and provide basic goods, services, jobs and incomes with the world's growing population" (Doppelt, 2003, p. 50). 
This phenomenon is not limited to developing countries; the same trends can be seen in the United States. For example, many small towns throughout the Northwest are struggling to survive due to declines in the logging industry, which has served as the cornerstone of these local economies. Availability of high-yield forests has waned after decades of heavy harvesting, and as support has galvanized for the preservation of public lands and for the protection of endangered species. However, pressures on these forests is increasing as today's depressed economy provides an atmosphere of increased political support for tapping into natural resources as a means of economic stimulus (Robinson, 2004; Oregon Natural Resource Council, 2002).

Economic Disparity \& Violence. Another concern on the social-economic front is that throughout the United States economic disparity between the rich and the poor is increasing (Shapiro \& Greenstein, 1999; Wolff, 2000), a trend that also appears to hold true globally (UNDP, 1998). A major concern raised is that conditions of poverty, and economic and political inequality increase personal and regional violence (UNDP, 1994). Violence under the label of "terrorism" has become a major focus of attention in recent years. Inquiry into the root cause of terrorism suggests that social injustice in the form of inequality, poverty, and the poor prospects for economic opportunity probably is a contributing factor of violent behavior against perceived oppressors (Ehrlich \& Jianguo, 2002; Wessels, 2002). As well as the obvious cost in human lives and health, violence jeopardizes the stability of regions and societies by aggravating political differences, increasing the 
risk of large scale conflict, as well as threatening economic systems and jeopardizing both personal safety and personal liberties.

Structural Violence. Brumbaugh-Smith, Wollman, and Yoder (2002) developed a national index of violence that adopts a broad definition of violence from Iadacola and Shupe (1998), viewing “violence (as) an action or structural arrangement that results in physical or non-physical harm to one or more persons" (Wollman, 2002, p. 1). This definition includes both personal violence (inter and intra-personal), and societal violence (institutional and structural). Personal violence is well understood. Structural violence represents "violence that occurs in the context of establishing, maintaining, extending, reducing or as a consequence of the hierarchical ordering of categories of people in a society" (Iadacola \& Shupe, 1998, as cited in Wollman, 2002, p. 2). At the heart of the matter is the question of whether the society is structured to address unmet basic needs of food, housing, health care and education. Brumbaugh-Smith, Wollman, and Yoder's (2002) findings illustrate dramatically increasing societal violence as indicated by emergency food requests, overflowing homeless shelters, numbers of American's without health insurance, and concerns about educational quality. The authors call to attention the threats that these insidious, less dramatic forms of violence might have in jeopardizing the integrity of the U.S. society. Without major structural changes, improvements are not projected for the foreseeable future. Reflecting on these indicators as "social negligence," Wollman ponders, "we are a society that talks about equality and the value of equality, but our institutions and social 
structures don't always serve that ideal. Sometimes they do the opposite" (as cited in Large, 2004. p. 1).

Beyond purely altruistic motives, society has a vested interest in addressing the problem of poverty. Poverty can both contribute to acceleration of the consumption of natural resources, and provide conditions that enhance violent interpersonal conflict, which puts human life at risk as well as social stability. Structural violence appears to contribute to issues of inequality and poverty, enhancing the desperation of people to satisfy their needs by whatever means necessary.

Treadmill of Production. Implicit in much of the above statements is the premise that the natural environment and society provide the context within which an economic system is embedded (see Figure 2). However, traditional modes of economic thinking and practice fail to account for the costs imposed on the social and environmental dimensions that the economy ultimately depends upon (Hart, 1995). Rather, the objective of growing financial capital compels efforts to reduce labor costs, exploit natural resources, and externalize the cost of environmental and social impacts (Hawken, 1993; Korten, 2001; Schnaiberg, 1980). Schnaiberg and Gould (1994) coin the present characteristics of economic activity as the "treadmill of production" (TOP). It should be acknowledged that a functioning society depends on a healthy economy to provide the stable conditions necessary to meet human needs; individual needs, and from a government perspective, broad social welfare and security. Subsequently, individuals and government become servants 
to the ceaseless expansion demanded by the TOP, the dominant economic model of the times (Schaiberg \& Gould, 1994). While short-term societal benefits are attained, the inherent conflict between the TOP's economic expansion with the spheres of society and the natural environment suggests the system is ultimately unsustainable.

Stress and Quality of Work Life. The nature of the TOP model creates increased pressure and demand for productivity at the levels of economies, organizations, and ultimately, individuals. Subsequently, hypertension is becoming known as a disease of industrialized society (Landsbergis, et al. 2003). Spielberger, Vagg, and Wasala (2003) estimate that stress disorders cost the U.S. economy $\$ 150$ billion annually due to decreased productivity, absenteeism, litigation, and job burnout. Such a figure says nothing of the human health costs, suffering, or general reduction in quality of life suffered by those experiencing high stress. While all the above issues (e.g., poverty, TOP, structural violence) have been discussed on a macro level, the workplace provides a local level setting where these trends can be reinforced, or countered. In other words, organizational practices and conditions of the work environment can support or undermine the well-being of employees and surrounding communities. While many matters such as toxic exposure and wage compensation are highly relevant to the conversation of sustainability, for the purposes of this study, I will focus on the notions of stress and general well-being. The risk to physical and mental health due to stress is most pronounced when workers face high workload demands or pressures, combined with low 
control or decision latitude in meeting those demands (Therorell, 2002; Karasek \& Theorell, 1990). Thus, providing employees with enhanced influence and autonomy over their work processes is an effective strategy to mitigate the risks of a demanding work environment.

The availability of social support is another factor that helps determine whether the experience of stress will significantly affect employee health and wellbeing. For example, research suggests that high levels of peer and supervisor social support in the workplace reduce the risks of cardiovascular disease (Schnall, Belkic, Landsbergis, \& Baker, 2000). Conversely, the absence of available social support, in combination with high job strain, labeled iso-strain for isolated high-strain work, further increases an employee's risk of CVD (Schnall, et al., 2000). Thus, employers should be sensitive to the level of strain imposed on employees and provide a work environment that enables social support.

Beyond the experience of stress, but related, is the overall satisfaction employees enjoy in their jobs. The notion of job-satisfaction can be understood as an affective response to facets of work, such as the conditions of the work environment, compensation, and opportunities to employ and develop skills (Bullock, 1984). Job satisfaction can be considered a general measure of psychological well-being in the workplace, and an important organizational climate indicator (Bruce \& Blackburn, 2002; Bullock, 1984). While the popular notion that job-satisfaction results in greater worker performance is not consistently 
demonstrated in research (Bruce \& Blackburn, 2002), the promotion of high jobsatisfaction can be an end in itself for socially conscious organizations.

Collectively, the four paragraphs above speak to the well-being and general quality of work-life experienced by employees within given organizational settings. The degree to which an organization is able to reduce employee exposure to stress, mitigate the risk of exposure where it exists through decision-latitude, and access to social support, as well as provide a satisfying work experience that reflects upon whether the organization enables the health and well-being of its employees.

Community Engagement. The sustainability movement has embraced the notion that community engagement is an integral component for creating sustainability, especially on the local level. A documented trend, at least in the United States, is that of a decline in civic engagement (Putnam, 2000). Putnam documents a rise and fall of American civic engagement over the course of the $20^{\text {th }}$ century as measured by diverse indicators ranging from formal membership in community organizations to voting patterns to the hosting of family and friends for dinner. The concept of social capital is employed to represent the value generated by social networks and community connection as defined by the strength of the relationships (i.e., "bonding") and the range of relationships with other well-bonded networks (i.e., "bridging”). Putnam (2000) links the decline of social capital with increased crime, and decreases in safety, child welfare, economic efficiency, and even life expectancy. The findings suggest that promoting the development of social capital is in the best interest of individual and community well-being. 
Social and economic factors, such as those discussed above, must be considered to gain a more comprehensive appreciation of the forces that threaten the environment. Further, if concern is about human health and well-being, then attention must also be invested towards socio-economic phenomena that either erode (e.g., structural violence) or promote quality of life (e.g., community engagement).

Aligning the Spheres of Ecology, Society and Economy

Relatively recently, a movement has arisen to create a symbiotic, mutually supportive relationship among the three spheres, ecology, society and economy, to provide the conditions necessary for a sustainable society. Figure 1 (see p. 14) is often presented to help orient people's thinking towards the potential for alignment of the three spheres. Figure 1 is of value in so far as it serves to bring the social and environmental dimensions into awareness, and promote the potential for synergy among the three spheres. However, I believe that Figure 1 is misleading as it implies the spheres exist with a greater degree of independence than is true of reality. Zwick (unpublished) asserts that "a system is 'incomplete' in so far as it has an environment, separate from itself, that is not only relevant to itself but actually obligatory for its existence" (p. 49). Zwick uses the term "incomplete" to capture the notion that the system is dependent on its environment for its very existence. As such, the economy is inherently constrained by the parameters of society and the environment. In other words, the economy is fully dependent on the context provided by society and the natural environment; removal of one or the 
other effectively eliminates the existence of the economy. No system can persist, let alone optimally, without considering the constraints imposed by the environmental context.

Figure 1:

Common depiction of the 3 dimensions of sustainability and their overlaps. Operating within the nexus is the goal of the sustainability $(\underline{\mathbf{S}})$ movement.

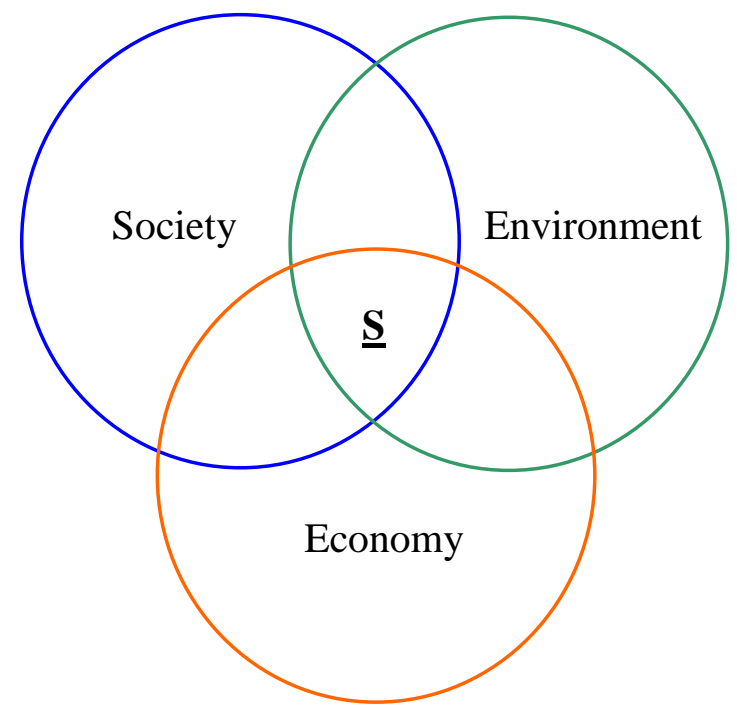

Embracing these ideas, I encourage the use of Figure 2 (see p. 15) to depict the economy's embeddedness within society, and the society within the natural environment. Figure 2 suggests a perspective that is fundamental to appreciating the questions raised by the sustainability movement; the open systems view, which emphasizes the interconnections between the system and its environment. The open system view asserts that there are matter, energy and information flows between the system and the environment. It implies that the system's ability to preserve itself as 
an entity, embedded but distinct, depends on preserving the flow of matter, energy and info between the system and environment. Rather than seeing the social and environmental dimensions as some added, confounding pair of constraints, the economic system should acknowledge them as constraints that have been present all along. Their presence has simply been marginalized in the awareness of economic decision-makers at all levels (i.e., individually to institutionally). Strengthening the economy without accounting for the inherent constraints of its social and environmental context is a temporary practice at best.

\section{Figure 2:}

Embeddedness of Economy within Society within the Environment with Matter, Energy and Information flows

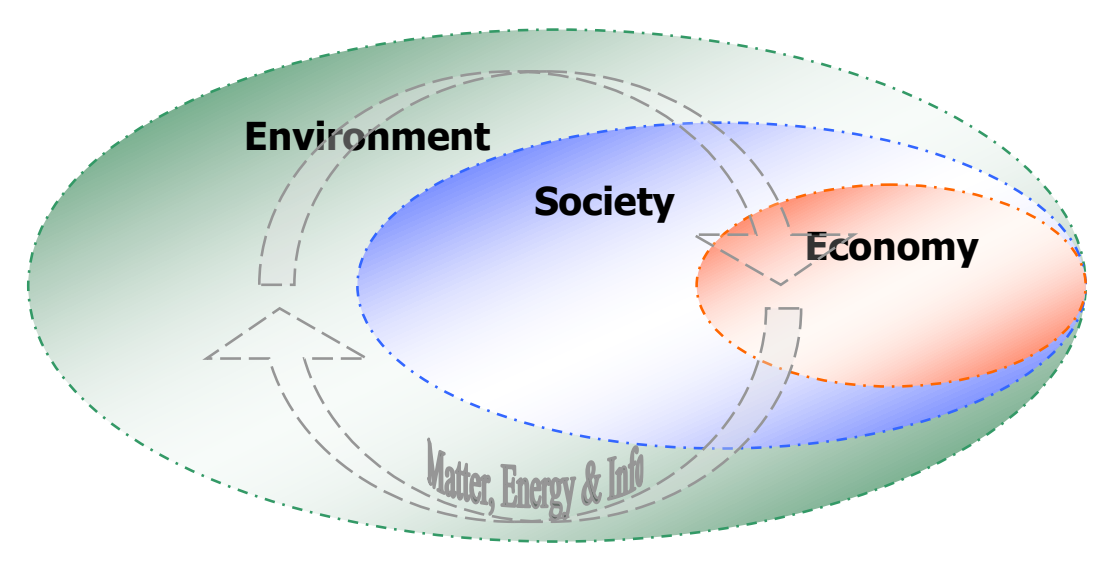

Recognizing the embedded nature of human systems within the natural environment has drawn attention to the need to create alignment between the economic, societal, and ecological dimensions. The concept of sustainability has been proposed to represent such alignment. The United Nation's (UN) World 
Commission for the Environment and Development (WCED) first defined sustainable development as "development that meets the needs of the present without compromising the ability of future generations to meet their own needs" (WCED, 1987, p. 13). In 1992, the U.N. Conference on Environment and Development (UNCED) in Rio de Janeiro, (i.e. the Earth Summit) called for sustainable development "to ensure socially responsible economic development while protecting the resource base and the environment for the benefit of future generations" (UNCED, 1992, p. 13). Following the same line of thought, Hawken (1993) characterizes sustainability as an economic state where the demands placed upon the environment by people and commerce can be met without reducing the capacity of the environment to provide for future generations. On an ethical level, "sustainability means leaving the world better than you found it, taking no more than you need, trying not to harm life or the environment, making amends if you do" (Hawken, 1993, p 139).

To provide an operational definition of these ideas, principles of sustainable practices have been established to guide effective utilization of the earth's resources within its carrying capacity. The Natural Step (TNS), a non-governmental organization (NGO) promoting sustainable practices, provides four scientifically derived system conditions of sustainability that reflect an open systems view. These conditions entail that, in a sustainable society, the earth will not be subjected 
to systematically increasing: (1) concentrations ${ }^{1}$ of substances extracted from the earth's crust; (2) concentrations of synthetically produced substances; (3) degradation of natural resources at rates faster than they are able to be replenished; and in that society (4) human needs will be met worldwide (Robert, 1997). The objective of TNS, and organizations that have adopted its framework, is to align human activities with these system conditions (for a complete guide to the principles and parameters of sustainability please refer to Basile \& Rosenblum, 2000; Robert, 1997; Rosenblum, 1999). While not everyone subscribes to the TNS framework, the fundamental objective it is geared to address is shared throughout the sustainability movement: to align human activities with the constraints and opportunities afforded by our environmental context.

The magnitude of the challenge faced by the sustainability movement is well illustrated by the reflections of Ruckelshaus (1989), former director of the Environmental Protection Agency (EPA):

Can we move nations and people in the direction of sustainability?

Such a move would be a modification of society comparable in a scale to only two other changes: the Agricultural Revolution of the late Neolithic and the Industrial Revolution of the past two centuries. These revolutions were gradual, spontaneous, and largely unconscious. This one will have to be a fully conscious operation,

\footnotetext{
${ }^{1}$ The term "concentrations" is used to denote the idea that as substances are extracted from the earth's crust, and/or produced synthetically, they build up in the biosphere. As the ratio of these substances to the natural chemical composition of the biosphere increases, the health and stability of life-systems become at risk.
} 
guided by the best foresight that science can provide. If we actually

do it, the undertaking will be absolutely unique in humanity's stay on earth (p.167).

\section{Towards Sustainability at the Organizational Level}

As vehicles of unsustainable practices, many businesses, NGOs, and civic organizations recognize their self-preserving need and their responsibility to address the challenge framed by Ruckelshaus. Further motivations exist for business to meet the challenge of improving environmental and social performance, including: gaining competitive advantage, decreasing regulatory liabilities, and the intrinsic value of environmental stewardship (Bansal \& Roth, 2000). Motivation to pursue sustainable practices due to a sense of stewardship often reflects the values and/or mission of the organization. Weiss (2003) strengthens the business case for adopting sustainability practices further by drawing attention to other potential benefits such as, reducing operational expenses through increased efficiency, tapping new revenue sources through recycling of byproducts, decreased liabilities, as well as improved relationship with and reputation among stakeholders.

Similarly, Hart (1995) proposes the opportunity for competitive advantage by adopting what he calls a natural-resource based view of business, which extends from strategic management's resource-based view (Barney, 1991). The naturalresource based view fully embraces the notions of embeddedness and inherent constraint imposed by the environment, as discussed above. Hart (1995) argues that by accepting this reality, firms can take advantage of opportunities for competitive 
advantage on the levels of pollution prevention (lower costs), product stewardship (preempt competitors), and sustainable development (future position).

A recent review of 95 studies exploring the relationship between financial performance and social performance suggests promise in the potential to gain competitive advantage by integrating broader societal interests with traditional profit motives. The review found that 55 studies showed a positive correlation between financial performance and social performance, 22 studies showed no relationship, 18 cases showed a mixed relationship, and only 4 showed a negative relationship (Margolis \& Walsh, 2001). Paine (2003) interprets these results cautiously, noting that shortcomings in the individual studies fail to demonstrate a definitive causal relationship between ethical performance and financial performance. However, the findings certainly challenge the industrial-era assumption within the business community that a negative relationship exists between ethical behavior and financial performance.

The relationship between performance and values may, in part, be linked to Paine's (2003) discussion of rising standards in the public's expectations of corporate conduct. Paine suggests that society is in the midst of a value shift towards assessing corporate performance according to financial and moral standards. Paine cites the increased prevalence and importance of corporate reputation studies, employee commitment surveys, best-company rankings, public opinion polls, and stock-price movements to positive or negative public relations as a few examples of the shift in evaluation standards of corporate behavior. Paine 
proposes that social responsibility, an umbrella term that captures responsible behavior in both social and environmental domains, is becoming the norm by which corporate behavior is assessed, and that corporations must respond to these shifting expectations by altering traditional business practices to be consistent with social values. Strong financial performance will certainly remain an important characteristic of viable organizations, but the point is that social responsibility may increasingly affect an organization's financial bottom line.

In summary, organizations may be drawn towards the sustainability movement as an expression of their core values, to enhance financial performance, and/or in response to societal values and accompanying pressures. Once an organization embraces sustainability as part of its business strategy, successfully integrating sustainability into its strategy and daily operations is fundamentally a matter of organizational change. Lack of success in other organizational transformation initiatives has been attributed to failing to systemically institutionalize the change effort and embed the change into the culture of the organization (Kotter, 1998). This lesson holds true for organizations attempting the transformation towards sustainability (Doppelt, 2003).

Evaluation of companies seeking to introduce new improvement methods (e.g. Total Quality Management) reveals that success or failure of new methods often has less to do with the method itself, and more to do with how that new method interacts with the physical, economic, social, and psychological elements of the organization (Repenning \& Sterman, 1998). For example, while many wrote off 
TQM as an ineffective method for process improvement based on research indicating inconsistent effects, a closer look shows that companies that fully committed to the method outperform their competitors (Easton \& Jarrell, 1998). Organizations with sustainability initiatives can borrow from this lesson; successful sustainability initiatives may require the organization's full commitment and integration of the values and practices of sustainability into the organization's culture.

A case study of an organization that has demonstrated this full commitment and integration of sustainability into the corporate culture is Norm Thompson Outfitters, Inc. (NTO). NTO recognizes that the success of its sustainability initiative requires that sustainability become a core value, integrated systemically throughout the company (Doppelt, 2003; L. Walzack \& D. Smith, personal communication, March 2003). Walzcak (personal communication, March 2003), characterizes the sustainability initiative of Norm Thompson Outfitters, Inc. as one “driven from a change management, and a very systemic perspective, we do everything we can to try to weave this community responsibility and this value responsibility into everything that happens in the organization."

Realization of the goals implied by the above statements ultimately depends upon the people who design and implement the organization's processes and procedures. Thus, integration of sustainability into those processes and procedures must manifest through employees' decisions and behaviors within the context of their roles. This assumption is captured in the comment of Derick Smith, Norm 
Thompson's Corporate Sustainability Manager: "We truly believe that it's the people here and their values and the expression of our values of the corporation that will create the change that we want. It's not going to be done through a program" (personal communication, March 2003). The statement implies that transformation towards sustainability will require a shift in the core value structures that guide the organization and people acting within that environment. This assumption turns my attention to the concepts of organizational culture, organizational climate, and psychological climate, which provide conceptualizations of the human dimensions of organizational life.

\section{Organizational Culture and Climate}

As Moran and Volkwein (1992) state, culture and climate "are perhaps the two most potent constructs available for understanding the expressive, communicative, human dimensions of organizations and their importance in shaping organizational life” (p. 22). While useful constructs, academics and practitioners alike have inconsistently applied the terms culture and climate, creating confusion about which construct reflects which dimension(s) of organization life. A quick review of the definition, appropriate application of each, and justification for my choice of terminology follows.

Organizational Culture. Culture has emerged as a term widely employed in both research inquiry and around the practitioner water cooler. However, inconsistencies can be found in the usage of the term, from describing the most mundane organizational routines to explaining deep symbolic meanings of 
organizational life. Even researchers have yet to establish a clear, shared agreement as to what the term represents (Denison, 1996). Despite apparent disparities in the specifics of the term's definition, it is generally agreed that an organization's culture is an important factor in determining employee behavior (Thompson \& Luthans, 1990). Regardless of the definition, the assumption is prevalent that understanding culture is necessary to understanding behavioral phenomena in organizations. Therefore, I will explore the meaning of culture as proposed by one of the preeminent culture scholars, Edgar Schein.

Schein (1992) defines culture as:

A pattern of shared basic assumptions that the group learned as it solved its problems of external adaptation and internal integration, that has worked well enough to be considered valid and, therefore, to be taught to new members as the correct way to perceive, think, and feel in relation to those problems" (p. 12).

He suggests that culture implies some structural stability to the group: "When we say that something is 'cultural,' we imply that it is not only shared but deep and stable" (Schein, 1992, p. 10). Additionally, culture implies patterning or integration of an organization's “elements into a larger paradigm or gestalt that ties together the various elements and that lies at a deeper level" (Schein, 1992, p. 10). Organizational elements here refer to rituals, values, behaviors, and climate, with the suggestion being that the essence of culture is the patterning of these elements together in a coherent whole. Schein noted that culture requires time to evolve, and 
requires some consistency over that time for it to develop a shared quality. This suggests that it is possible for an organization that lacks a certain degree of continuity of members to fail to ever develop an identifiable culture.

Summarizing the work of Schein and others, Burke (1994) proposed that culture can be understood as a "relatively enduring set of values and norms that underlie a social system," constituting a "meaning system" (p. 126). As such, culture is susceptible to change only in response to extended exposure to new environmental or organizational conditions of new meaning to produce new values and norms.

Organizational and Psychological Climate. The origin of the concept of climate dates back to a paper by Lewin, Lippitt, and White (1939), where the focus was on how different leadership styles created different psychological work environments, or climates. In their book reviewing the concept of climate, Tagiuri and Litwin (1968) characterize climate as a psychological state of employees that is influenced by the conditions within the organization, such as structure, process systems, and managerial behavior. This suggests climate as a malleable construct that can shift in response to changes in these organizational conditions. Tagiuri and Litwin (1968) also discuss how the dimensions of climate vary from one organization to another, and the description of climate depends upon the relevant human behavior involved. For example, two organizations in the same sector may have totally unique climates (also true of culture). Further, within each 
organization, the climate of employee-managerial relationships may be positive or negative, while simultaneously the climate of safety may be high or low.

Many of Tagiuri and Litwin's propositions are echoed by ensuing educated thought on the subject of climate, including the idea that organizations have multiple climates according to different dimensions of organizational life (Schneider, 1975; Johnston, 1976, Powell \& Butterfield, 1978). Another question emerged as to whether climate was a feature of the organization (Glick, 1985) or a psychological phenomenon that was only meaningful as an internal, personal experience (James, Joyce \& Slocum, 1988). Psychological climate entails individual's perceptions of the organization's structure, policies and procedures. Joyce and Slocum (1984) propose that organizational climate requires agreement across the psychological climate of organizational members. In other words, organizational climate requires that there must be perceived qualities of the organization (e.g. structure, policies, procedures), and those perceptions must be shared across members of the organization (Joyce \& Slocum, 1990). Inconsistent perceptions suggest that a clear climate has not developed, with respect to the dimension of organizational life of interest. Further, any given organization should be seen as consisting of multiple subsystems (e.g. departments, teams or work groups) that can develop unique sets of agreed upon perceptions with respect to the climate (Drexler, 1977; Howe, 1977).

Schneider (1990) covers elements of the above debate in his definition of climate as 'incumbents' perceptions of the events, practices, and procedures and the 
kinds of behaviors that get rewarded, supported, and expected in a setting" (p. 384). Schneider proposes this as a global term for climate and suggests that also applies to specific strategic foci (e.g. safety, service). Since this definition fails to express the element of agreement of "incumbents" perceptions, I turn to Joyce and Slocum (1990) who define collective climates as, "perceptions of particular organizational practices that are diffused through relational networks to affect individuals' behavior" (p. 134). Because the proposed definitions of culture and climate have some overlap, it is important to explore how they differ.

Distinguishing Culture and Climate. Moran and Volkwein (1992) state that culture and climate are distinct in that climate consists of observable attitudes and behaviors of employees, while culture consists of the assumptions, expectations, outlooks, and values that exist in the workplace. According to this distinction, culture determines climate. Denison (1996) cites the traditional distinctions: culture as "evolved context... rooted in history, collectively held, and sufficiently complex to resist many attempts at direct manipulation" (p. 644); where climate refers to a situation that can be embedded in that context "and its link to thoughts feelings, and behaviors of organizational members" (p. 644). However, Denison (1996) claims that this distinction is superficial, and that deeper examination of the literature shows extensive overlap of the constructs as they are studied. He claims that the distinction between the two then is more heavily rooted in different theoretical foundations; climate as quantitative from Lewinian field theory (Lewin, 1951) and culture as qualitative from the social construction framework (Berger \& Luckmann, 
1966, Mead, 1934), the boundaries between which have not held up as research in each area has progressed.

I have come to understand that culture encompasses climate. Thus, climate is a reflection of the culture of an organization. At the same time, climate reinforces culture, as people perceive the policies, practices and procedures as expressions of the value system of the organization. Between the two, culture appears to be the more elusive construct in terms of accessibility to the observing eye of a researcher, especially through quantitative measurement. Also, a stronger case has been made for the existence of multiple climates according to strategic focus (e.g. a climate for sustainability). While the interest of people attempting to implement sustainability is in changing organizational culture (i.e. creating a culture of sustainability), they should take heed of the suggestion that culture is only susceptible to change by means of extended exposure to environmental or organizational conditions of new meaning that produce new values and norms (Burke, 1994). I propose that climate provides an avenue to influence culture. Meaning, as a construct more susceptible to change (i.e. through the organization's structure, processes and managerial behavior; Taguiri \& Litwin, 1968), focus can be placed on changing climate as the means to change culture. Changing the climate sets the stage for extended exposure to new organizational conditions, the requirement for formation of new values and norms of a new organizational culture. If culture is the end, climate is the means. 
Climate and Behavior: The Case of Safety Climate. Research utilizing the concept of climate has explored its influence on behavior with respect to specific aspects of organizational life, including for example, the climate of service quality (see Schneider, 1990; Schneider, Bowen, Ehrhart, \& Holcombe, 2000) and the climate for safety (Zohar, 1980; Dedobbeleer \& Beland, 1991; Hofman \& Stetzer, 1996; Neal, Griffin, \& Hart, 2000; Parker, Axtell \& Turner, 2001; Zohar, 2000). Zohar (1980) provided the first empirical investigation into climate for a specific strategic focus of organizational life by focusing on safety climate. Zohar adapted James and Jones' (cited in Zohar, 1980) definition of organizational climate, "perceptions held by employees about aspects of their organizational environment, summarized over individual employees" (p. 96), mapping the concept onto occupational safety. The study's results indicated that levels of safety climate were positively related to the organization's promotion of compliance with safety regulations and actual safety records (Zohar, 1980).

Subsequent research confirms the relevance of safety climate to safety outcomes in organizations, suggesting the potential of safety climate to be predictive of safety outcomes (Dedobbeleer \& Beland, 1991; Hofman \& Stetzer, 1996; Neal, et al., 2000; Zohar, 2000; Parker, et al., 2001). It should be noted that while findings consistently demonstrate that safety climate plays an important role in the safety performance of organizations, there are inconsistencies in the models employed by researchers to represent safety climate. This can be attributed to differences in the researchers' employed definitions of climate, as well as their 
focus on different dimensions of the psychosocial environment for predicting safety performance. For example, the model of safety climate originally established by Zohar (1980) had eight factors (e.g. effects of safe conduct on promotion, and employee perceptions of the organization's safety committee). In contrast, Dedobeleer and Beland (1991) proposed a two-factor model of safety climate (i.e. managerial commitment, and employee safety involvement). The debate persists as to what constitutes the essential elements of safety climate.

In an attempt to bring clarity to the subject, Zohar has since updated his conceptualization of safety climate through an adaptation of Reichers and Schneider's (1990) definition of organizational climate. He now defines safety climate as the extent to which an organization promotes safe working behavior, through enforced practices, policies, and procedures, as perceived by the organization's employees in psychologically meaningful terms (Zohar, 2003). Time will tell if Zohar's conceptualization will provide consistency in the study of safety climate in safety research.

Specifics of the conceptualization aside, how does a safety climate influence safety outcomes, and would the same basic principles apply to the notion of sustainability climate and sustainability outcomes? Neal and Griffin propose that engagement in safety behaviors depends on three primary determinants, knowledge, skill, and motivation. To be capable of behaving safely, employees must possess the prerequisite knowledge and skills that inform and enable actual safe behaviors. Further they must have sufficient motivation to employ that knowledge and skill 
towards safe behavior. A strong safety climate implies that employees perceive that safety is valued in their organization. This perception is formed when the organization's policies, procedures and practices (3 P's) consistently relay the message that safety is a priority. For example, organizations can convey the priority of safety when a reward system incorporates safety records, a work routine is redesigned to eliminate a dangerous task, or training programs are initiated to enhance employees' abilities to recognize and respond to unsafe working conditions. Aspects of the work environment such as these positively influence employee knowledge, skill, and motivation to engage in the relevant behavior (Neal \& Griffin, 2004).

This same line of thought in the safety climate literature can be adopted for the development of the notion of sustainability climate. The extent to which employees perceive that their organization promotes sustainability, through enforced practices, policies, and procedures should contribute to the engagement (or lack thereof) in behaviors consistent with the principles of sustainability. Similarly, integrating sustainability into reward systems, organizational communications, and training sessions, conveys the message to employees that sustainability is valued by the organization. Subsequently, through these aspects of the work environment (constituting a sustainability climate), employees will incorporate sustainability oriented behaviors and decisions into their work routines. 


\section{CHAPTER III}

\section{THE MEASUREMENT NEED}

If one accepts the proposed importance of climate in an organization's efforts towards sustainability, then one should take heed of the popular thought that what gets measured matters. Currently, the sustainability movement does not have a validated set of measurement tools to provide organizations with an assessment of this notion of sustainability climate. Thus, the central purpose of this study is to design and validate a measure of sustainability climate, the Sustainability Climate Survey (SCS).

This thesis documents the development and proposed validation procedures of the SCS. The process included exploring the content areas for inclusion in the survey; describing the process of item-development for the content areas; review of a pilot study of the survey and subsequent lessons learned; making the case for the relevant content areas, including criterion measures; review of the items administered to a sample of Portland State University (PSU) employees; and conduction of statistical procedures to provide evidence of the SCS's validity. It should be noted here that measurement is designed to occur at the individual level, thus the psychological sustainability climate is being measured (see Figure 3, p 32). This study also evaluates the degree to which there is agreement among the perceptions of individual members, which determines whether an organizational sustainability climate exists. 
Figure 3:

\section{Model of levels relevant to the SCS}

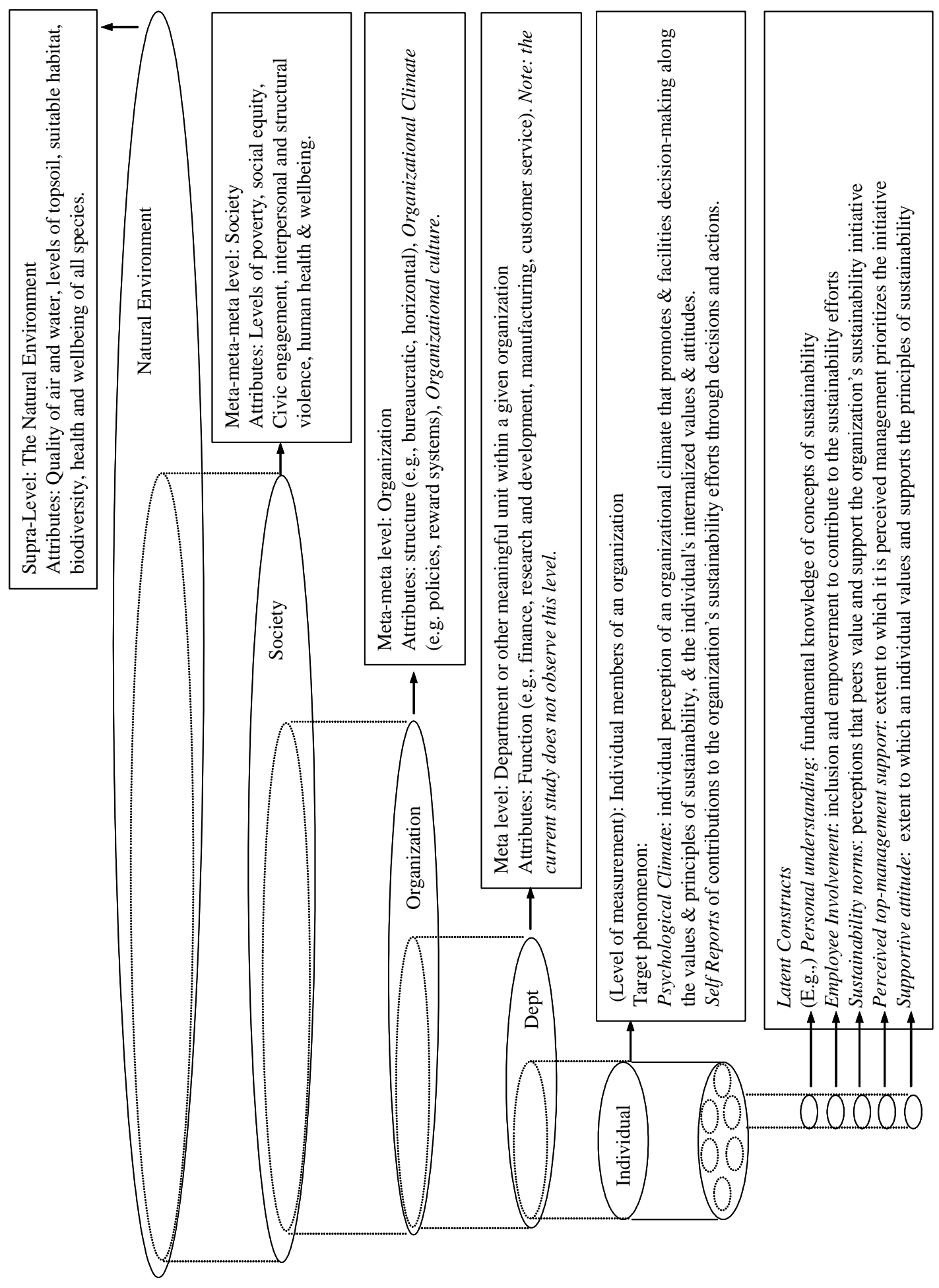




\section{Exploring Content Areas: SCS preliminary work}

Preliminary work on the development of the SCS took place in a study by Hall (2003). As documented in this study, initial exploration of the relevant content areas to include in the SCS was informed by reviewing the consultation guidelines

of The Natural Step, observing subject matter experts working within the context of organizations pursuing sustainability (observed through interview, workshop presentations, and informal conversation), and by reviews of literature in social psychology, namely Azjen and Fishbein's (1972) Theory of Reasoned Action (TRA), and Azjen's (1991) Theory of Planned Behavior (TPB). This early inquiry resulted in the identification of a number of important constructs, including, employee understanding of the concept of sustainability; employee involvement in the organization's efforts (i.e., top-bottom approach); norms or social expectations to value sustainability; personal beliefs regarding the importance of addressing sustainability, including recognized importance of sustainability; motivation to address the issues of sustainability; and the presence of visionary or transformational leadership within the organization.

Through a process of brainstorming involving myself and two undergraduate students, several (4-7) items were generated for each identified construct. These items were presented to a group of graduate and undergraduate psychology and education students enrolled in a course entitled Psychological Test Construction. The students reviewed the items for clarity and content consistency with the intended construct. The items were modified as necessary to incorporate 
the obtained feedback. The updated items were administered to PSU's

Sustainability Coordinator of Operations, and a group of 10 graduate students from various disciplines within the university, each of whom was pursuing some aspect of sustainability through their education. They were asked to review the items for clarity and assess whether any important content areas were missing from the survey. The items were updated to incorporate this feedback. The items were then submitted to a professor of sociology qualified as a subject matter expert (SME) for review of the survey's content validity. Based upon this feedback, some structural changes to the format of the survey were made and phrasing that elicited a participant's "role" in the university was removed because invoking the concept of role was determined to be inappropriate with a university student population. Additionally, a set of six true or false questions was composed to provide an objective test of participant understanding of the concept of sustainability. These items were statements developed based upon my personal understanding of sustainability. Statements either represented core themes of sustainability or represented themes that are not clearly aspects of sustainability. Participants' accuracy in their endorsements of the items as true or false served as a measure of their understanding of sustainability.

The resulting set of items was then reduced, eliminating as many redundancies as possible to reduce survey participant burden. The remaining set of items (see Table 1) was then administrated (along with several other surveys in a packet) to students in several undergraduate Psychology courses, an undergraduate 
Business course, and a Sociology course. The sample $(\mathrm{N}=330)$ consisted of $64.4 \%$ women $(n=219)$ and $31.5 \%$ men $(n=107)$, with a mean age of $25.89(\mathrm{SD}=7.70)$. Students were awarded extra-credit for their participation in all cases except the Business course.

Two sets of factor analyses employing oblique rotation were conducted of the responses, and provided a two-factor solution (see Table 2) and a four-factor solution respectively (see Table 3 ). These factors were named (1) connectedness, defined as the level of communication received from the university on the topic of sustainability, and their level of inclusion in efforts towards sustainability (see items 8-11, Table 2); (2) constructive attitude, defined as optimistic beliefs about the university's ability to address the challenge of sustainability, the resulting positive impact, and a general motivation to contribute (see items 12, 14 and 15, Table 2); (3) concept recognition, defined as understanding the concept of sustainability and recognizing the importance of addressing the issue (see items $24,25,27.28$, and 32-34, Table 3); (4) social pressure, defined as the perceived social pressure from peers to take the issue of sustainability seriously (see items 29-31, Table 3); (5) internalized values, defined as the level of concern regarding sustainability related issues and awareness of personal impact (see items 35-38 and 40, Table 3); and, (6) Shambala, defined as positive engagement with the subject of sustainability, in that one enjoys confronting the challenge and derives a greater sense of purpose through their efforts (see items 42 and 43, Table 3). Shambala is a Tibetan word referring to a legendary realm, and used as a reference to a path towards a more meaningful and 
fuller life. Those on the Shambala path accept the difficulties of life and face them with courage. Each of the constructs, with the exception of connectedness, was positively related to the outcome criterion self-reported sustainable behaviors (see Table 4).

Lessons learned. In addition to providing preliminary feedback on the reliability and validity of the SCS, this preliminary study also provided some valuable insights into the structure and content of the survey. The consistency between intention and interpretation of several items was called into question by the analysis. For example, one of the items intended as a measure of understanding ("I need more education on the concept of sustainability.") had low inter-item correlation with other items assessing understanding. Reflection, aided by several open-ended comments, led to the conclusion that although students may not have understood the concept of sustainability, they did not see it as a necessary part of their formal education. Thus, the item was more a measure of an attitude than a reflection of self-reported understanding of the concept.

Another lesson learned relates to my low confidence in the outcome criteria used to validate the SCS. The outcome criterion utilized to validate the scale clearly oversimplified sustainable behavior by reducing it to two items: measuring people's self-reported level of recycling, and the degree to which they sought to purchase recyclable materials whenever possible. While recycling and purchasing recycled products are certainly important pieces of the puzzle, to insist that such behaviors stand alone as satisfying the end of sustainability is a tremendously 
incomplete account. Hawken (1993) explicitly suggests that making such superficial changes such as recycling and reducing energy consumption are inadequate to attain sustainability. Rather sustainability involves a radical transformation of assumptions away from the mindset of discounting or failing to account for environmental and social impacts of decisions, which created the present dilemma. Therefore, subsequent versions of the SCS require improved outcomes that reflected meaningful engagement with sustainability and the range of relevant aspects that extend beyond recycling behaviors.

The preliminary study also exposed that evaluation of the social dimension of sustainability was inadequate. Of course, each item employing the term sustainability is intended to imply all three dimensions of ecology, society and economy. However, only a two items exclusively focused on the social dimension, while many more make specific reference to the environmental dimension. This is not unusual throughout the sustainability movement, which has placed greater emphasis on the environment. While any one study is sure to fall short of providing a full account of relevant social factors, the need is recognized to place greater weight on assessing the social dimension of sustainability. These lessons learned helped inform the next iteration of the SCS as presented below.

\section{Proposed content areas}

The preliminary validity and reliability evidence of the pilot study laid the foundation for the content of the SCS, while the lessons learned indicated opportunities for improvement. Two major reasons account for differences between 
the constructs resulting from the pilot study and the proposed content areas below. First, the circumstances of the pilot study's participant recruitment demanded a reduction of items to minimize survey response burden. Thus, in removing numerous items the subsequent factor structure may have been altered. Many of these items were included in the present study. Second, further review of the literature in the interim between the pilot study and the present study advanced my conceptualization of the concept of sustainability climate.

Building off the foundation of the pilot study with advancements in my conceptualization, I propose a set of factors as important determinants of the success or failure of a sustainability initiative. The first five factors fall under the umbrella term, sustainability climate. These factors include: the perceived topmanagement support for the organization's sustainability initiative; perceptions of sustainability norms that co-workers value sustainability; perceptions that efforts towards sustainability receive rewards, employee involvement in the organization's sustainability efforts; and, whether employees can identify a shared vision of what the organization is striving towards with respect to sustainability. Three additional proposed factors include: personal understanding of the concepts of sustainability; personal positive engagement in addressing the issue of sustainability; and beliefs that demonstrate a supportive attitude for addressing the issue of sustainability. Each of these constructs is discussed in greater detail below (see Table 7 for the items associated with each construct). 
Perceived top-management support. Zohar (1980) found that perceptions of top management's commitment to safety influenced the importance that employees placed on behaving safely on the job. Management demonstrated a commitment to safety through such means as establishing job training programs, placing safety officials at high ranks within the organization, as well as considering safety in job design and work pace expectations (Zohar, 1980). Numerous studies have demonstrated support for the importance that top-management commitment plays in the promotion of safety behaviors at work (e.g., Simard \& Marchand, 1997, Vredenburgh, 2002, Weyman, Clarke \& Cox, 2003). A meta-analysis by Rodgers and Hunter (1991) supported the hypothesis that when top-management commitment to a management by objectives (MBO) initiative was high, productivity was higher than when commitment was low. Another meta-analysis by Rodgers, Hunter, and Rogers (1993) also found that when top-management support for a MBO program for job satisfaction was high, the programs were more successful than when commitment was low.

These findings of the importance of top-management support for safety programs and $\mathrm{MBO}$ programs are expected to be applicable to the domain of sustainability. Perceptions that top-management is committed to an initiative are important to ensure that employees feel supported in investing their effort to advance the initiative. In the context of a traditional business model, an employee could potentially be reprimanded for exploring issues that call into question the business' environmental and social performance. Norm Thompson is able to avoid 
this potential conflict, because “(senior managers') values and beliefs have been communicated and supported and are recognized continuously by the employees, and the employees are never in a situation where, if they are moving forward on a sustainability activity, that it's questioned. Never.” (Smith, personal communication, March 2003) Such well established support from the top creates an open environment for honest exploration of difficult problems. Without the perceptions of top-management support, not only would employees not have any reason to place priority on the issue, but they could very well feel discouraged from independent pursuit even if it was of personal importance.

Namely, it is predicted that perceptions of support from top management for a sustainability initiative will correlate with whether employees actually engage in actions and behaviors consistent with the principles of sustainability. Thus, the following hypothesis:

Hypothesis 1: Perceptions of top-management support for the organization's sustainability initiative will positively correlate with sustainability role expectations, sustainability role behaviors, and environmental stewardship. Sustainability norms. Ajzen and Fishbein (1972) first proposed the influence of the subjective norm as a factor influencing behavioral intentions in the TRA, and retained in the evolved TPB (Ajzen, 1991). Subjective norms are defined as a function of a person's perception of social pressures to engage in a behavior and the person's motivation to conform to those pressures (Ajzen, 1991). "Norms should be viewed as explicit or implicit prescriptions concerning one's appropriate 
attitudes and behaviors as a member of a specific group in a specific context" (White, 2002, p. 92). In other words, norms are situation specific, and influence behavior through an individual's perception that the normative attitudes and behaviors are defining features of membership in a particular group.

However, in a review of studies utilizing the Theory of Planned Behavior (TPB), Azjen discovered that subjective norms were not significant predictors of behavior in over half the studies, and when they were significant predictors, the relationship was often weaker than other predictors. White (2002) found a moderating effect of social norms, such that individuals were more likely to behave congruently with their attitudes if they perceived normative support for their attitudes from a salient in-group. In another study, Fishbein, et al. (1992) investigated gay men's intentions to engage in sexual behaviors, each with varying risk of contracting the HIV virus. Results across multiple sites demonstrated that normative factors predicted behavioral intentions to engage in the sexual behaviors. Following their hypothesis, cities with stronger organized gay communities demonstrated increased influence of normative factors. These authors propose that social norms are better defined in closely connected and well organized communities than they are in loosely connected circles. Thus, in close communities the perceived norms are more salient and more likely to influence behavior (Fishbein et al., 1992).

The implication is that the degree to which there is a sense of community and employees identify themselves as members of an organization (or group, or 
unit) will determine the degree of influence of the subjective norm factor. For example, an individual's perception that others purchase local, organically grown foods, is more likely to influence the individual's food purchasing behavior when he or she feels a part of the community. In this study, cohesion is defined as the extent to which people perceive a sense of community in their workplace, where interactions are courteous and respectful, people have mutual concern for one another's welfare, and there is cooperation in problem-solving efforts. Cohesion is assessed by the sense of community measure and is including as a moderating variable. To examine the relationship between norms and behavior, and the theorized moderation of group cohesion on the relationship between social norms and behavior, I pose the following two hypotheses:

Hypothesis $2 a$ : Sustainability norms will be positively correlated with sustainability role expectations, sustainability role behaviors, and environmental stewardship.

Hypothesis $2 b$ : Sense of community will be a moderator in that as it increases, the strength of the relationships between sustainability norms with sustainability role behaviors, and environmental stewardship will increase.

Rewards. The seminal work of B.F. Skinner (1938) clearly illustrated the potential to influence behavior through the manipulation of consequences. Undesirable behaviors can be reduced or eliminated through introduction of adverse stimuli (positive punishment, e.g., an electric shock), or removal of a stimuli desired 
by the organism (negative punishment, e.g., food) when that undesired behavior is engaged. Desirable behavior can be promoted through the introduction of stimuli desired by the organism (positive reinforcement, e.g., food) or removal of adverse stimuli (negative reinforcement, e.g., distressing noise). The organism eventually makes the connection between its behavior and the stimuli, thus learns that through its choice of behavior it is able to control its experience of desired or adverse stimuli. Skinner ultimately emphasized that while punishment may be effective in stopping undesirable behavior, it is not effective in creating new desirable behavior routines as it fails to provide the organism with the lesson of what the new desirable behavior is. The lesson can be learned by introducing reinforcement to the organism immediately following the performance of a desired behavior. The basic implication of Skinner's work for human behavior in organizations is obvious: create rewards or incentive systems that pair those rewards with desired behavior.

Thompson and Luthans (1990) discuss the assimilation into an organization of a new employee, who learns appropriate and expected levels of performance and effort through observation and experience of the reinforcement practices by management. For example, if an employee makes a suggestion about an alternative non-toxic chemical agent in a production process, management's response, or lack thereof, conveys whether they desire such suggestions from employees. Thompson and Luthans suggest that the feedback management provides "transmits culture" (p.326). From my study's perspective, the practices of management to reinforce, or 
reward, particular behaviors will be considered as a dimension of organizational climate.

The rewards measure reflects instrumentality, or the perceived relationship between job performance and outcomes. Specifically, I am interested in whether employees perceive that incorporating sustainability into their work routines will result in positive performance appraisals and rewards. I expect the rewards measure to be positively correlated with sustainability-related behaviors in the workplace. Thus, the following hypothesis:

Hypothesis 3: Rewards will positively correlate with sustainability role expectations, sustainability role behaviors, and environmental stewardship.

Employee involvement. The Natural Step (TNS) encourages a top-to-bottom approach to pursuing sustainability in the workplace (TNS, 2001). Often "frontline" workers are more in touch with the tasks and responsibilities of daily organizational operations. It is assumed that empowering employees with knowledge about the concepts of sustainability and giving them opportunities to contribute their ideas and/or actions dramatically enhances the creative potential of the organization to discover solutions to the challenges of sustainability. Consistent with this perspective, evidence suggests that such empowerment efforts enhance creativity and innovation (Dess, \& Picken, 2000; Spreitser, 1995).

In general, the high-involvement strategy entails self-management, providing employees with information and training about the organization's 
operations, and empowering employees to influence decisions (Lawler, 1992). A primary assumption is that provided with motivating work, and a clear goal orientation, employees are capable of, and inclined to, self-regulate their behavior (Manz, 1980). Thus, a high-involvement strategy requires management to trust employees to carry forth the work that will move an organization towards a desired objective (e.g., sustainability).

Lawler (1992) explains that an involvement-oriented management strategy attempts to create a workforce that is responsive to change and capable of selfmodifying behavior as change warrants. Further, "the approach assumes that all individuals can add value to a product by using their minds as well as their hands" (Lawler, 1992, p. 29). The quote captures much of the Natural Step's reasoning about the importance of employee involvement in integrating sustainability into an organization's operations. Every aspect of the organization's operations must be taken into consideration to comprehensively address inconsistencies with the principles of sustainability. When you consider the knowledge and capacity required, it is an overwhelming proposition to assess and change every aspect of the organization's operations from a centralized point. Employees hold first hand knowledge of the organization's operations and functions; thus, involving employees leverages tremendous potential for insight and creativity throughout the organization. Essentially, the idea of employee involvement entails providing employees with information about the concept and principles of sustainability, empowering them to seek and find the means to advance the organization towards 
the desired state of sustainability. Involving employees on this level also conveys both the importance of sustainability and an expectation that it be integrated into their work routines, thus promoting the engagement of sustainability-related behaviors on the job. Thus, the following hypothesis:

Hypothesis 4: Employee involvement will be positively correlated with sustainability role expectations, sustainability role behaviors, and environmental stewardship.

Shared vision. Shared vision provides an orientation point for people to direct their energy. Senge (1990) frames the potential power of shared vision by discussing the creation of a gap between a present state and a desired state, as defined by the vision. This gap between the present and desired state creates a sense of tension. If properly channeled, the gap promotes creative tension, which spurs ideas and actions towards reducing the size of the gap between present and desired states. Further a shared vision has been shown to contribute to a work environment where employees demonstrate a higher degree of trust and collaboration, not to mention organizational commitment (Tjosvold \& Tsoa, 1989). A clear vision equates to a well-defined purpose, which provides direction and orientation for the types of decisions and actions required to attain a desired state. "It is difficult, if not impossible, to transform the culture of an organization without a clearly expressed vision of how it should look and function when it is sustainable" (Doppelt, 2003, p. 130). Doppelt also asserts that vision provides the set of beliefs and perspectives that draw clear distinctions between the old model of 
organizational operations and those expected to define the new aspirations of the organization. "Effective visions simultaneously abolish old perspectives that steer an organization away from sustainability while forming new perspectives and thought patterns that align people with the desired state of sustainability" (Doppelt, 2003, p.130). Smith (personal communication, 2003) concisely states the need for shared vision: "So (that) everyone has the same 'sheet of paper' that they are using as the guide, because otherwise confusion will occur."

Doppelt (2003) identifies some of the key features that define a quality vision. First, a vision should go beyond stating what should not be done or what should be avoided. Rather a vision should extend to forward thinking about what could be. The vision should be stated in simple and straightforward terms and should also provide some logic as to the importance of pursuing the purpose. Orientation towards higher order purposes and visions of great importance motivates people to work towards those ends. Castle (personal communication, 2003) contributes the thought: "A good vision is one that appeals to the higher sense of self; it appeals to what is possible. So it is framed in a way of what can be done. It's a stretch, it gives people a challenge, and ultimately it's inspirational." Such qualities of forward thinking, clarity, and higher order purpose are keys for a vision to enlist the commitment of the hearts and minds of employees.

Kotter (1995) reinforces the importance of establishing a clear vision, identifying the failure to do so as one of the primary reasons transformation efforts fail. He warns against establishing a vision that is too complicated, or generally 
blurry making it difficult for the vision to be communicated throughout the organization. Those pursuing sustainability should take heed of this warning, as the concept of sustainability is complex and tends to be ambiguous. These characteristics, coupled with the implication of requiring a major transformation of existing human systems, heighten the importance of articulating a clear vision for the pursuit of sustainability. Thus, I propose the following hypothesis:

Hypothesis 5: Shared vision will be positively correlated with sustainability role expectations, sustainability role behaviors, and environmental stewardship.

Personal understanding. Clearly it is difficult to behave proactively towards something without a basic understanding of what you are attempting to achieve. Sustainability may be an unfamiliar subject to people, and can be very confusing, so providing members of an organization with the prerequisite knowledge about how sustainability concepts are applicable to them is essential. Establishing such understanding provides people with a common reference point and facilitates the development of shared mental models of the problem.

The essential need to establish personal understanding of the concept of sustainability is reflected in the structure of the Natural Step's introductory workshop on sustainability in organizations. This workshop opens with articulation of the problem of an unsustainable society and exploration of relevant concepts. This process of educating employees on sustainability concepts and issues continues through their other workshops as well. Similarly, Norm Thompson and 
Wacker Siltronics both inform their employees with educational programs on the concepts of sustainability and the relevance to employees' jobs (Smith and Walczak, personal communication, 2003; Fahey, personal communication, 2003). These organizations recognize that successful pursuit of sustainability requires employees who are informed on the subject.

It is important to note that while knowledge may be a necessary component of the pursuit of sustainability, knowledge alone is not sufficient to bring about behavioral change. This is demonstrated by massive public health education campaigns that rely upon informing the public about health concerns and risks associated with particular behavior. Despite millions of dollars in investment, these public information campaigns appear to have minimal influence on changing behavior (Colligan \& Cohen, 2004). Thus, while the notion of providing employees with requisite understanding of sustainability is important, it must be in concert with changes in other aspects of an organization's sustainability climate to promote and facilitate the development of new behavioral patterns. Nevertheless, in acknowledgment of the importance of personal understanding, I propose the following hypothesis:

Hypothesis 6: Personal understanding will be positively correlated with sustainability role behaviors and environmental stewardship.

Supportive attitudes. The term 'attitude' typically refers to a "relatively enduring tendency to respond to someone or something in a way that reflects a positive or a negative evaluation of that person or thing" (Manstead, 1996, p. 3). 
The TRA and TPB models (Ajzen \& Fishbein, 1972; Ajzen, 1991) suggest that attitudes toward a behavior arise from a person's beliefs about the consequences resulting from performance of the behavior, and the person's affective response to those consequences. The proposition follows that performance of a behavior increases as attitudes toward the behavior become more favorable.

Social psychology has long considered attitudes as a relevant concept, and most social psychology theories assume that attitudes predict associated behaviors. For example, Festinger's (1957) theory of cognitive dissonance proposes that people seek consistency between their expressed attitudes and their behaviors. When people become consciously aware of attitude-behavior inconsistencies they will experience an undesirable psychological state of dissonance that they seek to alleviate through modification of their behavior or their attitudes. Following from this reasoning, I would expect a positive correlation between employee's sustainability attitudes and behaviors. If people expresses positive attitudes towards the idea of sustainability, but behave in a completely incongruent way (e.g., routinely throwing away recyclable materials, and/or failing to support social initiatives designed to mitigate inequities), then according to Festinger's cognitive dissonance theory they would be expected to eliminate this discrepancy by adopting new behaviors consistent with their attitudes, or shifting their attitudes to justify their behavior.

Despite the theoretical rationale for correlations between attitudes and behaviors, early research revealed a modest and often non-significant correlation 
between attitudes and behaviors (see Manstead, 1996). In response to this early research, Fishbein and Ajzen (1977, as cited by Manstead, 1996) buoyed the popular notion of the connection by illustrating the principles of aggregation and compatibility. The principle of aggregation demonstrates that since attitudes can be complex phenomena with multiple dimensions they can not be captured through single-item assessment. Attitude assessment should be conducted via responses to multiple items, aggregated into composites of those items. Similarly, assessment of behaviors should consist of multiple items aggregated into composites of those items formed for a more general index.

The principle of compatibility suggests that there should be consistency between the attitude assessment and the behavioral assessment in terms of specific actions, object, context, and time. If one were to assess a general attitude and correlate with the observation of a specific behavior, then the correlation is likely to be lower than if the attitude assessment was directly compatible with the specific behavior. When the principles of aggregation and compatibility are employed, the strength of the relationship between attitudes and behaviors significantly improves (see Manstead, 1996).

Following from this work, two examples of research reestablishing the link between attitudes and behaviors include the work of Fishbein et. al. (1992), and Boldero (1995). Fishbein et al. (1992) found attitudes to be significant predictors of behavioral intentions in their study conducted on gay men's intentions to perform various sexual behaviors, each with varying risk of contracting the HIV virus. 
Boldero (1995) found attitudes towards recycling to be significant predictors of household recycling of newspapers.

The sustainability movement owes much of its prominence to the evolution of the environmental movement and activism towards social justice and equality. These movements have a history of adversarial relationships with traditional elements of society as their agendas challenged dominant social paradigms. As such, a survey of the population might reveal a wide array of attitudes towards these respective movements, reflecting support, resistance, or apathy. The sustainability movement certainly carries the torch of challenging the traditional social paradigm. However, within the mainstream movement, the subject is approached with collaborative intentions and the proposition of a positive vision for the future. Despite these laudable characteristics, the potential exists for sustainability to inherit negative associations people may have developed with environmental and social activism. Or, people may simply disagree with the perceived or real goals of the sustainability movement. With this in mind, an assessment of employee support for pursuing sustainability within the organization will provide an important indication of whether employee resistance to organizational change may result from individual attitudes. Or, perhaps a supportive attitude exists, suggesting an opportunity for the organization to leverage employee support by emphasizing management support, and structuring the rewards system to reinforce integrating sustainability in job performance. Whichever the case, there is an anticipated 
relationship between attitudes about sustainability and engagement in sustainabilityrelated behaviors in the work place. Thus, I propose the following hypothesis:

Hypothesis 7: Supportive attitudes will be positively correlated with sustainability role behaviors, and environmental stewardship.

Positive engagement. In following the public dialogue and trade literature on the subject of sustainability, one regularly hears reference to the idea that the challenge of sustainability holds tremendous potential to tap motivation, as it provides "a mission worthy of people's commitment" (e.g., see Senge \& Carstedt, 2001, p. 33). I will briefly explore this assumption and address the question of whether sustainability can serve as a motivating force of employees' energy. If sustainability is such a motivator, the extent to which people are willing to fully invest themselves in the mission of sustainability could prove to be a significant predictor of whether employees behave in manner that moves the organization towards sustainability.

Perhaps consideration of sustainability in terms of striving to satisfy unmet human needs, ala Maslow (1954), can lend credence to the motivating power of sustainability efforts. Needs, in the context of sustainability, include those of the unmet intra-generational needs and a threat to inter-generational needs. These intra and inter-generational needs are primarily of the most basic lower level needs, physiological and safety needs, but also include higher-order notions of community and belongingness. People with these needs unmet, or who foresee an imminent risk of losing the fulfillment of these needs may be attracted to the sustainability 
movement's suggestions for alternative relationships with the earth and among people. Dealing with a population of employed people, it is reasonable to assume that their lower-order needs have been largely satisfied. Maslow (1954) proposes that higher-order needs of esteem and self-actualization are fundamental human needs, which people seek to satisfy once lower-order needs have been met. Addressing the unmet basic needs of others (of the present and/or the future) can provide a focus for individuals with their basic needs met to satisfy higher-order needs. The challenge of sustainability presents many obstacles to overcome and problem to solve. Those with an achievement orientation and desire to receive recognition and respect for their work may find the sustainability movement a fruitful field of opportunity. A step up the hierarchy, those seeking selfactualization, or realization of one's full, unique potential, tend to be problem oriented rather than self-centered, compassionate, and mission driven, as well as other positive attributes (Maslow, 1970). The altruistic pursuit of satisfying the unmet needs of others in this generation and beyond could indeed provide a powerful orientation for those seeking to satisfy higher-order needs.

This notion of people being positively engaged in the pursuit of sustainability was explored in the pilot study of the SCS, where the measure Shambala was the strongest predictor of sustainable behaviors of the six factors assessed (Hall, 2003). Pelletier et al. (1998) used a set of items in their assessment of intrinsic motivation to engage in pro-environmental behaviors that resemble the items I propose. They found that intrinsic motivation was a significant predictor of 
engagement in environmentally conscious behaviors (Pelletier et al., 1998).

Further, intrinsic motivation was negatively correlated with amotivation (absence of motivation) to behave pro-environmentally, which was linked to a sense of helplessness, or the belief that environmental problems were too large for their actions to make a difference (Pelletier, Dion, Tuson, \& Green-Demers, 1999). These findings suggest that while people may vary in their performance-outcome expectancies and subsequent motivation, those who see inherent value in behaving in pro-environmental ways are more likely to engage in pro-environmental behaviors.

The proposed factor of positive engagement reflects not only the degree to which people are motivated to address issues of sustainability, but also their inspiration in this endeavor, whether or not they enjoy engaging in the subsequent challenges, and the sense of purpose they feel in the pursuit of sustainability. Such a level of positive engagement is important, because in the words of a veteran practitioner, sustainability "needs people of passion, because...there's an aspect of despair. When you get into this you realize how much of what we are doing is not sustainable...It's important to be able to find the motivation to continue to work when everything around you looks like it's not working" (Castle, personal communication, 2003). As an individual's positive engagement with the pursuit of sustainability increase, her engagement in sustainability related behaviors should increase and she should integrate the concept of sustainability into their work roles. Thus, I propose the following hypothesis: 
Hypothesis 8: Positive engagement will be positively correlated with sustainability role behaviors and environmental stewardship.

\section{Criterion Measures}

As part of the scale development process, it is important to demonstrate an association between the proposed factors and some relevant variables, or criteria (DeVellis, 1991; Hinkin, 1998). I propose a set of criterion measures to assess whether the concept of sustainability is integrated into employees' daily routines. The measures include the degree to which engaging in actions that advance sustainability in the organization are a role expectation; the extent to which employees actually engage inactions that advance sustainability, reflected in a set of sustainability role behaviors; a set of personal behaviors representing environmental stewardship; and a set of personal behaviors reflecting community engagement (see Table 7).

Sustainability role expectations. Katz and Kahn (1978) conceived of organizations as systems of people playing roles in an interdependent network. As units of the system, members are psychologically linked together, providing the integrity that establishes the organization as an identifiable whole. Each member performs a specific role that contributes to a larger pattern of behavior constituting the function of the organization. Due to interdependencies, the performance of any given member in part determines the performance of other members. Members then become invested in the behavioral patterns of one another, and form beliefs and expectations about what constitutes appropriate role behaviors of others. In 
other words, projected role expectations give shape to the appropriate behaviors that one should perform in his/her role. Expectations are projected by members of a role-set, those in the work environment, usually defined by the organizational structure, work-flow, and/or geographic proximity, who directly associate with the focal member. Role-set members projections attempt to influence the focal person's behavior to conform to their expectations. The focal person's perception of the expectations conveyed by role-senders determines the degree and direction of the influence on his/her behavior. In this sense, role behaviors are motivated through "a process of learning the expectations of others, accepting them, and fulfilling them" (Katz \& Khan, 1978, p. 188) in order to obtain extrinsic as well as intrinsic rewards.

With respect to sustainability, my interest is whether integration of concepts of sustainability into the work routine is perceived as an expected part of the employee's role. For example, do supervisors and coworkers expect an employee to consider the environmental, social, and economic implications of work-related decisions? As indicated in the above hypotheses, I predict a positive correlation between the sustainability climate factors and the measure of sustainability role expectations, such that employees who perceive a more positive sustainability climate will perceive higher expectations to integrate sustainability principles into their role behavior.

Sustainability role behaviors. Taking a step beyond whether employees perceive an expectation to integrate sustainability principles into their work 
behavior, I am interested in whether employees actually adopt a set of role behaviors that reflect the integration of sustainability principles into their work routine. Thus, I assessed sustainability role behaviors via self-reports. This measure mirrored the sustainability role expectations measure. As suggested by the above hypotheses, I predict positive correlations between sustainability role behaviors and both the sustainability climate factors and personal measures, such that employees who perceive more positive sustainability climate factors and score higher on the personal measures will be more likely to engage in sustainability role behaviors.

Environmental stewardship. Employees individual behaviors significantly contribute to the organization's ecological footprint (Wackernegal \& Rees, 1995). An ecological footprint is a measure of the "load" imposed on the natural environment by a given population (i.e., members of the PSU community) and represents the land area necessary to sustain current levels of resource consumption and waste discharge by the population. Human activities such as eating, traveling, heating homes, and purchasing consumer items all contribute to ecological footprints (Wackernegal \& Rees, 1995). The Union of Concerned Scientists (UCS) conducted an analysis to determine the greatest threats to the environment, and what individual choices most significantly contributed to those threats (Brower \& Leon, 1999). Their findings highlight climate change, air pollution, water pollution, and habitat alteration as the 4 primary threats facing the environment. The individual consumer choices that most significantly contribute to these impacts were 
determine to fall under the categories of transportation, food, and housing/household operations.

How we move from one place to another has ramifications for the natural environment. Brower and Leon (1999) cite the impact personal automobiles have on changing the climate and contributing to air pollution, as well as associated impacts on habitat due to road construction. The manufacturing of automobiles also has a tremendous impact through raw resource acquisition (e.g. mining), and synthetic material production (e.g., plastics), and generally energy-intensive processes. The UCS recommendation is to reduce personal driving by engaging in alternatives such as carpooling, taking public transportation, bicycling, and walking. By engaging in alternative means of commuting employees can reduce their ecological footprint, as well as their organization's collective footprint.

Ecological footprints are also determined in part by food choice, as food systems have a significant impact on the environment from the production process to distribution. Raising livestock contributes to surface and ground water pollution, as well as contributing to deterioration of habitat as forests are cleared for grazing, which contributes to loss of productive top soil. The production of vegetables, fruits, and grains also impacts water systems through use of pesticides and other chemicals, and consumptive irrigation practices (Brower \& Leon, 1999). Additionally, as food production systems follow the trend of globalization, food is transported over greater distances, consuming more fossil fuels, thus contributing to air pollution and global warming (Brower \& Leon, 1999). In response to these 
concerns, the UCS recommended a reduction in the consumption of meat, selecting certified organic ${ }^{2}$ foods whenever available, and purchasing from local food producers. Purchasing locally also strengthens local economies by keeping dollars circulating among community members (Schuman, 1998).

The third category, housing and household operations, significantly impacts the environment. However, the interest of this study remains in the work setting. Matters of location, energy use, and building materials are important dimensions of an organization's ecological footprint. According to the Environmental Protection Agency (EPA) U.S. institutions, businesses, and residents produced 229 million tons of municipal solid waste in 2001, which equals 4.4 pounds of waste per person each day. Reduction, reuse, and recycling strategies can reduce this amount of waste production. Benefits include the conservation of resources for future generations, prevention of greenhouse gas emissions, reduction in water pollutants, creation of a supply of valuable resources for industry (recycling), and reduction of the need for landfills and incinerators (see: www.epa.gov/epaoswer/nonhw/muncpl/reduce.htm\#recycle). Employees can reduce costs and reduce the impact on the environment by being conservative in their use of resources at work, and recycling materials such as paper, cardboard, glass, plastics and metals. Quality of work life. Interest in the social dimension of the pursuit of sustainability motivates the inclusion of several quality of work life indicators,

\footnotetext{
${ }^{2}$ The U.S. Department of Agriculture (USDA) offers the certified organic label to fresh and processed foods that are produced using methods recognized to not harm human, animal, or soil life. Producers must develop an organic farm management plan, keep detailed records and are subjected to annual inspection by accredited certification agencies (see: www.certifiedorginc.org/).
} 
including: work load, serving as an indicator of stress levels; job-decision latitude, to assess the sense of control that employees enjoy in the organization; a sense of community, which pertains to the quality of the social networks among employees; and job satisfaction, which reflects employees' general well-being. These measures are intended to provide an organization with a profile of the level of well-being enjoyed by employees within their work environment. For the purpose of this study, these measures will also be utilized as part of the discriminant validity analysis.

Community engagement. Social capital was discussed as important to the sustainability movement; thus, I included a measure of community engagement as a social indicator. The community engagement measure is designed to assess the degree to which employees are active participants in social causes within their respective communities. From a systemic perspective, employee behavior in the local community is a factor of the organizations' impact on the community. The extent to which people are engaged in their community also indicates social capital, which promotes individual and community well-being (Putnam, 2000).

\section{Study Purpose}

The general purpose of this study is to develop and validate the Sustainability Climate Survey (SCS). The SCS is intended to assess, at an individual level, the content domains of the factors proposed above. These factors are theorized to be predictive of behavior that advances an organization towards sustainability. Thus, the data gathered can serve as a strategic guide for an 
organization seeking to promote the advancement of sustainability in their operations. To provide evidence of this practical application, the purpose of this study is to provide preliminary assessment of the reliability and validity of the SCS. This study also examines whether there is agreement among individual responses to the sustainability climate measures that might constitute a sustainability climate at the organizational level. 


\section{CHAPTER IV}

\section{METHOD}

\section{Organizational Context}

The participating organization was Portland State University (PSU), a large urban university located in downtown Portland, OR. At the time of data collection, PSU employed 1,004 non-instructional and classified staff, as well as nearly 2,300 full-time and part-time instructional faculty, and had an enrollment of over 22,000 students. PSU began actively pursuing the notion of sustainability around the turn of the millennium. Initially driven by stakeholder pressure from students and faculty, key decision-makers in the administration embraced the concept as a natural extension of the values and mission of the university. Further, the university recognized the opportunity to position itself as a leading educational institution in exploration of the subject of sustainability (i.e., as competitive advantage in attracting students, faculty, and research funding), as well as an opportunity to reform its internal operations to reduce the organization's ecological footprint, and decrease operating costs through enhanced efficiencies. Efforts to further institutionalize sustainability as a core focus of the university in operations and academics are ongoing.

Sample

The sample consists of non-instructional faculty $(n=125)$, classified staff $(n$ $=87$, Facilities and Planning (FAP) employees $(n=40)$, from the PSU community (total $n=252)$; a response rate of 25.1 percent. The final sample of gender $(\mathrm{F}=$ 
$60.8 \%, \mathrm{M}=39.2 \%)$ and employment type (Full-time $=87.7 \%$, Part-time $=12.3 \%)$ were fairly representative of the population, based on the university's fall 2004 demographic data $($ Female $=62.4 \%$, Male $=37.6 \% ;$ Full-time $=88.5 \%$, Part-time $=$ $11.5 \%$ ). No comparable data were available to assess the representativeness of the sample's length of tenure with the university $(0-1 \mathrm{yrs}=11.2 \% ; 1-5 \mathrm{yrs}=39.2 \% ; 5$ $10 \mathrm{yrs}=22.4 \% ; 10-20 \mathrm{yrs}=13.9 \% ;>20 \mathrm{yrs}=13.2 \%)$.

\section{Measurement Process}

The SCS was developed for administration both in hardcopy format (see Appendix E), and on-line using the software Websurveyor. Hardcopies were administered to Facilities and Planning employees, via the office mailbox system. Crew supervisors were provided multiple copies to distribute to their crew members. This version of the survey was presented with a letter from the Director of FAP encouraging participation (see Appendix C).

The on-line version was distributed via direct e-mail from the mailbox of the university's Vice President, who encouraged employee participation (see Appendix A). Announcements of the survey were also made through the internal newsletter, Currently (see Appendix B). Recruitment was supplemented through direct personal contact with an estimated 150 employees, disproportionately FAP employees.

Employees who selected to participate in the study encountered a letter of informed consent that conveyed the study's purpose, their rights as a participant, and essential contact information to address their questions or concerns (see 
Appendix D). Instructions were presented in bold and generally asked participants to select responses to Likert scale items that best represented their perspective. The Likert scales used for each measure are specified in the section below (see also Scale Key for Table 6 and Table 7). At one point, subjects were instructed to read a short narrative, and several opportunities for open-ended responses were provided. The reader is encouraged to review Appendix E for further appreciation of the measurement process from the participant's perspective.

\section{Sustainability Climate Measures}

Top-management (i.e., administrative) support. Four items were developed to assess the extent to which employees perceived the PSU administration as supportive of efforts towards sustainability (see Table 6, items \# 18-21). For example, "PSU's administration has clearly demonstrated support for efforts towards sustainability." All items employed the use of a 5-point "strongly agreestrongly disagree" scale.

Sustainability norms. Five items were developed to assess employee perceptions that co-workers valued and took the subject of sustainability seriously (See Table 5, items 22-26). A sample item is, "My coworkers take the subject of sustainability very seriously." Item 23 was adopted from Doppelt (2003), and items 25 and 26 are modified from the Hoffman, et al. (2003) measure of safety climate. All items employed the use of a 5-point "strongly agree-strongly disagree" scale.

Rewards. To determine the extent to which employees perceive actions towards sustainability at PSU to be rewarded, four items were developed (see Table 
6, items 27-30). An example item is, "At PSU, aligning work practices with sustainability is rewarded.” Item 28 was modified from the Hoffman, et al. (2003) measure of safety climate. All items employed the use of a 5-point "strongly agree-strongly disagree" scale.

Employee involvement. Four items were developed to assess whether each employee had been involved in the effort to advance PSU's sustainability objectives (see Table 6, items 31-34). An example item is, "I have had the opportunity to contribute to PSU's sustainability efforts." Additionally, employee involvement was defined as being informed or educated about the concepts of sustainability, as well as feeling encouraged and open to share ideas related to sustainability. Single items were developed to capture each of these two aspects of the employee involvement construct. All items employed the use of a 5-point "strongly agreestrongly disagree" scale.

Shared vision. To assess the factor of the presence of a clear vision known to employees, 4 items were developed (see Table 6, items 35-38). An example item is, "My colleagues and I have a clear shared understanding of PSU's vision regarding sustainability." Items 35 and 36 are modified from items originally developed by Doppelt (2003). All items employed the use of a 5-point "strongly agree-strongly disagree" scale.

\section{Sustainability Beliefs Measures}

Personal understanding. Two methods of assessing understanding of the concept of sustainability were employed. The first method entailed instructing 
participants to read a brief synopsis of the concept of sustainability, which was followed by three self-report items asking their understanding of the concept (see Table 6, items 1-3). For example, "I still have very little understanding of this idea of sustainability." These items employed the use of a 5-point "strongly agreestrongly disagree" scale.

Additionally, ten sets of paired items were developed. These items were developed to prime participants on the survey's intended usage of the term sustainability on subsequent items. Collectively, these items serve as a screen of subjects with poor understanding of sustainability. Each pair contains a term or phrase common in the on-going public dialogue about sustainability representing a central idea or theme of the concept, along side an antonym of that term or phrase (see Table 6, items 8-17). For example, the term "community" was paired with the term "isolation," and the terms "consumption" and "conservation" were paired together. Subjects were asked to select the option that was most consistent with the concept of sustainability. An option of "unsure" was included with each pair to provide subjects with the opportunity to concede uncertainty about which option was the appropriate response. Responses to these items were scored according to the following point scheme: one point for a correct response; minus one point for selecting the antonym; and zero points for selecting "unsure." As such, a higher summed score of the ten items demonstrates greater personal understanding of the concept of sustainability. It was determined that subjects ought to score a minimum of six points on the screen to qualify for inclusion in subsequent analysis. Failure to 
attain a score higher than six points suggests a potential lack of understanding of the concept of sustainability as it is being employed in this context. Thus, all future responses to items evoking the term "sustainability" may be generating invalid responses.

Supportive attitude. To assess individual attitudes towards sustainability, nine items were developed (see Table 6, items 43-51). These items tap people's recognition of the problems assumed by the sustainability movement and their perceptions of the importance of confronting those problems. Sample items include, "It is our responsibility as a public institution to strive towards sustainability," and, "There is nothing to worry about, technology always has and always will solve the problems threatening the environment." As indicated by the last item, an opportunity is provided for subjects to not only disagree with statements in affirmation of the importance of sustainability, but also to agree with potential perspectives that suggest sustainability is not that pressing of a concern. All items employed the use of a 5-point "strongly agree-strongly disagree" scale.

Positive engagement. Also known as the Shambala factor, four items were developed to evaluate whether addressing the subject of sustainability enhances employees' levels of positive engagement with their work (see Table 6, items 3942). An example item is, "I am motivated by the challenge of addressing sustainability." All items employed the use of a 5-point "strongly agree—strongly disagree" scale. 


\section{Criterion Measures}

Sustainability role expectations. Modeled after the Hofman et al. (2003) measure of safety role expectations, eight items were developed to measure role expectation with respect to sustainability. Items 71 and 74 were directly adopted from Hoffman et al. (2003), with appropriate changes in terminology (see Table 6, items 70-77). An example item is, "Making suggestions about how to integrate sustainability into policies and procedures." Response options fall along a five point scale with anchors at the first, third and fifth points: "Definitely expected part of my job," "Somewhat beyond expectations," and "Definitely above and beyond expectations," respectively.

Sustainability role behaviors. Mirroring the sustainability role expectations items, an equal number of role behavior items were developed to assess whether or not people actually engaged in behaviors and decision-making that reflected active exploration of the concept of sustainability (see Table 6, items 78-85). Response options followed a 5-point "never-very often" scale.

Environmental stewardship. Through a brainstorming process with SMEs of the environmental movement, a list of behaviors was generated that reflected a conscious individual effort to reduce one's ecological footprint. This list was refined through reflection on the applicability of these behaviors to work-life in a University setting. The result is a set of 7 environmental behavior items assessed on a 5-point scale ranging from "never-always" (see Table 6, items 86-92). Each item reflects a dimension of personal behaviors that potentially affects the 
environment: transportation, food consumption, purchasing decisions, resource use, and recycling. For example, "I am very conservative in my use of resources and supplies at work."

Quality of Work Life Measures

Sense of community. To determine the extent to which employees perceive PSU as a place where people interact with each other in a positive and mutually supportive manner, four items were developed (see Table 6, items 52-55). An example item is, "People look out for the welfare of one another at PSU." These items employed the use of a 5-point "strongly agree-strongly disagree" scale.

Community engagement. As an outcome measure of the degree to which employees of PSU are civically engaged in their community, four items were developed (see Table 6, items 93-96). An example item is, "I'm actively involved in addressing social issues." Response options to these items followed a 5-point "never-very often" scale.

Work overload. Four items were adopted from Cammann, Fichman, Jenkins, and Klesh (1983) scale assessing work overload (see Table 6, items 56-59). An example item is, "I never seem to have enough time to get everything done." The factor is included as both a measure of work stress, thus a social sustainability indicator, and for evaluation in the test for discriminant validity (see heading, "Convergent and divergent validity" below). These items employed the use of a 5point "strongly agree-strongly disagree" scale. 
Job-decision latitude. Five items were selected from the Karasek (1979)

Job Content Questionaire (JCQ) as a measure of control one has in their job (see Table 6, items 60-64). The construct of job-decision latitude, represents two dimensions of decision authority, and skill discretion. Two items assess decision authority, for example, "My job allows me to make a lot of decisions on my own." Three items assess skill discretion, for example, "I get to do a variety of different things on my job." These items employed the use of a 5-point "strongly agreestrongly disagree" scale.

Job satisfaction. To tap the construct of job satisfaction, 5 items were adopted from the Warr, Cook and Wall (1979) measure. Items were selectively chosen to represent key dimensions of the job satisfaction construct, including satisfaction with working conditions, compensation, opportunity to use abilities, and recognition received. A global assessment of overall satisfaction was included (see Table 6, items 65-69). An example item is, "Your level of satisfaction with: recognition you get for good work." These items employed the use of a 5-point "very dissatisfied-very satisfied" scale. 


\section{CHAPTER V}

\section{RESULTS}

The first analysis conducted was an evaluation of participants' performance on the personal understanding screen of the paired items. It was noted that a substantially larger number of participants responded incorrectly or with the "unsure' response to the seventh pair (see item 14, Table 6). Review of this item suggested it was relatively ambiguous, and that depending on the perspective taken one could make a case for either response. Thus, item 14 was removed from the analysis, and the final score requirement was relaxed from six points to five. Perfect scores of nine were attained by $69.4 \%$ of the participants, while an additional $23 \%$ scored seven or eight. Only three subjects (1.2\%) failed to satisfy the minimum requirement of five to be included in subsequent analyses.

The subsequent analyses can be understood to serve the end of establishing construct validation. As such, the question is essentially whether the developed instrument measuring the underlying constructs it is intended to measure (Hinkin, 1998). To answer this question a series of analyses were conducted, including, two separate factor analyses of the sustainability climate measures and the measures of sustainability beliefs, a higher-order factor analysis, assessment of internal consistency of each established factor, and an examination of convergent and divergent validity. Further, criterion validities are explored which includes examination of each hypothesis, hierarchical regressions are conducted to assess the degree to which each factor uniquely predicts the different criteria, and agreement 
among responses is reviewed to determine if the psychological climate data can be aggregated to the level of organizational climate.

\section{Factor Analysis}

Two separate factor analyses of participants' responses were conducted. The first analysis considered the proposed sustainability climate items (Table 6, items 18-38), while the second analysis considered the personal items (Table 6, items 1-3 and 39-15). Both analyses employed the same methods, utilizing common factor analysis and oblique rotation. Common factors analysis, namely Principal Axis Factoring, was employed due to my interest in relationships among theoretically established latent variables, beyond interest in maximizing the amount of variance explained (Ford, MacCallum, \& Tait, 1986). An oblique rotation, namely Direct Oblimin (delta $=0)$, allowed some correlation between distinct constructs, providing a more accurate representation as factors in the real world are rarely uncorrelated (Ford et. al., 1986). An appropriate factor solution was explored, considering the eigenvalues above (or near) one, a scree test of the variance explained (Cattell, 1966; Russel, 2002), and interpretability of the factors (Hinkin, 1998).

Factor analysis of sustainability climate items. The above-described methods of Principle Axis Factoring, and Direct Oblimin rotation, were employed on items 18-38. The rule of thumb of observing eigenvalues above one suggested a model with five factors. The fifth factor registered an eigenvalue of 1.17 , while the sixth factor registered at only 0.70 . Review of the scree plot reinforced that a five- 
factor model should be pursued. The five-factor solution accounted for $67.5 \%$ of variance.

The five-factor model made clear theoretical sense as the items loaded fairly cleanly within the originally proposed factors, top-management support, sustainability norms, rewards, employee involvement, and shared vision. There is one exception to the cleanliness of the loadings. The loading of item 31 (involv_1) on its theorized factor is only 0.34 , and it also loads at 0.28 and 0.27 on the vision and top-management support factors respectively. Item 31 also had the lowest communality (0.50) of all the items. Reflection on the content of this item shed light on why this item may not have loaded cleanly. Item 31 suggests the passive reception of information on the subject of sustainability from the ambiguous source "PSU." In contrast, the other three involvement items speak to more direct and active engagement with the university's pursuit of sustainability.

The factor analysis was conducted again, this time without item 31, using the same methods of Principle Axis Factoring, and Direct Oblimin rotation. Once again a five-factor model was indicated by the eigenvalues above 1.0 and the scree plot analysis, accounting for $68.62 \%$ of the variance. The interpretability of this factor solution was consistent with the theorized constructs, and in observing the loadings there were no problematic items (see Table 8). Thus, the sustainability climate items load into a five-factor solution of top-management support, sustainability norms, rewards, employee involvement, and shared vision. 
Factor analysis of personal sustainability items. The same methods of Principle Axis Factoring, and Direct Oblimin rotation described above were employed on items 1-3 and 39-51. The rule of thumb of observing eigenvalues above 1.0 suggested a model of three factors. The third factor registered an eigenvalue of 1.70 , while the fourth factor registered an eigenvalue of 0.96 . Review of the scree plot reinforced that a three-factor model should be pursued. The threefactor solution accounted for $57.6 \%$ of variance. The three-factor model made clear theoretical sense as a simple structure was attained that was consistent with the originally proposed factors: personal understanding, positive engagement, and supportive attitudes (see Table 9).

Noting that the fourth factor's eigenvalue (.96) was near the arbitrary cut off of 1.0, a four-factor solution was also explored. This fourth factor only accounted for an additional $3.5 \%$ of variance. A near simple structure was obtained. The fourth factor consisted of three of the four items that were reverse coded. Each of these three items gives respondents an opportunity to disagree or agree with statements that suggest circumstances are not as bad as some may make them out to be. These are reverse coded, as one would expect agreement with these items to be opposite of agreement to other belief items that speak to the importance of addressing sustainability. It is tempting to declare this fourth factor as indicative of some sense of risk perception, or degree of the problem. However, review of the other attitudinal items suggests that this latent construct may already be captured. Why else would one express agreement with the notion that addressing 
sustainability is essential to the long term existence of human society, including PSU if there wasn't perceived risk? The same, but reversed logic holds true if one disagrees. Noting the minimal added variance accounted for (3.5\%), as well as the strong correlation (0.80) between this fourth factor and the supportive attitude factor, the more parsimonious three-factor solution is determined to be the most appropriate. Thus, the personal sustainability items settle into a three-factor model, organized into the theoretical constructs, personal understanding, positive engagement, and supportive attitude.

Higher-order factor analysis. Using composite scores for all eight of the established factors from the above models (excluding items identified as problematic from the internal consistency analyses below), a higher-order factor analysis was conducted to determine whether there was a meaningful theme uniting the established factors. Principle Axis Factoring and Direct Oblimin rotation were employed, indicating a two-factor model by the eigenvalues above one and the scree plot analysis, accounting for $57.97 \%$ of the variance. The pattern structure (see Table 10) was consistent with the already proposed factor themes of sustainability climate, and sustainability beliefs. Noting the relatively weak loading of employee understanding on the personal sustainability factor, as well as a third eignevalue near $1(.914)$, and a potential increase of $11.5 \%$ in variance accounted for, prompted exploration of a three-factor solution. SPSS was unable to converge the composite variables into three-factors, abandoning the effort after 1000 
iterations. Thus, I rest upon the parsimonious and interpretable two-factor solution of sustainability climate measures, and sustainability beliefs.

\section{Internal consistency}

The internal consistency of each factor was assessed with attention to coefficient alpha, alpha-if-item-deleted, and item standard deviations. Coefficient alpha was observed to confirm the unidimensionality of the above-established factors (Cortina, 1993). Alphas for each of the scales can be seen in Table 11. If the deletion of an item from a factor solution noticeably increased the inter-item correlation, then that item was considered for removal from the scale (Cortina, 1993). Attention was also given to the standard deviations of responses to each item to ensure that a reasonable amount of variance was obtained.

Items comprising top-management support $(\alpha=0.88)$ had standard deviations ranging from 0.86 to 0.95 , and the alpha of the scale did not improve with the deletion of any items. Items comprising sustainability norms $(\alpha=0.91)$ had standard deviations ranging from 0.83 to 1.0 , and the deletion of any of the items did not improve the alpha of the scale. Items comprising the rewards scale ( $\alpha$ $=.85$ ) had standard deviations ranging from 0.82 to 1.04 . The removal of the second reward item (see Table 6, item 28) increased the alpha of the scale to 0.89. This item also displayed the lowest inter-item correlation $(r=0.52)$ of the scale, including a paltry 0.38 correlation with the first item of the scale (see Table 6 , item 27). Review of item 28 revealed the question was qualitatively distinct from the other reward items. While each of the other items sought insight into what was 
rewarded, item 28 sought insight into whether "negative performance evaluations" were delivered to those who fail to consider each of the three dimensions of environment, economy and society in their decisions. Based upon this evidence it was decided that item 28 should be removed from the reward scale.

Continuing with the analysis of the factors within the meta-construct of sustainability climate, the items comprising the scale of employee involvement $(\alpha=$ 0.82) have standard deviations ranging from 0.89 to 0.98 . Deletion of any of these items does not improve the alpha of the scale. Items comprising shared vision $(\alpha=$ 0.90 ) each demonstrated standard deviations ranging from 0.88 to 0.92 , and the deletion of any of the items did not improve the alpha of the scale.

Moving to the internal consistency analysis of the factors within the sustainability beliefs meta-construct it is observed that the items comprising personal understanding $(\alpha=0.73)$ had standard deviations ranging from 0.92 to 1.09. The deletion of any of these items did not improve the alpha of the scale. Items comprising positive engagement $(\alpha=0.92)$ had standard deviations ranging from 0.86 to 0.99 , and deletion of any of the items did not improve the scale's alpha. Items comprising supportive attitude $(\alpha=0.88)$ had standard deviations ranging from 0.57 to 0.99 . The 0.57 standard deviation of item 43 as well as the 0.67 and 0.69 standard deviations of items 44 and 45 respectively, raises some concern about the amount of variance obtained by these variables. Deletion of these items or any other items within the scale fails to improve the overall alpha. However, it is noted that the alpha remains strong ( 0.86 or greater) if any one of 
these items is removed from the scale. Future applications of the SCS may consider taking the liberty of reducing the nine items to a shorter set for assessing general attitudes towards sustainability.

Despite being a seven-item measure, a low internal-consistency was noted for the outcome, environmental stewardship (alpha $=.60$ ), raising some concern about whether the criterion is a psychometrically sound construct. To see if a more coherent scale could be achieved, alpha-if-item-deleted was observed, and factor analyses of the items were conducted. The elimination of item (persbeh_2, see table) slightly increased the alpha (0.62). Subsequent deletion of item (persbeh_7), then item (persbeh_1) was only able to modestly improve the alpha of the remaining items to 0.65 . Deletion of further items failed to improve the alpha. Further, a factor analysis failed to organize the items into a meaningful factor structure, regardless of the number of items preserved in the scale.

\section{Convergent and Divergent Validity}

Further effort to demonstrate construct validity employed a correlation matrix to examine convergent validity (see Table 11) and divergent (i.e., discriminant) validity evidence (see Table 12). Such evidence is defined as "the extent to which the scales correlate with other measures designed to assess similar constructs (convergent validity), and to which they do not correlate with dissimilar measures (discriminant validity)" (Hinkin, 1998, p 116). Below I discuss what constitutes similar constructs and dissimilar constructs. 
As anticipated, all of the sustainability climate factors demonstrate strong positive correlations with one another (see Table 11). Each of these factors represents aspects of work life with respect to the subject of sustainability. In a context where there is legitimate effort, or the lack of effort, to integrate sustainability into the workplace it is expect that these measures would vary with some uniformity. Similarly, the personal measures all significantly correlated with one another. There was an especially strong correlation noted between the positive engagement factor and the supportive attitude factor $(\mathrm{r}=.59, \mathrm{p}<.001)$. Such a relationship is not of surprise; people with a more supportive attitude towards the concept of sustainability should be more personally compelled by actual engagement in sustainability efforts.

Positive engagement also correlated with each of the sustainability climate measures, with the exception of top-management support. The strongest of these correlations is observed between positive engagement and employee involvement ( $\mathrm{r}$ $=.33, \mathrm{p}<.001)$. Such a relationship may result from employees being more inclined to seek personal involvement if the employee is intrinsically motivated to address sustainability. Alternatively, involvement may provide a truly engaging and meaningful experience for employees. The relationship between positive engagement and sustainability norms $(r=.20, p<.01)$ could be the result of peer groups developing shared attitudes through interactions over time. The relationship between positive engagement and rewards $(r=.15, \mathrm{p}<.05)$ might result from those who are personally engaged are more likely to have direct experience receiving 
rewards for the contributions they have made to the organization's sustainability objectives. Considering the anticipated relationships, and having reasonable interpretations of unanticipated relationships, I consider the above as satisfactory evidence of convergent validity.

To examine discriminant validity, two measures were used, including a scale assessing stress adopted from Cammann, et al. (1983), and a scale of work control adopted from the job-decision latitude construct in the JCQ (Karasek, 1979). The results show that most of the sustainability climate and personal measures scales were uncorrelated with the stress scale or the job-decision latitude scale, with a few relatively minor exceptions (see Table 12). Top-management support $(\mathrm{r}=$ $.21, \mathrm{p}<0.001)$ and rewards $(\mathrm{r}=.21, \mathrm{p}<0.001)$ both correlated with job-decision latitude. Beyond possibly reflecting aspects of global organizational climate (Sinclair, personal communication, 2005), I am unable to identify a meaningful rationale for why these measures correlate as they do. Despite the observed significance, the correlations are smaller than the size of theoretically more meaningful relationships.

Another apparent exception to the precision of the divergent validity evidence includes the correlations between employee involvement with both work overload $(\mathrm{r}=.12, \mathrm{p}<.05)$ and job-decision latitude $(\mathrm{r}=.13, \mathrm{p}<.05)$. The correlation with work overload can be understood due to the fact that involvement in sustainability efforts may add one more thing to an employee's work demands. That and/or individuals who have been called upon to contribute to sustainability 
are also relied upon for more responsibilities in general. Regarding the job-decision latitude correlation, it may be that the degree of employee involvement in the university's sustainability efforts operates, in part, as a factor of their latitude to seek involvement if they desire. Or, the university's inclinations to involve its employees in such efforts may correlate with the decision-latitude afforded to employees because of a more fundamental aspect of the university's culture; the degree to which the university values the perspectives and autonomy of its employees. It should also be noted that relative to anticipated relationships, these correlations are fairly low.

Taken as a whole, the above results provide satisfactory evidence for convergent and divergent validity. Subsequently, I have increased confidence that my scales are measuring the latent constructs they are intended to measure.

\section{Criterion Validity}

To ascertain criterion validity evidence for the SCS, three outcome measures were designed to assess the university's progress in terms of: (1) sustainability role expectations, the perception that integrating the concept of sustainability into one's work role is expected; (2) sustainability role behaviors, whether they actually integrate the concept of sustainability into their work role; and (3) environmental stewardship, personal behaviors that minimize one's ecological footprint. These measures were included in a correlation matrix (see Table 12) and were held as the criteria against which the predictor constructs were compared. 
Hypothesis 1 predicted that perceptions of top-management support for the organizations sustainability initiative would positively correlate with sustainability role expectations (SRE), sustainability role behaviors (SRB), and environmental stewardship (ES). Table 12 illustrates that top-management support predicts SRE (r $=.15, \mathrm{p}=.022)$ and $\mathrm{SRB}(\mathrm{r}=.18, \mathrm{p}=.006)$, while the measure failed to correlate significantly with ES ( $r=-.03, \mathrm{~ns})$. These results suggest employees who perceive greater support from the university's administration, are more likely to consider sustainability as part of their work role, and integrate the principles of sustainability into their work routine. However, when it comes to discrete behaviors, as measured by environmental stewardship, an increase in perception of administrative support does not increase the likelihood those behaviors will be engaged.

Hypothesis 2a predicted that sustainability norms would positively correlate with sustainability role expectations, sustainability role behaviors, and environmental stewardship. The first two-thirds of this hypothesis was confirmed, as sustainability norms significantly correlated with $\operatorname{SRE}(r=.24, \mathrm{p}<.001)$ and SRB $(r=.31, \mathrm{p}<.001)$, but not with ES $(r=.06, \mathrm{~ns})$. These results suggest that perceived expectations to integrate sustainability into one's role, and the likelihood that they will actually do so increase as perceptions that coworkers personally value the concept of sustainability and take such issues seriously increase. However, perceptions that coworkers value and integrate sustainability into their work do not hold a relationship with an individual's engagement in environmentally conscious behaviors. 
Hypothesis $2 \mathrm{~b}$ predicted that as sense of community would be a moderator in that as it increased, the strength of the relationship between sustainability norms with sustainability role behaviors, and environmental stewardship would increase. To assess hypothesis $2 \mathrm{~b}$ the scales for sense of community and sustainability norms were centered to reduce potential colinearity effects. A regression analyses reconfirmed a main effect of the significant relationship between sustainability norms and $\operatorname{SRB}(B=.296, \mathrm{t}(242)=4.63, \mathrm{p}<.001)$, while showing no relationship between sense of community and $\operatorname{SRB}(B=.024, \mathrm{t}(242)=0.38, \mathrm{~ns})$. The interaction term $\left(\mathrm{nrm}^{*}\right.$ comm $)$ failed to explain additional variance in $\mathrm{SRB}\left(\Delta R^{2}=\right.$ $.02, \mathrm{t}(242)=-.75, \mathrm{~ns})$. Further investigation confirms the non-significance of the interaction (see Figure 4, p. 85).

A second regression analysis with respect to ES showed no main effects for sustainability norms $(B=.076, \mathrm{t}(243)=1.13, \mathrm{~ns})$, nor sense of community $(B=-$ $.051, \mathrm{t}(243)=-0.77, \mathrm{~ns})$. The interaction failed to explain additional variance in ES $\left(\Delta R^{2}=.00, \mathrm{t}(243)=.05, \mathrm{~ns}\right)$. These results lead me to reject hypothesis $2 \mathrm{~b}$, as the strength of the relationship between the social norms and an individual's engagement in sustainability related behaviors does not increase with higher levels of group cohesion.

Hypothesis 3 predicted that rewards would positively correlate with SRE, $\mathrm{SRB}$, and ES. Of these predicted relationships, rewards significantly correlated with SRE $(r=.20, p<.01)$, but the measure was not related to SRB $(r=.12, n s)$ and ES $(r=.01, n s)$. These results show that greater prominence of rewards for 
Figure 4:

Investigation of interaction between sense of community and sustainability norms on SRE.

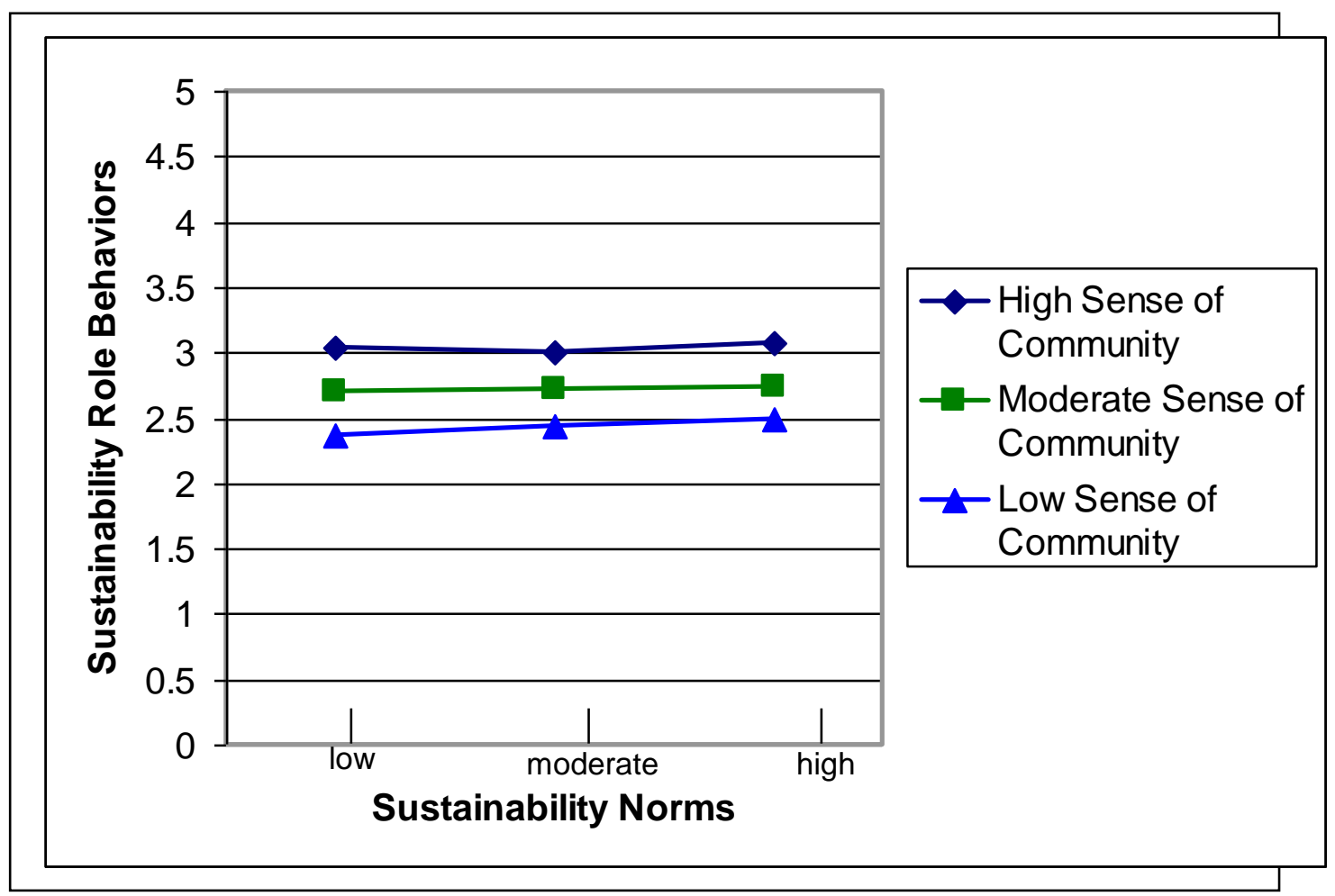

integrating sustainability into work practices increases the perception that sustainable work practices are expected of employees. However, the rewards measure fails to predict whether people will integrate sustainability into their role, or engage in personal behaviors that reduce one's ecological footprint.

Hypothesis 4 predicted that employee involvement would be positively correlated with SRE, SRB, and ES. These relationships were confirmed; employee involvement correlated significantly with SRE $(\mathrm{r}=.19, \mathrm{p}<.01), \operatorname{SRB}(\mathrm{r}=.44, \mathrm{p}<$ $.001)$, and ES $(r=.19, \mathrm{p}<.01)$. These results suggest that the degree to which 
employees are included in an organization's efforts to advance a sustainability agenda increases the likelihood that they will perceive an expectation and actually integrate sustainability into their work role, as well as engage in environmental stewardship behaviors.

Hypothesis 5 predicted that shared vision would be positively correlated with SRE, SRB, and ES. Two-thirds of this hypothesis was confirmed as shared vision demostrated significant correlations with $\operatorname{SRE}(r=.29, \mathrm{p}<.001)$ and $\mathrm{SRB}(\mathrm{r}$ $=.29 . \mathrm{p}<.001)$, but was not related to ES $(\mathrm{r}=.08, \mathrm{~ns})$. These results show that employees who are familiar with the organization's vision of sustainability are more likely to consider sustainability as part of their role, and integrate the concept into their work routine. However, an increase in awareness of the organization's vision for sustainability does not predict an increase in the likelihood employees will engage in environmental stewardship behaviors.

Hypotheses regarding the measures of sustainability beliefs (hypotheses 6, 7, and 8) predicted that the three factors, personal understanding, positive engagement, and supportive attitude would all be positively correlated with SRB and ES, though not with SRE. Each of these hypotheses was confirmed. Personal understanding correlated significantly with $\mathrm{SRB}(\mathrm{r}=.25, \mathrm{p}<.001)$ and $\mathrm{ES}(\mathrm{r}=.23$, $\mathrm{p}<.001)$, while demonstrating a non-significant relationship with SRE $(\mathrm{r}=.03, \mathrm{~ns})$. Likewise, positive engagement correlated significantly with $\operatorname{SRB}(r=.52, \mathrm{p}<.001)$ and ES $(r=.44, p<.001)$, while this measure demonstrated a non-significant relationship with SRE $(r=.07, \mathrm{~ns})$. Additionally, supportive attitude correlated 
significantly with SRB $(\mathrm{r}=.34, \mathrm{p}<.001)$ and ES $(\mathrm{r}=.41, \mathrm{p}<.001)$, while demonstrating a non-significant relationship with SRE $(r=.00, n s)$. These results show that employees who understand the concept of sustainability and who value sustainability are more likely to integrate sustainability into their work roles, as well as engage in concrete personal behaviors that reduce their ecological footprint at work. For example, individuals who do not support efforts to address sustainability will be less likely to consider sustainability in their work routines or engage in proenvironmental behaviors than an individual who scores high on the attitudinal measure. These results also show that responses to the personal measures are unrelated to perceptions that employees are expected to integrate sustainability into their work routine. Overall, significance in the correlations of hypothesized relationships between the predictor factors and the outcome measures provides decent but mixed evidence for the criterion validity of the SCS.

\section{Hierarchical Regression}

Hierarchical regressions were conducted to assess the unique variance accounted for in the criterion measures by the climate and beliefs factors. Three sets of analyses were conducted, each controlling for several demographic variables (gender, length of tenure, and academic versus non-academic affiliation). The first analysis included the five sustainability climate measures (top-management support, sustainability norms, rewards, employee involvement, and shared vision) and explored the variance accounted for in SRE and SRB. ES was not examined as a dependent variable of these factors as only one of the sustainability climate 
measures predicted ES even without controlling for other factors. The second analysis included the three measures of sustainability beliefs (personal understanding, positive engagement, and supportive attitude), and explored the variance accounted for in SRB and ES. SRE was not evaluated, because as anticipated, these factors were not correlated with the SRE criterion. Finally, an analysis was conducted that explored the collective power of the sustainability climate and the sustainability beliefs factors in accounting for the variance of SRB, while controlling for the demographics.

Sustainability Climate Analysis. As displayed in Table 15, a hierarchical regression analysis revealed that after controlling for demographics, the sustainability climate measures accounted for $10.8 \%$ of the variance of SRE $\left(R^{2}=\right.$ $.11, F(5,227)=3.59, p=.001)$. Sustainability norms $(B=.16, t(235)=2.29, p=$ .02$.$) and shared vision (B=.19, t(235)=2.06, p=.04)$ were the only two unique predictors of sustainability role expectations.

After controlling for the demographics, the sustainability climate measures accounted for $27.5 \%$ of the variance of SRB $\left(R^{2}=.28, F(5,230)=11.25, p<.001\right)$. Sustainability norms $(B=.29, t(238)=4.58, p<.001)$ and employee involvement $(B=.43, t(238)=5.99, p<.001)$ were the only two unique predictors of sustainability role behaviors (see Table 16). Tolerance statistics for the sustainability climate regressions ranged from .47 to .81 , well above the .20 level that would indicate multicolinearity problems (Tabachnick \& Fidell, 2001). 
Sustainability Beliefs Analysis. As shown in Table 17, a hierarchical regression analysis revealed that after controlling for the demographics, sustainability beliefs accounted for $30.0 \%$ of the variance in $\mathrm{SRB}\left(R^{2}=.30, F(3\right.$, $230)=16.86, p<.001)$. Personal understanding $(B=.16, t(236)=2.85, p=.005)$ and positive engagement $(B=.45, t(236)=6.42, p<.001)$ were unique predictors of SRB.

After controlling for the demographics, the measures of sustainability beliefs accounted for $23.2 \%$ of the variance in $\operatorname{ES}\left(R^{2}=.23, F(3,230)=13.49, p<\right.$ $.001)$. As shown in Table 18, all three of the measures, personal understanding $(B=$ $.12, t(236)=2.07, p=.04)$, positive engagement $(B=.32, t(236)=4.40, p<.001$, and supportive attitude $(B=.17, t(236)=2.24, p=.03)$ were unique predictors of ES. Tolerance statistics for the sustainability beliefs regressions ranged from .64 to .94 easing concerns about multicolinearity (Tabachnick \& Fidell, 2001).

Analysis of Sustainability Climate and Sustainability Beliefs Factors. After controlling for the demographics, collectively the factors of the two models accounted for $42.2 \%$ of the variance in $\operatorname{SRB}\left(R^{2}=.42, F(8,224)=15.20, p<.001\right)$ (see Table 19). Controlling for all other factors, only sustainability norms $(B=.22$, $t(235)=3.73, p<.001)$, employee involvement $(B=.27, t(235)=4.07, p<.001)$, personal understanding $(B=.13, t(235)=2.49, p=.01)$ and positive engagement $(B$ $=.33, t(235)=4.86, p<.001)$ demonstrated unique predictive power. These regressions including all sustainability climate and sustainability beliefs factors had 
tolerance statistics ranging from .46 to .89 , easing concerns about multicolinearity (Tabachnick \& Fidell, 2001).

\section{Predicting Environmental Stewardship Items}

Closer examination was given to the relationship between the sustainability climate measures and the individual items comprising the ES criterion. This examination was deemed appropriate due to suspicion that the individual items did not hold together as a coherent construct, and that each may have unique predictors. Results show that most of the sustainability climate measures fail to significantly correlate with most of the ES items, with employee involvement demonstrating the strongest pattern of relationships as a predictor (see Table 14). A different pattern was observed with respect to the third and fourth ES items. The third ES item reflects recycling of papers products, and the fourth ES reflects recycling of all other recyclable material. With the exception of rewards, each of the other climate measures significantly correlate with these two items. A hierarchical regression reveals that the model of sustainability climate measures explains $8.4 \%$ of the variance in paper recycling $\left(R^{2}=.084, F(5,240)=4.37, p=.001\right)$, and $11.8 \%$ of the variance in all other recycling $\left(R^{2}=.118, F(5,239)=6.39, p<.001\right)$. Employee involvement $(B=.276, t(240)=3.60, p<.001)$ was the only unique predictor of paper recycling. Employee involvement $(B=.327, t(239)=4.34, p<.001)$ and rewards $(B=-.164, t(239)=-2.10, p<.05)$ were the only two unique predictors of recycling all non-paper recyclables. Controlling for sustainability beliefs employee 
involvement remained a significant predictor of both paper recycling $(B=.195$, $t(240)=2.46, p<.05)$ and non-paper recycling $(B=.222, t(239)=2.87, p<.01)$.

\section{From Psychological Climate to Organizational Climate}

As noted earlier, measurement took place on the individual level, thus responses to the sustainability climate measures provide a picture of the psychological climate within the organization. However, the question remains about the nature of the organizational climate. This is of interest because it is through the establishment and maintenance of a strong organizational climate of sustainability that theoretically will create a new organizational culture of sustainability. To declare the presence of an organizational climate, agreement among individual responses to the sustainability climate measures must be established. To make this determination, the measure of standard deviation for each scale was recorded (see Table 13), and frequency distributions were observed. Standard deviations at and below 0.50 were taken to indicate relative agreement among participants, as that would suggest that $68 \%$ of participants responded within a range of 1.0. Frequency distributions were eyeballed to identify any unusual patterns that may not be reflected in the means or standard deviations.

As observed in Table 13, none of the measures have standard deviations at or below 0.50 . Review of the frequency distributions shows uniqueness in the patterns of responses to different measures, but there was no trend of consistent agreement among subjects. Thus, I am unable to declare that there as an agreed upon perception of the presence of an organizational climate of sustainability. 


\section{CHAPTER VI}

\section{DISCUSSION}

This study sought to build off previous efforts (Hall, 2003) to develop and validate the Sustainability Climate Survey (SCS). Success in this endeavor holds promise to provide organizations with a tool to assist strategic efforts to integrate sustainability into organizational operations and ultimate their culture. Collective results from the administration of the SCS to a population of university employees suggest that the SCS demonstrates sound construct validity, meaning the survey measures what it is theoretically intended to measure. One shortcoming relates to relatively low power of the established factors in predicting the engagement of sustainability related behaviors in the workplace, or perceived expectations to integrate the principles of sustainability into work roles. Some additional limitations of the present study need to be acknowledged, and appropriate application of the SCS explored. These matters and recommendations for future research are discussed below.

Construct validation began with two exploratory factor analyses of the items comprising the SCS, which resulted in factors that aligned with the theory of my original measurement design. The first of two factor analyses focused on items designed to assess dimensions of the meta-construct of sustainability climate. The results revealed that the theorized five factors of perceived top-management support, sustainability norms, rewards, employee involvement, and shared vision, constituted an appropriate model. The second factor analysis of items designed 
under the meta-construct of sustainability beliefs, confirmed the appropriateness of a three-factor solution of personal understanding, positive engagement and supportive attitude. A higher-order factor analysis supported the appropriateness of distinguishing between the two themes of sustainability climate and sustainability beliefs. These themes provide a meaningful framework for organizing factors relevant to the advancement of a sustainability initiative. The climate factors constitute employee perceptions of the work environment specific to sustainability, while sustainability beliefs constitute employee's attitudes towards and knowledge about sustainability. As the following discussion will explore, these factors may represent key targets within management's range of influence to create an environment that supports and promotes the pursuit of sustainability.

Each of the identified scales had relatively strong internal-consistencies, giving confidence to reliability of the sets of items used to assess the latent constructs (Cortina, 1993). One change was deemed appropriate through this set of analyses. Attention was drawn to item 28, which when removed increased the alpha of the rewards scale. Review of the item revealed a qualitative difference from the other items in the scale. Namely, this item inquired into practices of punishment for failure to consider the notion of sustainability in decision-making. This angle contrasted with the other items of the scale, which focused on the practice of reinforcement for effectively considering the notion. Thus, the item was removed. Development of additional items around the notion of punishment is not suggested. The punishment of undesired behavior tells employees only what not to 
do, not what they should be doing (Nairne, 2003). Punishment could also create poor relations between employees and management. Thus, when it comes to promoting sustainability, an organization's focus should be on rewarding behavior deemed desirable.

A reasonable degree of divergent and convergent validity was established, providing further support that the scales measure the constructs they are intended to measure (Hinkin, 1998). As anticipated, all of the sustainability climate measures correlated with one another, and each of the measures of sustainability beliefs correlated with one another. As measuring aspects of work life with respect to sustainability, we would expect the climate measures to correspond with one another. Among the sustainability beliefs measures, it is of no surprise that people with a positive attitude towards that concept are more likely to be compelled by the challenge, and to have greater understanding of the concept.

Divergent validity was explored using the scales assessing stress and jobdecision latitude. A few modest exceptions to expectations were observed, including job-decision latitude's correlations with top-management support, rewards, and employee involvement, as well as a correlation between work overload and employee involvement. Reasonable rationales for these small relationships with employee involvement were identified. Job-decision latitudes relationship with the climate measures can best be explained as a reflection of the global organizational climate. In asking the question whether this evidence challenges the theoretical validity of the constructs, I gain some reassurance in 
recognizing that the strength of these relationships was less than those of theorized relationships. Further, more patterns of relationships corresponded with expectations than conflicted. Taken as a whole, I view the observed patterns of convergent and divergent relationships as additional support for the construct validity of the SCS.

Having established the core factors of the SCS, I turn attention to my hypotheses. Beginning with those proposing sustainability climate measures as predictors, I observed identical patterns in the results for hypotheses 1, 2a, and 5 . The first two-thirds of each of these hypotheses was confirmed as the measures of perceived administrative support, sustainability norms, and shared vision all showed positive relationships with sustainability role expectations and sustainability role behaviors. This demonstrates employees are more likely to perceive an expectation that they integrate the principles of sustainability into their role and actually engage in such integration as these three factors of the sustainability climate increase. As factors that are at least partially within management's control, these findings suggest some opportunities for influence. For example, visible demonstration of support for sustainability by leadership conveys a message to employees of the organization's sincerity towards the cause. Such a message then increases the likelihood that the employee will internalize the cause and address the issue through their work role. Also, appreciating that group norms factor into an employee's perception of their work role, and behavior within that role, suggests work units as a whole should be targeted to influence said perception and behaviors. Identifying influential 
individuals, or opinion leaders among work groups and gaining their support may be an effective strategy for creating social norms consistent with the organization's sustainability objectives, as has been illustrated in other settings (Lam \& Schaubroeck, 2000; Rogers, 1995). Further, communicating a clear vision provides employees with an orientation for their efforts, and helps them to make the connection between aspects of their work role and the vision. Care should be taken to ensure that the vision is not overly complicated or ambiguous (Kotter, 1995), and that it conveys a clear course of action (Doppelt, 2003).

However, the later third of hypotheses $1,2 \mathrm{a}$, and 5 were rejected as none of the measures of perceived administrative support, sustainability norms, or shared vision demonstrated a significant relationship with environmental stewardship (ES). As noted above, perhaps these behaviors are considered to be independent from work roles, thus the perceived climate bears no relevance to whether employees engage in those behaviors. Supporting this interpretation, SRE does not correlate with ES. In other words, regardless of perceived expectations to integrate the principles of sustainability into work roles, employees are no more or less likely to engage in the behaviors constituting ES. Thus, engagement in ES may be more a factor of personal attitudes, beliefs and values, or other structural factors that determine convenience. Indeed, the sustainability beliefs demonstrated significant relationships with ES. Again, the implication of this suggests that there may be certain behaviors that operate independently of workplace climate, and are 
dependent on other factors such as personal attitudes, access and structural ease to engage in the behavior.

Another possible interpretation of this failure to confirm these hypotheses concerning ES could be attributed to a lack of coherence of the measure. Low internal consistency was observed among the items comprising ES, and three items demonstrated especially low standard deviations, which may have contributed to range restriction that masked true relationships between ES and some predictors. However, eliminating these problematic items, and searching for sub-factors failed to establish a psychometrically sound construct. This is likely because the different behaviors that comprise ES run a broad range, from recycling paper products to modes of transportation taken to work. As such, each behavior may have a unique set of predictors.

Exploring this question of unique predictors further, I discovered that there were different patterns of relationships between the sustainability climate measures and the individual ES items. Employee involvement proved to be the most consistent predictor of these behaviors, and a relationship was found between all climate measures, except rewards, and the two items about recycling at work; one specific to paper recycling, the other specific to recycling all other recyclable material. These results reinforce the interpretation that the different behaviors comprising ES have different patterns of predictors, and that some of these behaviors operate independently of the workplace's sustainability climate. For example, whether someone eats organically and/or locally grown foods at work 
may be largely determined by the availability (i.e. proximity) of those foods to the individual. Since such foods are often more expensive, the level of financial security the person enjoys may be another determinant completely independent of the sustainability climate of the workplace. As another example, modes of transportation to work demonstrated the greatest variance, with subjects largely clustering around never taking alternative modes of transportation to work, or always taking alternative modes. Sustainability climate may not influence this behavior at all, rather, factors such as proximity between home and campus, access to public transportation, and parenting or other responsibilities may determine an individual's means of transportation.

Reflection on these results warrants the recommendation that future efforts to build on the validation of the SCS should consider each of the ES items as independent measures of distinct behaviors. If reliability is a concern, then perhaps additional items can be developed around the more general themes of transportation, food, and housing/household (campus) operations (Brower \& Leon, 1999). Further, awareness should be held that such behaviors may have other more significant predictors independent of the workplace climate. If prediction of these behaviors is of interest, then a more comprehensive assessment of variables (e.g., housing location, or perceived accessibility to organic foods) should be undertaken.

Another sustainability climate factor, rewards, only demonstrated a positive relationship with perceptions that considering sustainability is an expected aspect of one's work role. An absence of significant relationships with sustainability role 
behaviors and environmental stewardship means rejection of the later two-thirds of hypothesis 3 . One interpretation of this finding is that the rewards offered are not compelling enough to exert any influence over the behavior of employees on the job. Indeed, PSU has no formal reward system for sustainability, so what rewards do exist would primarily be on the level of positive feedback from peers and/or supervisors. Thus, it came as little surprise to observe that scores on the rewards measure were relatively low, and variance modest $(\mathrm{M}=2.58, \mathrm{SD}=0.75)$.

Alternatively, there may be issues with the measure itself. Participants may have differed in interpretations of the notion of being rewarded. To some informal positive feedback and localized recognition may constitute "rewarded," whereas others may require a formal and/or more substantive rewards system to endorse the rewards items. Also, it may not have been clear to participants whether a "disagree" response on the five-point scale reflected not merely the absence of rewards, but also some connotation of punishment. Such differing interpretations of the items may have masked a relationship between sustainability related behavior and the perception that the organization rewards such behavior. Future research might reconsider the method of measuring the rewards by conducting focus groups to explore possible variations in interpretations of the items. If deemed a reliable measure, then it would be interesting to study whether work groups with a rewards system for sustainability would show different patterns of criteria prediction from work groups that have no such rewards system. 
Contrary to the theoretical tragedy of hypothesis 3 , hypothesis 4 was confirmed. A positive relationship between employee involvement and each of the criteria suggests that as involvement increases, the likelihood increases that employees perceive sustainability to be an expected part of their role, actually integrate the principles of sustainability into their work routine, and engage in important environmentally conscious behaviors at work. It is worth noting that employee involvement was the only predictor to demonstrate significant relationships with all three of the outcomes. As such, this factor holds promise to be one of the most influential catalysts available to organizations to advance their sustainability objectives. Many unsustainable practices will require many solutions; the greater the degree to which an organization can leverage the knowledge and experience of their entire workforce to actively engage in exploring solutions to these inefficiencies the better.

It should also be noted that there is no implied causal arrow in the relationships between employee involvement and the criteria, or any other significant relationships found in this study. For example, those who take advantage of PSU's recycling program may cite that as indication of their contribution and involvement in the university's efforts. In a sense, these results merely reveal that employees who are engaged in the organization's efforts towards sustainability have been engaged. Future research might explore the most constructive avenues for organizations to involve their employees. Is it a matter of creating opportunities for employees to participate (e.g., a recycling program, green 
purchasing guides, community service opportunities)? Should the employees be empowered to develop and implement their own systems addressing aspects of sustainability? Likely, some combination of the two is warranted, and answers will surely vary across and within organizations depending on the nature of different work and job contexts.

Results also confirmed hypotheses 6,7 , and 8 as each of the sustainability beliefs measures, employee understanding, positive engagement and supportive attitude, significantly correlated with both sustainability role expectations and environmental stewardship. The positive relationships suggest that as each of these measures increase the likelihood that employees integrate sustainability into their work roles increases. Additionally, as each sustainability belief measure increase, employee engagement in concrete personal behaviors that reduce ecological footprints within the context of their work life increases. There are numerous implications of these results. Generally speaking, these results imply that an organization must go beyond the factors constituting climate and address individual characteristics of employees including their understanding the concept of sustainability, and the range of attitudes held towards the concept. For employers who are serious about advancing towards sustainability, the knowledge, attitudes and values relevant to sustainability of future applicants for hire may be important qualities for the organization to include in its employee selection strategy.

Even without an explicit hiring policy to include such criteria, PSU appears to be fortunate on this level as the sample scored high on each of the measures of 
sustainability beliefs. While these results may be augmented by participant selfselection and social desirability, another likely factor is the sample is drawn from the context of Portland and the Pacific Northwest where environmental and social values are defining characteristics of the people (SOER Science Panel, 2000, Northwest Environment Watch, 2002). A profile such as the one observed in this study bodes well for an organization. Assurance is gained that little resistance will be encountered to the theoretical idea of pursuing sustainability. Organizations with employees who have little understanding of the concept and do not hold explicit values consistent with the concept should beware of potential resistance and should proactively address the matter. Much can be learned from the rich and diverse experiential knowledge that is being cultivated and shared among the participating organizational members of the Oregon Natural Step Network. Future research should focus on developing and evaluating programs to promote the understanding of sustainability in organizations, and cultivating supportive attitudes among employees.

While this study had great success in establishing theoretical constructs and confirmed the majority of the hypotheses, an overall low power in uniquely predicting criteria suggests potential for improving upon the SCS. I will first summarize the results of the hierarchical regressions then discuss some perspectives on means to improve the SCS. The separate models of sustainability climate measures and sustainability beliefs accounted for modest amounts of variance in the respective criteria, with sustainability beliefs performing slightly better than the 
climate measures in explaining the variance of SRB, and significantly better in explaining the variance of ES. Across the board, some losses were observed in the unique predictive power of the individual factors. Tolerance statistics discounted the possible role of multicolinearity. When both models were included together in the prediction of $\mathrm{SRB}$, a reasonably robust amount of variance in SRB was explained. However, only sustainability norms, employee involvement, and positive engagement were unique predictors. Tolerance statistics once again discounted the possible role of multicolinearity.

Evidence from previous analyses provides firm ground to stand upon and defend the psychometric quality of the SCS constructs. However, it is possible that these constructs are too narrow in their focus, and thus capture only small amounts of the given criterion space. Or, similarly, the outcome criteria may be too broad in the domains they represent. A review of the items comprising the outcome criteria lends credence to this idea. Below, this issue is given closer scrutiny specific to the ES measure. As a general comment, such broad definition of the outcomes is a pervasive difficulty when dealing with the broad, sometimes unwieldy concept of sustainability. Future research should address these possibilities by considering expansion of the predictive constructs while remaining true to their central themes, or more narrowly focusing the criteria. The latter might mean increasing the number of criteria included in the study to ensure appropriate sampling of the broad domain of sustainability. 
Sustainability Climate Survey 104

Another likely possibility to help explain the relatively low predictive power is that the SCS may not include some essential factors that are important determinants in whether employees perceive their role to include the integration of principles of sustainability into work routines, actually work towards such integration, or engage in personal behaviors that reduce ecological footprints. Future research should address this possibility by exploring the potential of other predictive factors. (The reader will see this matter addressed further in

\section{Limitations.)}

Another perspective on the results of the hierarchical analyses is that the predicting factors are explaining the same variance of the respective criteria. While this is important psychometric evidence, its implications for future administrations of the SCS really depend upon the objectives of the user. If the objective is to predict the perceived expectations, role behaviors and environmental stewardship behaviors, then focus should be placed on those factors that uniquely contribute to such predictions. In other words, the evidence of this study would suggest that those factors with unique predictive power may offer more significant leverage points for encouraging organizational change. Thus, in the name of efficient use of time and resources the recommendation would be to administer and analyze sustainability norms, employee involvement, and positive engagement. However, if the user desires to monitor each factor as part of a systemic approach towards creating a climate and ultimately a culture of sustainability, then the user is invited to obtain feedback on each of these dimensions. For example, shared vision did not 
retain unique predictive power, but the leadership of an organization may still be interested in monitoring whether employees are developing a sense of the organization's vision for sustainability. Additional issues to consider in using the SCS are discussed below (see Applications).

\section{Limitations}

While much of the evidence obtained in this study reflects favorably on the reliability and validity of the SCS, some important limitations need to be acknowledged. For validation purposes, ideally, behaviors reflective of environmental stewardship would be assessed via some means independent from self-reports provided by employees. Two basic problems exist through this means of data collection: first, because of social desirability employees may intentionally or unintentionally inflate the degree of their engagement in such behaviors (Paulhus, 1984); second, since the same methods are used to assess responses to the sustainability climate and sustainability beliefs, the observed relationship between these measures and the ES criterion (as well as SRE and SRB) may be overestimated due to common method variance (Feldman \& Lynch, 1988). These problems reduce confidence in the validity evidence, and speak to the need to develop measures of sustainability related behaviors that go beyond self-reports.

It is assumed that achievement of sustainability will require more than broad adoption of appropriate individual behaviors (e.g., recycling, purchasing organic foods, community involvement). It will also require the gradual redefinition of our economic and social systems to achieve alignment with the constraints and 
opportunities provided by the natural environment. This study attempts to capture this notion of gradual redefinition in an organizational context through the criteria of sustainability role expectations and sustainability role behaviors. Rather than tap the construct of discrete behaviors (as achieved by environmental stewardship), these measures seek to assess whether employees consider the objective of sustainability as they approach each and every facet of their responsibilities. Responses to these measures should speak to whether the opportunity for systemic changes, however gradual, is being considered in each and every decision. However, I must concede that such measures fail to directly assess this systemic change.

With this shortcoming in mind, it should be noted that the SCS is designed as a complimentary tool for an organization to employ as part of a broader assessment of its organizational activities towards sustainable operations (see Application). A particular valuable addition to a broader assessment would be organizational level measures of various aspects of the organization's ecological footprint (e.g., $\mathrm{CO}^{2}$ emissions, resource consumption) and "sociological footprint" (e.g., percentage of employees earning a living wage, turnover, amount of resources invested in the community, safety records). Linking organizational level metrics such as these to data obtained through the SCS would be a wonderful avenue for future research and could provide further validation evidence for this instrument. An ideal research design would identify work units whose responsibilities could be linked to particular organizational-level metrics. The perceived climate among 
these units could then be observed to see whether climate predicted improvements in the associated organizational level outcomes. The challenges of such a research design would indeed be considerable, but the results would provide strong evidence of the true worth of the SCS.

Concern persists about the external validity of this study's assessment of employee understanding of the concept of sustainability. The construct of understanding was assessed via response to self-report items that followed a brief summary of sustainability. The items essentially asked whether employees had been exposed to the idea before and if their understanding equaled or went beyond the concept as described in the summary. To compliment this, paired items were presented as a test to ensure that subjects could correctly identify some of the central themes and ideas of the sustainability movement. In hindsight, accurate response to some of these pairs is debatable depending upon one's philosophy and assumptions about sustainability. Development of a definitive test assessing understanding might be premature as the conditions and characteristics required for establishing a sustainable society continues to be explored by practitioners and academics. However, absent another means, I do believe the paired items work well as a primer to orient participants towards the intended meaning of sustainability. This priming helps to ensure validity of future items that invoke the notion of sustainability. However, this is an untested assumption that should be addressed by future research. An experimental design could be employed where individuals in one group are simply asked to explain the concept of sustainability. 
A second group could be administered the list of paired items, and asked to explain the concept of sustainability. Comparisons of the two groups' explanations would provide evidence to support or discount the value of the paired items as primers for invoking the SCS's intended usage of the term "sustainability."

Another limitation of the present study is that the analyses were conducted without the inclusion of a criterion of behaviors within the social dimension equivalent to the environmental stewardship measure. The measure community engagement was designed with this intention, however, the behaviors included were external to the work context. Thus, engagement in these behaviors is likely to occur independently of the organization's sustainability climate, and be more a reflection of personal attitudes and values. Indeed, positive engagement and supportive attitude were the two strongest predictors of community engagement. This raises the challenging question of what constitutes socially conscious behaviors within the workplace that are relevant to sustainability. As with the environmental dimension it may be most appropriate and insightful for these measures to be at the organizational level rather than measures of individual behaviors. For example, those aspects of the sociological footprint identified above (e.g., living wage) may be the most relevant impacts of an organization. Additional research is needed to address this challenge of identifying the most appropriate measures to capture an organization's social footprint, and determine if these outcomes can be linked to individual perceptions and attitudes. 
A concern noted through feedback from several participants indicated their belief that the survey was biased in its content. For example, one participated stated, "The liberal political bias in this survey is far too strong." Another stated, "A very lopsided, loaded survey." Yet another added, "It strikes me as extremely one sided in its viewpoint." Being the designer of the survey with a strong personal bias on the topic of sustainability, I was aware of this potential throughout construction. Even recognizing this potential, and now with feedback confirming the concern, it is difficult for me to conceive of how else to approach the topic. Perhaps a valuable exercise would be to convene a small group with diverse perspectives on sustainability and explore the content of the survey with the intent of identifying and neutralizing bias.

A limitation of this particular application of the SCS concerns the sample of participants. Only non-instructional faculty and classified staff were invited to participate in the study, thus excluding instructional faculty, who represent a vitally important element of the university's population of employees. Instructional faculty were intended to be included in the study, however, university administrators decided to exclude this portion of the population shortly before distribution of the SCS. Two reasons were cited, including survey response burden and concern about the appropriateness of content of some items for an instructional faculty audience. Subsequently, an incomplete picture of PSU's sustainability climate was analyzed. Conclusions drawn can only be extended to the noninstructional dimension of campus work life. This is disappointing because the sub- 
sample of instructional faculty could have provided insight into the generalizability of the SCS across differing work roles. This limitation speaks to the importance of including all employees in the recruitment process to ensure a comprehensive picture of the organization's sustainability climate is taken.

Future efforts to validate the SCS should address the limitations identified above. Additionally, critical thought should never subside regarding what the most relevant and appropriate factors are in organizational life that support and encourage the advancement of sustainability. For example, transformational leadership may be a key factor to inspire significant and lasting change in an organization's operations and/or culture (Bass, 1985). Barling, Loughlin and Kelloway (2002) found that safety specific transformational leadership was an important predictor of perceived safety climate, as well as safety consciousness and important safety outcomes. Perhaps the presence of such leadership is important for organizations to make the transformation to sustainability. Further, to illuminate questions regarding sustainability related decision-making processes and organizational learning inquiry must go beyond the snap shot of organizational life provided by the SCS. Marcus (2004) has carved inroads into understanding effective decision-making processes towards sustainability, while Halme (2002) provides insight into the learning process required for the transformation towards sustainability to occur. The SCS may benefit from the inclusion of such process and learning oriented factors. Reflecting upon the overall low predictive power of 
the measures included in the SCS, this task of finding other important predictors should be consider a priority of future efforts to improve upon the SCS.

\section{Application}

Despite its limitations, the SCS can still serve as a valuable tool to advance sustainability at the organizational level. The intent of the SCS is to provide organizations with an assessment of their internal climate on the topic of sustainability and the degree to which that reflects an institutionalized approach to integrating the principles of sustainability into their operations. The SCS should compliment a broader organizational assessment of policies, practices, stakeholder relationships, and overall operations. The strength of the SCS lies in its assessment of an organization's sustainability efforts from the perspective of employees. Through such feedback, management's awareness of appropriate strategies for initiative advancement should be enhanced. Further, the SCS holds potential to provide an excellent conversation piece for dialogue on where the given organization is excelling and where it is lacking in its efforts towards sustainability.

While a university setting was the context of this initial application of the SCS, it was designed to be generalizable to most organizational settings. As characteristics and needs certainly vary from one organization to the next, the SCS should be reviewed before each application to ensure its wording is context appropriate. For example, the items comprising the perceived top-management support measure were reworded in the present application to refer to the university's administration. Beyond changes in basic wording, reviews of the SCS prior to 
application should be open to the possibility of entire factors being irrelevant, or inappropriate for that particular setting.

For this particular setting, a summarized profile of participant responses to the SCS factors is presented in Table 13. The profile provides the essential information of the mean and median scores of each measure and the degree of variability in those responses. Further refining the profiles into meaningful subunits could help target where scores are lowest and help the organization strategically allocate resources towards improving particular factors. For example, it may be observed that one subunit scores low on perceptions of top-management support for the sustainability initiative, but has a high level of understanding of the concept. Meanwhile, a second subunit perceives high support, but has low understanding. Such circumstances suggest that management target the first subunit by scripting messages, making personal visits, and taking other measures to demonstrate their support of the organization's sustainability efforts. The second subunit requires no such attention, but an educational training should be provided to build the necessary knowledge of the concept of sustainability so that those employees can more effectively contribute to the organization's goal of sustainability. Through such informed allocation of attention and resources, an organization can more efficiently and effectively advance towards the objective of sustainability.

The participation organization, PSU, is shown to have a contrasting results of its profile. As noted above, the measure sustainability beliefs are remarkably 
high among the sample of participants. This bodes well for the organization's interests to advance towards sustainability as the employees can be regarded as well informed about the concept, and hold a set of attitudes that are supportive of the pursuit of such an objective. Further, the positive engagement measure suggests that sustainability could be a powerful motivating force among many employees. On the other hand, the profile reveals fairly low scores on the sustainability climate measures. This implies that there is work to be done by the leadership of PSU to create a more supportive and facilitating environment for the integration of sustainability into the organization's way of life. Recent developments are encouraging on this front, as a visioning and strategic planning process has been embarked to provide a coherent guide towards sustainability, as well as to establish sustainability as a core organizational priority. This effort, in concert with others, is necessary for the organization to be successful in the long-term pursuit of sustainability.

The SCS also serves a practical role by embodying key elements that have been demonstrated by this study as important to the advancement of an organization's sustainability efforts. First, the SCS contributes to employee involvement by seeking the participation of all employees at all levels of the organization. Second, the SCS can help demonstrate top-management support, especially when its distribution is accompanied by a letter of endorsement from prominent members of the organization. Third, it serves as a means to raise awareness and provide basic education, enhancing familiarity of the subject within 
the context of the workplace. When asked about the nature of the survey, numerous participants recognized this value as illustrated by such comments as, "just by having this survey you have raised my consciousness." Another individual stated, "I think it's a good starting place to help the whole university understand. What's the next step?" This last comment speaks to an important point; the value of the SCS as means to enhance awareness and basic understanding, encourage involvement, and demonstrate top-management support is totally lost if it is administered in isolation. Finally, and perhaps most importantly, the SCS is a formal feedback mechanism complete with the opportunity of open-ended qualitative responses. Questions inquire into: (1) what people see as barriers to implementing sustainability into the organization's operations, (2) perceived opportunities to implement sustainability, and (3) any other thoughts or concerns related to sustainability at the given organization. By asking such questions in an open-ended format more complicated ideas and insights of employees can be gathered, and concerns that otherwise might not be heard have a place to be expressed.

Regarding the feedback gathered by the SCS, responsibility falls upon the researcher and project sponsors to listen to the feedback, provide a summary of the findings, and act in accordance with those findings. The ultimate value of this research is lost without taking action in response to the findings. This perspective is supportive by the renowned researcher Kurt Lewin who summarized the important relationship between research and action by stating that there is "no action without 
research, and no research without action" (Lewin, 1946, as cited in Burke, 1994, p. 55). Doing nothing with the results can be detrimental to the trust between employees and the organization; eroding the likelihood employees will participate in future efforts to obtain their perspective. However, by featuring the results, and visibly acting on those results, the SCS can serve as an important centerpiece to facilitate a broader dialogue towards the end of creating a culture of sustainability. Failure to systematically engage in such constructive activities is a glaring letdown of this developmental administration of the SCS. Future administrations of the SCS should ensure there is sufficient capacity to adequately follow through and leverage the full potential of the research process.

\section{Concluding Remarks}

Systems emerge from the values and assumptions of their designers. As gracefully illustrated by Quinn (1992), our culture operates with some zealous values and assumptions, which are not necessarily explicit, including: that evolution stopped with Homo sapiens; that nature provides an abundance of resources that exist for human use and exploitation; that the laws of nature do not apply to humans; and that growth is good. From these and other assumptions and with tremendous advances in mechanical knowledge of the world, an extraordinary society has arisen. However, it is a society on an unsustainable trajectory. Our public institutions and business organizations perpetuate this trajectory, and by default preserve the values and ways of thinking that have given rise to our present predicament. 
Recalling Schein's (1992) definition of culture as "a pattern of shared basic assumptions" (p. 12), I highlight that cultures take the form they do because there was some functionality experienced by their members. Recognition must grow that our assumptions that solved problems of the past are no longer valid to solve today's problems that threaten quantity and quality of life. Einstein's famous commentary comes to mind, that the significant problems we face cannot be solved on the same level of thinking with which we created them. Similarly, the degree to which we are able to relinquish old assumptions and values and adopt a set that is conducive to sustainability represents a key point of leverage for change (Meadows, 1997). A new set of assumptions might begin by abandoning an anthropocentric view, and embracing an ecocentric view (Capra, 1996). The ecocentric view values all life on par with human life; neither elevating humans above other forms of life, nor subsuming human interests to some external environment. Rather, it celebrates the unity and interdependences of the community of life. Widespread adoption of such a perspective would be a powerful precursor to the redefinition of our social and economic systems towards alignment with the inherent constraints imposed and opportunities afforded by the natural environment. Perhaps with such redefinition of our way of life we may avoid a tragedy of the commons on a global scale. 
Sustainability Climate Survey 117

TABLES

Table 1:

Pilot study items (Note items 1-7 and items 17-23, Transformational leadership, not

included) (Hall, 2003)

\begin{tabular}{ll}
\hline$\#$ & \multicolumn{1}{c}{ Item } \\
\hline \hline 8 & $\begin{array}{l}\text { The PSU administration has done a good job of clarifying sustainability as a University } \\
\text { priority. }\end{array}$ \\
\hline 9 & Our department has done a good job of clarifying sustainability as a Departmental priority. \\
\hline 10 & I feel included in the process of addressing PSU's sustainability issues. \\
\hline 11 & I've had the opportunity to contribute to PSU's sustainability efforts. \\
\hline 12 & I'm motivated to contribute to PSU's sustainability efforts. \\
\hline 13 & I'm inspired by PSU's sustainability efforts. \\
\hline 14 & PSU is making a positive difference in the world by addressing sustainability. \\
\hline 15 & I believe that we can successfully meet and/or exceed our goals to become sustainable. \\
\hline 16 & I believe PSU is addressing sustainability for the primary reason of saving money. \\
\hline 24 & I understand the concept of sustainability. \\
\hline 25 & I understand the concept of sustainability as it applies to me as a student at PSU. \\
\hline 26 & I need more education about the concept of sustainability. \\
\hline 27 & I understand how my activities have an impact on the natural environment. \\
\hline 28 & I can see how some of our activities as humans are unsustainable. \\
\hline 29 & $\begin{array}{l}\text { My fellow students expect me to make decisions that are guided by the principles of } \\
\text { sustainability. }\end{array}$ \\
\hline 30 & $\begin{array}{l}\text { The University expects me to make decisions that are guided by the principles of } \\
\text { sustainability. }\end{array}$ \\
\hline 31 & My fellow students take the issues of sustainability seriously. \\
\hline 32 & As a public institution it is our responsibility to strive towards sustainability. \\
\hline 33 & Addressing sustainability is vital to the long-term viability of our society. \\
\hline 34 & Addressing sustainability is vital the long-term viability of PSU. \\
\hline 35 & I'm concerned about the health of the natural environment. \\
\hline 36 & I'm concerned about issues of social equity. \\
\hline 37 & I believe as a student I have environmental responsibilities. \\
\hline 38 & I think about how much waste I generate. \\
\hline 39 & Whenever possible I purchase products that are made from recyclable materials. \\
\hline 40 & I think about how much energy I consume. \\
\hline 41 & I go out of my way to recycle \\
\hline 42 & I enjoy confronting the challenges involved in addressing sustainability. \\
\hline 43 & Considering the issues of sustainability fills me with a greater sense of purpose. \\
\hline &
\end{tabular}


Table 2:

Factor loadings for items 8-15 (minus 13) (Hall, 2003)

\begin{tabular}{clcc}
\hline \multirow{2}{*}{$\#$} & \multicolumn{1}{c}{ Item } & \multicolumn{2}{c}{ Factor } \\
\cline { 3 - 4 } 8 & $\begin{array}{l}\text { The PSU administration has done a good job of } \\
\text { clarifying sustainability as a University priority }\end{array}$ &. $\mathbf{5 9}$ & .29 \\
\hline \hline 9 & $\begin{array}{l}\text { Our department has done a good job of clarifying } \\
\text { sustainability as a Departmental priority }\end{array}$ & $\mathbf{. 6 4}$ & .36 \\
\hline 10 & $\begin{array}{l}\text { I feel included in the process of addressing PSU's } \\
\text { sustainability issues }\end{array}$ & $\mathbf{. 7 3}$ & .13 \\
\hline 11 & $\begin{array}{l}\text { I've had the opportunity to contribute to PSU's } \\
\text { sustainability efforts }\end{array}$ &. $\mathbf{6 1}$ & .01 \\
\hline 12 & $\begin{array}{l}\text { I'm motivated to contribute to PSU's } \\
\text { sustainability efforts }\end{array}$ & .19 & $\mathbf{. 4 8}$ \\
\hline 14 & $\begin{array}{l}\text { PSU is making a positive difference in the world } \\
\text { by addressing sustainability }\end{array}$ & .22 & $\mathbf{. 7 0}$ \\
\hline 15 & $\begin{array}{l}\text { I believe that we can successfully meet and/or } \\
\text { exceed our goals to become sustainable }\end{array}$ & .11 & $\mathbf{. 7 2}$ \\
\hline
\end{tabular}

Extraction Method: Principal Axis Factoring. Rotation Method: Varimax with Kaiser Normalization.

a Rotation converged in 3 iterations. 
Table 3:

Factor Loadings for items 24-43 (minus 26, 39, 41) (Hall, 2003)

\begin{tabular}{|c|c|c|c|c|}
\hline \multirow[b]{2}{*}{ Item } & \multicolumn{4}{|c|}{ Factor } \\
\hline & $\begin{array}{c}\text { Concept } \\
\text { Recognition }\end{array}$ & $\begin{array}{l}\text { Internalized } \\
\quad \text { values }\end{array}$ & $\begin{array}{c}\text { Social } \\
\text { Pressure }\end{array}$ & Shambala \\
\hline 24 I understand the concept of sustainability & .80 & .01 & .00 & .14 \\
\hline $\begin{array}{l}\text { I understand the concept of sustainability } \\
\text { as it applies to me as a student at PSU }\end{array}$ & .57 & .00 & .27 & .12 \\
\hline $\begin{array}{l}\text { I understand how my activities have an } \\
\text { impact on the natural environment }\end{array}$ & .58 & .35 & .01 & .00 \\
\hline $\begin{array}{l}\text { I can see how some of our activities as } \\
\text { humans are unsustainable }\end{array}$ & .63 & .35 & .14 & .01 \\
\hline $\begin{array}{l}\text { As a public institution it is our } \\
32 \text { responsibility to strive towards } \\
\text { sustainability }\end{array}$ & .69 & .41 & .23 & .22 \\
\hline $\begin{array}{l}\text { Addressing sustainability is vital to the } \\
\text { long-term viability of our society }\end{array}$ & .72 & .47 & .11 & .16 \\
\hline $\begin{array}{l}\text { Addressing sustainability is vital the } \\
\text { long-term viability of PSU }\end{array}$ & .47 & .29 & .22 & .24 \\
\hline $\begin{array}{l}\text { My fellow students expect me to make } \\
29 \text { decisions that are guided by the } \\
\text { principles of sustainability }\end{array}$ & .11 & .01 & .85 & .01 \\
\hline $\begin{array}{l}\text { The University expects me to make } \\
30 \text { decisions that are guided by the } \\
\text { principles of sustainability }\end{array}$ & .01 & .00 & .81 & -.01 \\
\hline $\begin{array}{l}31 \text { My fellow students take the issues of } \\
\text { sustainability seriously }\end{array}$ & .15 & .00 & .56 & .01 \\
\hline $\begin{array}{l}35 \text { I'm concerned about the health of the } \\
\text { natural environment }\end{array}$ & .32 & .74 & .00 & .17 \\
\hline $\begin{array}{l}36 \text { I'm concerned about issues of social } \\
\text { equity }\end{array}$ & .30 & .66 & .00 & .16 \\
\hline $\begin{array}{l}\text { I believe as a student I have } \\
\text { environmental responsibilities }\end{array}$ & .32 & .72 & .00 & .14 \\
\hline 38 I think about how much waste I generate & .00 & .73 & .00 & .27 \\
\hline $\begin{array}{l}\text { I think about how much energy I } \\
\text { consume }\end{array}$ & .14 & .53 & .13 & .37 \\
\hline $\begin{array}{l}\text { I enjoy confronting the challenges } \\
\text { involved in addressing sustainability }\end{array}$ & .21 & .32 & .01 & .75 \\
\hline $\begin{array}{l}\text { Considering the issues of sustainability } \\
\text { fills me with a greater sense of purpose }\end{array}$ & .20 & .36 & .16 & .75 \\
\hline
\end{tabular}

Extraction Method: Principal Axis Factoring. Rotation Method: Varimax with Kaiser Normalization.

a Rotation converged in 6 iterations. 
Table 4:

Correlations Matrix and Alphas (Hall, 2003)

\begin{tabular}{|c|c|c|c|c|c|c|c|c|}
\hline Scale & $\begin{array}{c}\text { Affective } \\
\text { Commit- } \\
\text { ment }\end{array}$ & $\begin{array}{c}\text { Connected- } \\
\text { ness }\end{array}$ & $\begin{array}{c}\text { Construc- } \\
\text { tive } \\
\text { Attitude }\end{array}$ & $\begin{array}{c}\text { Concept } \\
\text { Recogn- } \\
\text { ition }\end{array}$ & $\begin{array}{c}\text { Social } \\
\text { Pressure }\end{array}$ & $\begin{array}{c}\text { Inter- } \\
\text { nalized } \\
\text { Values }\end{array}$ & Shambala & $\begin{array}{c}\text { Sustain- } \\
\text { able } \\
\text { Behaviors }\end{array}$ \\
\hline $\begin{array}{c}\text { Affective } \\
\text { Commitment }\end{array}$ & $(.87)$ & & & & & & & \\
\hline $\begin{array}{l}\text { Connected- } \\
\text { ness }\end{array}$ & $.26 * *$ & $(.77)$ & & & & & & \\
\hline $\begin{array}{c}\text { Constructive } \\
\text { Attitude }\end{array}$ & $.30 * *$ & $.40 * * *$ & (.68) & & & & & \\
\hline $\begin{array}{c}\text { Concept } \\
\text { Recognition }\end{array}$ & $.15^{*}$ & .18 & $.60 * * *$ & $(.88)$ & & & & \\
\hline $\begin{array}{c}\text { Social } \\
\text { Pressure } \\
\end{array}$ & $.26 * * *$ & $.39 * * *$ & .02 & $.28 * * *$ & $(.79)$ & & & \\
\hline $\begin{array}{c}\text { Internalized } \\
\text { Values } \\
\end{array}$ & $.14 *$ & .11 & $.57 * * *$ & $.58 * * *$ & .11 & $(.81)$ & & \\
\hline Shambala & $.20 * *$ & .10 & $.33 * *$ & $.48 * * *$ & $.21 * *$ & $.60 * * *$ & $(.86)$ & \\
\hline $\begin{array}{c}\text { Sustain-able } \\
\text { Behaviors }\end{array}$ & .11 & .07 & $.43 * * *$ & $.43 * * *$ & $.19 * *$ & $.64 * * *$ & $.62 * * *$ & $(.77)$ \\
\hline
\end{tabular}

*** Correlation is significant at the 0.001 level (2-tailed)

** Correlation is significant at the 0.01 level (2-tailed).

* Correlation is significant at the 0.05 level (2-tailed).

Note: Due to missing data, some correlations are more significant than others despite lower r-values. 
Table 5:

Hypotheses

\begin{tabular}{|c|c|}
\hline Hypothesis 1 & $\begin{array}{l}\text { Perceptions of top-management support for the organization's } \\
\text { sustainability initiative will positively correlate with } \\
\text { sustainability role expectations, sustainability role behaviors, } \\
\text { and environmental stewardship. }\end{array}$ \\
\hline Hypothesis $2 a$ & $\begin{array}{l}\text { Sustainability norms will be positively correlated with } \\
\text { sustainability role expectations, sustainability role behaviors, } \\
\text { and environmental stewardship. }\end{array}$ \\
\hline Hypothesis $2 b$ & $\begin{array}{l}\text { Sense of community will be a moderator in that as it increases, } \\
\text { the strength of the relationships between sustainability norms } \\
\text { with sustainability role behaviors, and environmental } \\
\text { stewardship will increase. }\end{array}$ \\
\hline Hypothesis 3 & $\begin{array}{l}\text { Rewards will positively correlate with sustainability role } \\
\text { expectations, sustainability role behaviors, and environmental } \\
\text { stewardship. }\end{array}$ \\
\hline Hypothesis 4 & $\begin{array}{l}\text { Employee involvement will be positively correlated with } \\
\text { sustainability role expectations, sustainability role behaviors, } \\
\text { and environmental stewardship. }\end{array}$ \\
\hline Hypothesis 5 & $\begin{array}{l}\text { Shared vision will be positively correlated with sustainability } \\
\text { role expectations, sustainability role behaviors, and } \\
\text { environmental stewardship. }\end{array}$ \\
\hline Hypothesis 6 & $\begin{array}{l}\text { Personal understanding will be positively correlated with } \\
\text { sustainability role behaviors and environmental stewardship. }\end{array}$ \\
\hline Hypothesis 7 & $\begin{array}{l}\text { Supportive attitudes will be a positive correlated with } \\
\text { sustainability role behaviors, and environmental stewardship. }\end{array}$ \\
\hline Hypothesis 8 & $\begin{array}{l}\text { Positive engagement will be positively correlated with } \\
\text { sustainability role behaviors and environmental stewardship. }\end{array}$ \\
\hline
\end{tabular}


Table 6:

\section{SCS Item List}

\begin{tabular}{|c|c|c|c|}
\hline \# & Item & Scale & Proposed Factor \\
\hline 1 & $\begin{array}{l}\text { The above paragraphs are my first introduction to } \\
\text { the idea of sustainability. }\end{array}$ & A-D & $\begin{array}{l}\text { Personal } \\
\text { understanding }\end{array}$ \\
\hline 2 & $\begin{array}{l}\text { I still have very little understanding of this idea of } \\
\text { sustainability. }\end{array}$ & A-D & $\begin{array}{l}\text { Personal } \\
\text { understanding }\end{array}$ \\
\hline 3 & $\begin{array}{l}\text { My understanding of sustainability goes well } \\
\text { beyond this introduction. }\end{array}$ & A-D & $\begin{array}{l}\text { Personal } \\
\text { understanding }\end{array}$ \\
\hline 4 & $\begin{array}{l}\text { This idea of sustainability is relevant to my job at } \\
\text { PSU. }\end{array}$ & A-D & NA \\
\hline 5 & I agree with the above description of sustainability. & A-D & NA \\
\hline 6 & $\begin{array}{l}\text { If you disagree with the above description of } \\
\text { sustainability, we'd value your comments: }\end{array}$ & Open & NA \\
\hline 7 & $\begin{array}{l}\text { If you have additional thoughts about what } \\
\text { sustainability means, we'd love to hear them: }\end{array}$ & Open & NA \\
\hline 8 & Renewable resources VS Non-renewable resources & Select one & Pers. understanding \\
\hline 9 & Linear VS Cyclical & Select one & Pers. understanding \\
\hline 10 & Gap between rich and poor VS Social equity & Select one & Pers. understanding \\
\hline 11 & Interdependence VS Independence & Select one & Pers. understanding \\
\hline 12 & Isolation VS Community & Select one & Pers. understanding \\
\hline 13 & $\begin{array}{l}\text { "Take-make-waste" production VS "Borrow-use- } \\
\text { return" Production }\end{array}$ & Select one & Pers. understanding \\
\hline 14 & Diversity VS Uniformity & Select one & Pers. understanding \\
\hline 15 & Wealth VS Quality of Life & Select one & Pers. understanding \\
\hline 16 & Consumption VS Conservation & Select one & Pers. understanding \\
\hline 17 & Economical VS Inefficient & Select one & Pers. understanding \\
\hline 18 & $\begin{array}{l}\text { PSU's administration has done a good job of } \\
\text { communicating that sustainability is a University } \\
\text { priority. }\end{array}$ & A-D & Mngmt-support \\
\hline 19 & $\begin{array}{l}\text { PSU's administration takes the subject of } \\
\text { sustainability very seriously. }\end{array}$ & A-D & Mngmt-support \\
\hline 20 & $\begin{array}{l}\text { PSU's administration has clearly demonstrated } \\
\text { support for efforts towards sustainability. }\end{array}$ & A-D & Mngmt-support \\
\hline 21 & $\begin{array}{l}\text { I believe that PSU's administration sincerely } \\
\text { supports efforts towards sustainability. }\end{array}$ & A-D & Mngmt-support \\
\hline 22 & $\begin{array}{l}\text { My coworkers take the subject of sustainability } \\
\text { very seriously. }\end{array}$ & A-D & Sustainability norm \\
\hline 23 & $\begin{array}{l}\text { My coworkers feel a compelling need to adopt } \\
\text { sustainability practices and thinking. }\end{array}$ & A-D & Sustainability norm \\
\hline 24 & $\begin{array}{l}\text { My coworkers are truly concerned about issues of } \\
\text { social justice AND the health of the environment. }\end{array}$ & A-D & Sustainability norm \\
\hline 25 & My coworkers care about sustainability. & A-D & Sustainability norm \\
\hline 26 & My coworkers remind each other of the importance & A-D & Sustainability norm \\
\hline
\end{tabular}


Sustainability Climate Survey 123

\begin{tabular}{|c|c|c|c|}
\hline & of considering sustainability issues. & & \\
\hline 27 & Working towards sustainability is rewarded at PSU. & A-D & Reward \\
\hline 28 & $\begin{array}{l}\text { Failing to consider the environmental, social, AND } \\
\text { economic impacts of decisions will result in a } \\
\text { negative performance assessment. }\end{array}$ & A-D & Reward \\
\hline 29 & $\begin{array}{l}\text { At PSU, aligning work practices with sustainability } \\
\text { is rewarded. }\end{array}$ & A-D & Reward \\
\hline 30 & $\begin{array}{l}\text { At PSU, contributing to the University's } \\
\text { sustainability efforts is rewarded. }\end{array}$ & A-D & Reward \\
\hline 31 & $\begin{array}{l}\text { PSU has made information about sustainability } \\
\text { available to me. }\end{array}$ & A-D & Emp. involvement \\
\hline 32 & I have been involved in PSU's sustainability efforts. & A-D & Emp. involvement \\
\hline 33 & $\begin{array}{l}\text { I feel encouraged to share my ideas related to } \\
\text { PSU's sustainability efforts. }\end{array}$ & A-D & Emp. involvement \\
\hline 34 & $\begin{array}{l}\text { I have had the opportunity to contribute to PSU's } \\
\text { sustainability efforts. }\end{array}$ & A-D & Emp. involvement \\
\hline 35 & $\begin{array}{l}\text { My colleagues and I have a clear shared } \\
\text { understanding of PSU's vision regarding } \\
\text { sustainability. }\end{array}$ & A-D & Shared vision \\
\hline 36 & $\begin{array}{l}\text { PSU's vision and strategies regarding sustainability } \\
\text { are regularly communicated. }\end{array}$ & A-D & Shared vision \\
\hline 37 & PSU's vision of sustainability is clear to me. & A-D & Shared vision \\
\hline 38 & I can describe PSU's vision of sustainability. & A-D & Shared vision \\
\hline 39 & $\begin{array}{l}\text { I enjoy dealing with the challenge of addressing } \\
\text { sustainability. }\end{array}$ & A-D & Positive engagement \\
\hline 40 & $\begin{array}{l}\text { I am motivated by the challenge of addressing } \\
\text { sustainability. }\end{array}$ & A-D & Positive engagement \\
\hline 41 & Efforts towards sustainability inspire me. & A-D & Positive engagement \\
\hline 42 & $\begin{array}{l}\text { Addressing sustainability fills me with a greater } \\
\text { sense of purpose. }\end{array}$ & A-D & Positive engagement \\
\hline 43 & $\begin{array}{l}\text { Our decisions and actions today hold significant } \\
\text { consequences for future generations. }\end{array}$ & A-D & Supportive attitude \\
\hline 44 & $\begin{array}{l}\text { It is our responsibility as a public institution to } \\
\text { strive towards sustainability. }\end{array}$ & A-D & Supportive attitude \\
\hline 45 & $\begin{array}{l}\text { Addressing sustainability is essential to the long- } \\
\text { term existence of human society. }\end{array}$ & A-D & Supportive attitude \\
\hline 46 & $\begin{array}{l}\text { Addressing sustainability is essential to the long- } \\
\text { term existence of PSU. }\end{array}$ & A-D & Supportive attitude \\
\hline 47 & Many aspects of today's society are unsustainable. & A-D & Supportive attitude \\
\hline 48 & Societal problems are exaggerated. & A-D & Supportive attitude \\
\hline 49 & Environmental problems are exaggerated. & A-D & Supportive attitude \\
\hline 50 & $\begin{array}{l}\text { There is nothing to worry about, technology always } \\
\text { has and always will solve the problems threatening } \\
\text { the environment. }\end{array}$ & A-D & Supportive attitude \\
\hline 51 & $\begin{array}{l}\text { There are more important issues than sustainability } \\
\text { to which PSU should devote attention. }\end{array}$ & A-D & Supportive attitude \\
\hline 52 & There is a strong sense of community at PSU. & A-D & Sense of Community \\
\hline
\end{tabular}


Sustainability Climate Survey 124

\begin{tabular}{|c|c|c|c|}
\hline 53 & $\begin{array}{l}\text { People at PSU are courteous and respectful of one } \\
\text { another. }\end{array}$ & A-D & Sense of Community \\
\hline 54 & $\begin{array}{l}\text { People look out for the welfare of one another at } \\
\text { PSU. }\end{array}$ & A-D & Sense of Community \\
\hline 55 & People at PSU work together to solve problems & A-D & Sense of Community \\
\hline 56 & $\begin{array}{l}\text { I have so much work to do, I cannot do everything } \\
\text { well. }\end{array}$ & A-D & Work overload \\
\hline 57 & $\begin{array}{l}\text { I never seem to have enough time to get everything } \\
\text { done. }\end{array}$ & A-D & Work overload \\
\hline 58 & My job leaves me with little time to get things done. & A-D & Work overload \\
\hline 59 & I have a hard time meeting the demands of my job. & A-D & Work overload \\
\hline 60 & I have a lot of say about what happens on my job. & A-D & Decision-latitude \\
\hline 61 & $\begin{array}{l}\text { My job allows me to make a lot of decisions on my } \\
\text { own. }\end{array}$ & A-D & Decision-latitude \\
\hline 62 & I get to do a variety of different things on my job. & A-D & Decision-latitude \\
\hline 63 & My job allows me to be creative. & A-D & Decision-latitude \\
\hline 64 & I have an opportunity to develop my abilities. & A-D & Decision-latitude \\
\hline 65 & $\begin{array}{l}\text { Your level of satisfaction with: physical working } \\
\text { conditions. }\end{array}$ & Dis-Sat & Job satisfaction \\
\hline 66 & $\begin{array}{l}\text { Your level of satisfaction with: recognition you get } \\
\text { for good work. }\end{array}$ & Dis-Sat & Job satisfaction \\
\hline 67 & Your level of satisfaction with: your compensation. & Dis-Sat & Job satisfaction \\
\hline 68 & $\begin{array}{l}\text { Your level of satisfaction with: your opportunity to } \\
\text { use your abilities. }\end{array}$ & Dis-Sat & Job satisfaction \\
\hline 69 & Overall satisfaction with your job. & Dis-Sat & Job satisfaction \\
\hline 70 & $\begin{array}{l}\text { Making suggestions about how to integrate } \\
\text { sustainability into policies and procedures. }\end{array}$ & $\begin{array}{l}\text { Exp-Not } \\
\text { Exp }\end{array}$ & Role expectations \\
\hline 71 & $\begin{array}{l}\text { Raising concerns about sustainability issues during } \\
\text { meetings. }\end{array}$ & $\begin{array}{l}\text { Exp-Not } \\
\text { Exp }\end{array}$ & Role expectations \\
\hline 72 & $\begin{array}{l}\text { Improving my knowledge and understanding of } \\
\text { sustainability. }\end{array}$ & $\begin{array}{l}\text { Exp-Not } \\
\text { Exp }\end{array}$ & Role expectations \\
\hline 73 & $\begin{array}{l}\text { Reminding coworkers to consider issues of } \\
\text { sustainability. }\end{array}$ & $\begin{array}{l}\text { Exp-Not } \\
\text { Exp }\end{array}$ & Role expectations \\
\hline 74 & $\begin{array}{l}\text { Helping my coworkers to learn about issues of } \\
\text { sustainability. }\end{array}$ & $\begin{array}{l}\text { Exp-Not } \\
\text { Exp }\end{array}$ & Role expectations \\
\hline 75 & $\begin{array}{l}\text { Making decisions with consideration of the } \\
\text { environmental, social AND economic implications. }\end{array}$ & $\begin{array}{l}\text { Exp-Not } \\
\text { Exp }\end{array}$ & Role expectations \\
\hline 76 & $\begin{array}{l}\text { Aligning my work practices with the concept of } \\
\text { sustainability. }\end{array}$ & $\begin{array}{l}\text { Exp-Not } \\
\text { Exp }\end{array}$ & Role expectations \\
\hline 77 & $\begin{array}{l}\text { Integrating the concept of sustainability into my } \\
\text { work practices. }\end{array}$ & $\begin{array}{l}\text { Exp-Not } \\
\text { Exp }\end{array}$ & Role expectations \\
\hline 78 & $\begin{array}{l}\text { I make suggestions about how to integrate } \\
\text { sustainability into policies and procedures. }\end{array}$ & $\mathrm{N}-\mathrm{O}$ & Role behavior \\
\hline 79 & $\begin{array}{l}\text { I raise concerns about sustainability issues during } \\
\text { planning meetings. }\end{array}$ & $\mathrm{N}-\mathrm{O}$ & Role behavior \\
\hline 80 & $\begin{array}{l}\text { I work to improve my knowledge and } \\
\text { understanding of sustainability. }\end{array}$ & $\mathrm{N}-\mathrm{O}$ & Role behavior \\
\hline 81 & I remind coworkers to consider issues of & $\mathrm{N}-\mathrm{O}$ & Role behavior \\
\hline
\end{tabular}


Sustainability Climate Survey 125

\begin{tabular}{|c|c|c|c|}
\hline & sustainability. & & \\
\hline 82 & $\begin{array}{l}\text { I help my coworkers to learn about issues of } \\
\text { sustainability. }\end{array}$ & $\mathrm{N}-\mathrm{O}$ & Role behavior \\
\hline 83 & $\begin{array}{l}\text { I make decisions with consideration of the } \\
\text { environmental, social AND economic implications. }\end{array}$ & $\mathrm{N}-\mathrm{O}$ & Role behavior \\
\hline 84 & $\begin{array}{l}\text { I align my work practices with the concept of } \\
\text { sustainability. }\end{array}$ & $\mathrm{N}-\mathrm{O}$ & Role behavior \\
\hline 85 & $\begin{array}{l}\text { I integrate the concept of sustainability into my } \\
\text { work practices. }\end{array}$ & $\mathrm{N}-\mathrm{O}$ & Role behavior \\
\hline 86 & $\begin{array}{l}\text { I am very conservative in my use of resources and } \\
\text { supplies at work. }\end{array}$ & $\mathrm{N}-\mathrm{A}$ & $\begin{array}{l}\text { Environmental } \\
\text { stewardship }\end{array}$ \\
\hline 87 & $\begin{array}{l}\text { I take public transportation, walk, bicycle, or car } \\
\text { pool to work. }\end{array}$ & $\mathrm{N}-\mathrm{A}$ & $\begin{array}{l}\text { Environmental } \\
\text { stewardship }\end{array}$ \\
\hline 88 & At work I recycle paper products & $\mathrm{N}-\mathrm{A}$ & $\begin{array}{l}\text { Environmental } \\
\text { stewardship }\end{array}$ \\
\hline 89 & $\begin{array}{l}\text { At work I ensure I recycle all other recyclable } \\
\text { materials. }\end{array}$ & $\mathrm{N}-\mathrm{A}$ & $\begin{array}{l}\text { Environmental } \\
\text { stewardship }\end{array}$ \\
\hline 90 & $\begin{array}{l}\text { I seek reused or recycled products for work related } \\
\text { purchases. }\end{array}$ & $\mathrm{N}-\mathrm{A}$ & $\begin{array}{l}\text { Environmental } \\
\text { stewardship }\end{array}$ \\
\hline 91 & At work I eat organic and/or locally grown foods. & $\mathrm{N}-\mathrm{A}$ & $\begin{array}{l}\text { Environmental } \\
\text { stewardship }\end{array}$ \\
\hline 92 & I use a non-disposable beverage container at work. & $\mathrm{N}-\mathrm{A}$ & $\begin{array}{l}\text { Environmental } \\
\text { stewardship }\end{array}$ \\
\hline 93 & I put time and effort into promoting social causes. & $\mathrm{N}-\mathrm{O}$ & $\begin{array}{l}\text { Community } \\
\text { engagement }\end{array}$ \\
\hline 94 & I'm an active member of my community. & $\mathrm{N}-\mathrm{O}$ & $\begin{array}{l}\text { Community } \\
\text { engagement }\end{array}$ \\
\hline 95 & I'm actively involved in addressing social issues. & $\mathrm{N}-\mathrm{O}$ & $\begin{array}{l}\text { Community } \\
\text { engagement }\end{array}$ \\
\hline 96 & I participate in community service. & $\mathrm{N}-\mathrm{O}$ & $\begin{array}{l}\text { Community } \\
\text { engagement }\end{array}$ \\
\hline 97 & $\begin{array}{l}\text { What would help you to contribute to PSU's } \\
\text { sustainability efforts? }\end{array}$ & $\begin{array}{l}\text { All that } \\
\text { apply }\end{array}$ & NA \\
\hline 98 & $\begin{array}{l}\text { What do you see as the greatest barriers to } \\
\text { implementing sustainability into PSU's campus } \\
\text { operations? }\end{array}$ & Open & NA \\
\hline 99 & $\begin{array}{l}\text { What do you see as some of the best opportunities } \\
\text { for PSU to contribute to the advancement of the } \\
\text { sustainability movement? }\end{array}$ & Open & NA \\
\hline 100 & $\begin{array}{l}\text { Please share any other thoughts or concerns you } \\
\text { have about sustainability at PSU: }\end{array}$ & Open & NA \\
\hline 101 & $\begin{array}{l}\text { Please share any thoughts you may have about the } \\
\text { nature of this survey: }\end{array}$ & Open & NA \\
\hline
\end{tabular}

\section{Scale Key (reference for Table 6 and Table 7)}

\begin{tabular}{ll}
\hline Abbreviation & \multicolumn{1}{c}{ Complete scales } \\
\hline \hline A-D & Strongly Disagree; Disagree; Neutral; Agree; Strongly Agree \\
\hline All that apply & Check all that apply
\end{tabular}




\begin{tabular}{ll}
\hline Dis-Sat & Very dissatisfied; Dissatisfied; Undecided; Satisfied; Very satisfied \\
\hline Exp-Not Exp & $\begin{array}{l}\text { (1) Definitely expected part of my job ; (2); (3) Somewhat beyond expectations; } \\
\text { (4); (5) Definitely above and beyond expectations }\end{array}$ \\
\hline N-A & Never; Rarely; Sometimes; Often; Very often \\
\hline N-O & Never, Rarely; Sometimes; Usually; Always \\
\hline Open & Open ended questions \\
\hline
\end{tabular}

Table 7:

Factor groupings, names \& items

\begin{tabular}{|c|c|c|c|}
\hline Proposed Factor & Item & Scale & $\#$ \\
\hline \multicolumn{4}{|c|}{ Climate Measures } \\
\hline Mngmt-support & $\begin{array}{l}\text { PSU's administration has done a good job of } \\
\text { communicating that sustainability is a University } \\
\text { priority. }\end{array}$ & A-D & 18 \\
\hline Mngmt-support & $\begin{array}{l}\text { PSU's administration takes the subject of } \\
\text { sustainability very seriously. }\end{array}$ & A-D & 19 \\
\hline Mngmt-support & $\begin{array}{l}\text { PSU's administration has clearly demonstrated } \\
\text { support for efforts towards sustainability. }\end{array}$ & A-D & 20 \\
\hline Mngmt-support & $\begin{array}{l}\text { I believe that PSU's administration sincerely } \\
\text { supports efforts towards sustainability. }\end{array}$ & A-D & 21 \\
\hline Sustainability norm & $\begin{array}{l}\text { My coworkers take the subject of sustainability } \\
\text { very seriously. }\end{array}$ & A-D & 22 \\
\hline Sustainability norm & $\begin{array}{l}\text { My coworkers feel a compelling need to adopt } \\
\text { sustainability practices and thinking. }\end{array}$ & A-D & 23 \\
\hline Sustainability norm & $\begin{array}{l}\text { My coworkers are truly concerned about issues of } \\
\text { social justice AND the health of the environment. }\end{array}$ & A-D & 24 \\
\hline Sustainability norm & My coworkers care about sustainability. & A-D & 25 \\
\hline Sustainability norm & $\begin{array}{l}\text { My coworkers remind each other of the importance } \\
\text { of considering sustainability issues. }\end{array}$ & A-D & 26 \\
\hline Reward & Working towards sustainability is rewarded at PSU. & A-D & 27 \\
\hline Reward & $\begin{array}{l}\text { Failing to consider the environmental, social, AND } \\
\text { economic impacts of decisions will result in a } \\
\text { negative performance assessment. }\end{array}$ & A-D & 28 \\
\hline Reward & $\begin{array}{l}\text { At PSU, aligning work practices with sustainability } \\
\text { is rewarded. }\end{array}$ & A-D & 29 \\
\hline Reward & $\begin{array}{l}\text { At PSU, contributing to the University's } \\
\text { sustainability efforts is rewarded. }\end{array}$ & A-D & 30 \\
\hline Emp. involvement & $\begin{array}{l}\text { PSU has made information about sustainability } \\
\text { available to me. }\end{array}$ & A-D & 31 \\
\hline Emp. involvement & I have been involved in PSU's sustainability efforts. & A-D & 32 \\
\hline Emp. involvement & $\begin{array}{l}\text { I feel encouraged to share my ideas related to } \\
\text { PSU's sustainability efforts. }\end{array}$ & A-D & 33 \\
\hline Emp. involvement & I have had the opportunity to contribute to PSU's & A-D & 34 \\
\hline
\end{tabular}




\section{Sustainability Climate Survey 127}

\begin{tabular}{|c|c|c|c|}
\hline & sustainability efforts. & & \\
\hline Shared vision & $\begin{array}{l}\text { My colleagues and I have a clear shared } \\
\text { understanding of PSU's vision regarding } \\
\text { sustainability. }\end{array}$ & A-D & 35 \\
\hline Shared vision & $\begin{array}{l}\text { PSU's vision and strategies regarding sustainability } \\
\text { are regularly communicated. }\end{array}$ & A-D & 36 \\
\hline Shared vision & PSU's vision of sustainability is clear to me. & A-D & 37 \\
\hline Shared vision & I can describe PSU's vision of sustainability. & A-D & 38 \\
\hline \multicolumn{4}{|c|}{ Sustainability Beliefs } \\
\hline Personal understanding & $\begin{array}{l}\text { The above paragraphs are my first introduction to } \\
\text { the idea of sustainability. }\end{array}$ & A-D & 1 \\
\hline Personal understanding & $\begin{array}{l}\text { I still have very little understanding of this idea of } \\
\text { sustainability. }\end{array}$ & A-D & 2 \\
\hline Personal understanding & $\begin{array}{l}\text { My understanding of sustainability goes well } \\
\text { beyond this introduction. }\end{array}$ & A-D & 3 \\
\hline Personal. understanding & Renewable resources VS Non-renewable resources & $\begin{array}{l}\text { Select } \\
\text { one }\end{array}$ & 8 \\
\hline Personal understanding & Linear VS Cyclical & $\begin{array}{l}\text { Select } \\
\text { one }\end{array}$ & 9 \\
\hline Personal understanding & Gap between rich and poor VS Social equity & $\begin{array}{l}\text { Select } \\
\text { one }\end{array}$ & 10 \\
\hline Personal understanding & Interdependence VS Independence & $\begin{array}{l}\text { Select } \\
\text { one }\end{array}$ & 11 \\
\hline Personal understanding & Isolation VS Community & $\begin{array}{l}\text { Select } \\
\text { one }\end{array}$ & 12 \\
\hline Personal. understanding & $\begin{array}{l}\text { "Take-make-waste" production VS "Borrow-use- } \\
\text { return" Production }\end{array}$ & $\begin{array}{l}\text { Select } \\
\text { one }\end{array}$ & 13 \\
\hline Personal understanding & Diversity VS Uniformity & $\begin{array}{l}\text { Select } \\
\text { one }\end{array}$ & 14 \\
\hline Personal understanding & Wealth VS Quality of Life & $\begin{array}{l}\text { Select } \\
\text { one }\end{array}$ & 15 \\
\hline Personal understanding & Consumption VS Conservation & $\begin{array}{l}\text { Select } \\
\text { one }\end{array}$ & 16 \\
\hline Personal understanding & Economical VS Inefficient & $\begin{array}{l}\text { Select } \\
\text { one }\end{array}$ & 17 \\
\hline Positive engagement & $\begin{array}{l}\text { I enjoy dealing with the challenge of addressing } \\
\text { sustainability. }\end{array}$ & A-D & 39 \\
\hline Positive engagement & $\begin{array}{l}\text { I am motivated by the challenge of addressing } \\
\text { sustainability. }\end{array}$ & A-D & 40 \\
\hline Positive engagement & Efforts towards sustainability inspire me. & A-D & 41 \\
\hline Positive engagement & $\begin{array}{l}\text { Addressing sustainability fills me with a greater } \\
\text { sense of purpose. }\end{array}$ & A-D & 42 \\
\hline Supportive attitude & $\begin{array}{l}\text { Our decisions and actions today hold significant } \\
\text { consequences for future generations. }\end{array}$ & A-D & 43 \\
\hline Supportive attitude & $\begin{array}{l}\text { It is our responsibility as a public institution to } \\
\text { strive towards sustainability. }\end{array}$ & A-D & 44 \\
\hline Supportive attitude & $\begin{array}{l}\text { Addressing sustainability is essential to the long- } \\
\text { term existence of human society. }\end{array}$ & A-D & 45 \\
\hline Supportive attitude & Addressing sustainability is essential to the long- & A-D & 46 \\
\hline
\end{tabular}




\section{Sustainability Climate Survey 128}

\begin{tabular}{|c|c|c|c|}
\hline & term existence of PSU. & & \\
\hline Supportive attitude & Many aspects of today's society are unsustainable. & A-D & 47 \\
\hline Supportive attitude & Societal problems are exaggerated. & A-D & 48 \\
\hline Supportive attitude & Environmental problems are exaggerated. & A-D & 49 \\
\hline Supportive attitude & $\begin{array}{l}\text { There is nothing to worry about, technology always } \\
\text { has and always will solve the problems threatening } \\
\text { the environment. }\end{array}$ & A-D & 50 \\
\hline Supportive attitude & $\begin{array}{l}\text { There are more important issues than sustainability } \\
\text { to which PSU should devote attention. }\end{array}$ & A-D & 51 \\
\hline \multicolumn{4}{|c|}{ Criteria Measures } \\
\hline Role expectations & $\begin{array}{l}\text { Making suggestions about how to integrate } \\
\text { sustainability into policies and procedures. }\end{array}$ & $\begin{array}{l}\text { Exp-Not } \\
\text { Exp }\end{array}$ & 70 \\
\hline Role expectations & $\begin{array}{l}\text { Raising concerns about sustainability issues during } \\
\text { meetings. }\end{array}$ & $\begin{array}{l}\text { Exp-Not } \\
\text { Exp }\end{array}$ & 71 \\
\hline Role expectations & $\begin{array}{l}\text { Improving my knowledge and understanding of } \\
\text { sustainability. }\end{array}$ & $\begin{array}{l}\text { Exp-Not } \\
\text { Exp }\end{array}$ & 72 \\
\hline Role expectations & $\begin{array}{l}\text { Reminding coworkers to consider issues of } \\
\text { sustainability. }\end{array}$ & $\begin{array}{l}\text { Exp-Not } \\
\text { Exp }\end{array}$ & 73 \\
\hline Role expectations & $\begin{array}{l}\text { Helping my coworkers to learn about issues of } \\
\text { sustainability. }\end{array}$ & $\begin{array}{l}\text { Exp-Not } \\
\text { Exp }\end{array}$ & 74 \\
\hline Role expectations & $\begin{array}{l}\text { Making decisions with consideration of the } \\
\text { environmental, social AND economic implications. }\end{array}$ & $\begin{array}{l}\text { Exp-Not } \\
\text { Exp }\end{array}$ & 75 \\
\hline Role expectations & $\begin{array}{l}\text { Aligning my work practices with the concept of } \\
\text { sustainability. }\end{array}$ & $\begin{array}{l}\text { Exp-Not } \\
\text { Exp }\end{array}$ & 76 \\
\hline Role expectations & $\begin{array}{l}\text { Integrating the concept of sustainability into my } \\
\text { work practices. }\end{array}$ & $\begin{array}{l}\text { Exp-Not } \\
\text { Exp }\end{array}$ & 77 \\
\hline Role behavior & $\begin{array}{l}\text { I make suggestions about how to integrate } \\
\text { sustainability into policies and procedures. }\end{array}$ & $\mathrm{N}-\mathrm{O}$ & 78 \\
\hline Role behavior & $\begin{array}{l}\text { I raise concerns about sustainability issues during } \\
\text { planning meetings. }\end{array}$ & $\mathrm{N}-\mathrm{O}$ & 79 \\
\hline Role behavior & $\begin{array}{l}\text { I work to improve my knowledge and } \\
\text { understanding of sustainability. }\end{array}$ & $\mathrm{N}-\mathrm{O}$ & 80 \\
\hline Role behavior & $\begin{array}{l}\text { I remind coworkers to consider issues of } \\
\text { sustainability. }\end{array}$ & $\mathrm{N}-\mathrm{O}$ & 81 \\
\hline Role behavior & $\begin{array}{l}\text { I help my coworkers to learn about issues of } \\
\text { sustainability. }\end{array}$ & $\mathrm{N}-\mathrm{O}$ & 82 \\
\hline Role behavior & $\begin{array}{l}\text { I make decisions with consideration of the } \\
\text { environmental, social AND economic implications. }\end{array}$ & $\mathrm{N}-\mathrm{O}$ & 83 \\
\hline Role behavior & $\begin{array}{l}\text { I align my work practices with the concept of } \\
\text { sustainability. }\end{array}$ & $\mathrm{N}-\mathrm{O}$ & 84 \\
\hline Role behavior & $\begin{array}{l}\text { I integrate the concept of sustainability into my } \\
\text { work practices. }\end{array}$ & $\mathrm{N}-\mathrm{O}$ & 85 \\
\hline $\begin{array}{l}\text { Environmental } \\
\text { stewardship }\end{array}$ & $\begin{array}{l}\text { I am very conservative in my use of resources and } \\
\text { supplies at work. }\end{array}$ & $\mathrm{N}-\mathrm{A}$ & 86 \\
\hline $\begin{array}{l}\text { Environmental } \\
\text { stewardship }\end{array}$ & $\begin{array}{l}\text { I take public transportation, walk, bicycle, or car } \\
\text { pool to work. }\end{array}$ & $\mathrm{N}-\mathrm{A}$ & 87 \\
\hline $\begin{array}{c}\text { Environmental } \\
\text { stewardship }\end{array}$ & At work I recycle paper products & $\mathrm{N}-\mathrm{A}$ & 88 \\
\hline
\end{tabular}


Sustainability Climate Survey 129

\begin{tabular}{|c|c|c|c|}
\hline $\begin{array}{l}\text { Environmental } \\
\text { stewardship }\end{array}$ & $\begin{array}{l}\text { At work I ensure I recycle all other recyclable } \\
\text { materials. }\end{array}$ & $\mathrm{N}-\mathrm{A}$ & 89 \\
\hline $\begin{array}{l}\text { Environmental } \\
\text { stewardship }\end{array}$ & $\begin{array}{l}\text { I seek reused or recycled products for work related } \\
\text { purchases. }\end{array}$ & $\mathrm{N}-\mathrm{A}$ & 90 \\
\hline $\begin{array}{l}\text { Environmental } \\
\text { stewardship }\end{array}$ & At work I eat organic and/or locally grown foods. & $\mathrm{N}-\mathrm{A}$ & 91 \\
\hline $\begin{array}{c}\text { Environmental } \\
\text { stewardship }\end{array}$ & I use a non-disposable beverage container at work. & $\mathrm{N}-\mathrm{A}$ & 92 \\
\hline \multicolumn{4}{|c|}{ Social Indicator Measures } \\
\hline Sense of Community & There is a strong sense of community at PSU. & A-D & 52 \\
\hline Sense of Community & $\begin{array}{l}\text { People at PSU are courteous and respectful of one } \\
\text { another. }\end{array}$ & A-D & 53 \\
\hline Sense of Community & $\begin{array}{l}\text { People look out for the welfare of one another at } \\
\text { PSU. }\end{array}$ & A-D & 54 \\
\hline Sense of Community & People at PSU work together to solve problems & A-D & 55 \\
\hline Work overload & $\begin{array}{l}\text { I have so much work to do, I cannot do everything } \\
\text { well. }\end{array}$ & A-D & 56 \\
\hline Work overload & $\begin{array}{l}\text { I never seem to have enough time to get everything } \\
\text { done. }\end{array}$ & A-D & 57 \\
\hline Work overload & $\begin{array}{l}\text { My job leaves me with little time to get things } \\
\text { done. }\end{array}$ & A-D & 58 \\
\hline Work overload & I have a hard time meeting the demands of my job. & A-D & 59 \\
\hline Decision-latitude & I have a lot of say about what happens on my job. & A-D & 60 \\
\hline Decision-latitude & $\begin{array}{l}\text { My job allows me to make a lot of decisions on my } \\
\text { own. }\end{array}$ & A-D & 61 \\
\hline Decision-latitude & I get to do a variety of different things on my job. & A-D & 62 \\
\hline Decision-latitude & My job allows me to be creative. & A-D & 63 \\
\hline Decision-latitude & I have an opportunity to develop my abilities. & A-D & 64 \\
\hline Job satisfaction & $\begin{array}{l}\text { Your level of satisfaction with: physical working } \\
\text { conditions. }\end{array}$ & Dis-Sat & 65 \\
\hline Job satisfaction & $\begin{array}{l}\text { Your level of satisfaction with: recognition you get } \\
\text { for good work. }\end{array}$ & Dis-Sat & 66 \\
\hline Job satisfaction & Your level of satisfaction with: your compensation. & Dis-Sat & 67 \\
\hline Job satisfaction & $\begin{array}{l}\text { Your level of satisfaction with: your opportunity to } \\
\text { use your abilities. }\end{array}$ & Dis-Sat & 68 \\
\hline Job satisfaction & Overall satisfaction with your job. & Dis-Sat & 69 \\
\hline Community engagement & I put time and effort into promoting social causes. & $\mathrm{N}-\mathrm{O}$ & 93 \\
\hline Community engagement & I'm an active member of my community. & $\mathrm{N}-\mathrm{O}$ & 94 \\
\hline Community engagement & I'm actively involved in addressing social issues. & $\mathrm{N}-\mathrm{O}$ & 95 \\
\hline Community engagement & I participate in community service. & $\mathrm{N}-\mathrm{O}$ & 96 \\
\hline
\end{tabular}


Table 8:

Pattern Matrix 1

\begin{tabular}{|c|c|c|c|c|c|}
\hline \multirow[t]{2}{*}{ Variable } & \multicolumn{5}{|c|}{ Factor } \\
\hline & 1 & 2 & 3 & 4 & 5 \\
\hline MNGSUP1 & .58 & -.02 & -.05 & .06 & .23 \\
\hline MNGSUP2 & .81 & .04 & -.01 & -.10 & .15 \\
\hline MNGSUP3 & .82 & .02 & -.07 & .16 & -.12 \\
\hline MNGSUP4 & .74 & .05 & -.04 & .06 & .01 \\
\hline SOCNORM1 & .08 & .86 & .05 & -.09 & .08 \\
\hline SOCNORM2 & -.02 & .88 & .01 & -.07 & .15 \\
\hline SOCNORM3 & -.04 & .82 & .01 & .09 & -.08 \\
\hline SOCNORM4 & .11 & .84 & .05 & .03 & -.06 \\
\hline SOCNORM5 & -.06 & .66 & -.22 & .06 & -.02 \\
\hline REWARD1 & .21 & .02 & -.59 & -.02 & .07 \\
\hline REWARD2 & -.12 & .18 & -.51 & -.03 & .09 \\
\hline REWARD3 & .12 & -.06 & -.93 & .01 & -.03 \\
\hline REWARD4 & .03 & -.08 & -.87 & .09 & .03 \\
\hline INVOLV_2 & .06 & .01 & .08 & .69 & .10 \\
\hline INVOLV_3 & .02 & -.01 & -.17 & .66 & .04 \\
\hline INVOLV_4 & .02 & .02 & .03 & .89 & -.01 \\
\hline VISION_1 & -.01 & .21 & -.04 & .25 & .53 \\
\hline VISION_2 & .13 & .00 & -.06 & .09 & .68 \\
\hline VISION_3 & .06 & -.03 & -.03 & -.01 & .93 \\
\hline VISION_4 & -.01 & .00 & -.03 & .03 & .80 \\
\hline
\end{tabular}

Extraction Method: Principal Axis Factoring.

Rotation Method: Oblimin with Kaiser Normalization.

a Rotation converged in 8 iterations.

Variable Key

MNGSUP = Top-management support item

SOCNOR $=$ Sustainability norms item

REWARD $=$ Rewards item

INVOLV = Employee Involvement item

VISION $=$ Shared vision item 
Table 9:

Pattern Matrix 2

\begin{tabular}{lccc}
\hline Variable & \multicolumn{3}{c}{ Factor } \\
\cline { 2 - 4 } & 1 & 2 & 3 \\
\hline UNDRST_1 & $\mathbf{. 7 1}$ & .06 & -.04 \\
\hline UNDRST_2 & $\mathbf{. 7 7}$ & .06 & -.07 \\
\hline UNDRST_3 & $\mathbf{. 6 0}$ & -.16 & .07 \\
\hline PURPOS_1 & -.03 & $\mathbf{. 8 8}$ & -.06 \\
\hline PURPOS_2 & -.05 & $\mathbf{. 9 2}$ & -.02 \\
\hline PURPOS_3 & -.07 & $\mathbf{. 7 0}$ & .25 \\
\hline PURPOS_4 & .01 & $\mathbf{. 7 3}$ & .26 \\
\hline BELIEF_1 & .00 & .04 & $\mathbf{. 6 5}$ \\
\hline BELIEF_2 & -.02 & .22 & $\mathbf{. 6 8}$ \\
\hline BELIEF_3 & .06 & .10 & $\mathbf{. 7 7}$ \\
\hline BELIEF_4 & .09 & .29 & $\mathbf{. 5 3}$ \\
\hline BELIEF_5 & -.06 & .08 & $\mathbf{. 4 7}$ \\
\hline BELIE_6R & -.04 & -.06 & $\mathbf{. 7 3}$ \\
\hline BELIE_7R & .00 & -.16 & $\mathbf{. 8 9}$ \\
\hline BELIE_8R & -.06 & -.09 & $\mathbf{. 6 0}$ \\
\hline BELIE_9R & .04 & .17 & $\mathbf{. 5 3}$ \\
\hline ExLIE_t9
\end{tabular}

Extraction Method: Principal Axis Factoring.

Rotation Method: Oblimin with Kaiser Normalization.

a Rotation converged in 6 iterations.

Variable Key

UNDRST $=$ Personal understanding item

PURPOS $=$ Positive engagement item

BELIEF = Supportive attitude item

BELIE_R = Reverse coded Supportive attitude item 
Table 10:

Pattern Matrix of higher-order FA

\begin{tabular}{lcc}
\hline \multirow{2}{*}{ Variable } & \multicolumn{2}{c}{ Factor } \\
\cline { 2 - 3 } & 1 & 2 \\
\hline MNGSUP_S & $\mathbf{. 7 6}$ & -.16 \\
\hline SOCNOR_S & $\mathbf{. 4 2}$ & .14 \\
\hline REWARD_S & $\mathbf{. 7 0}$ & -.08 \\
\hline INVOLV_S & $\mathbf{. 6 2}$ & .18 \\
\hline VISION_S & $\mathbf{. 8 4}$ & -.05 \\
\hline UNDRST_S & -.02 & $\mathbf{. 3 0}$ \\
\hline PURPOS_S & .15 & $\mathbf{. 7 6}$ \\
\hline BELIEF_S & -.05 & $\mathbf{. 7 7}$
\end{tabular}

Extraction Method: Principal Axis Factoring.

Rotation Method: Oblimin with Kaiser Normalization.

a Rotation converged in 4 iterations.

Variable Key (see Table 6 for item \#s)

MNGSUP_S = Top-management support Scale (items 18-21)

SOCNOR_S = Sustainability norms Scale (items 22-26)

REWARD_S = Rewards Scale (items 27, 29-30)

INVOLV_S = Employee Involvement Scale (items 32-34)

VISION_S = Shared vision Scale (items 35-38)

UNDRST_S = Personal understanding Scale (items 1-3)

PURPOS_S = Positive engagement Scale (items 39-42)

BELIEF_S = Supportive attitude Scale (items 43-51) 
Table 11:

Scale alphas and correlations

\begin{tabular}{|c|c|c|c|c|c|c|c|c|}
\hline Scale & $\begin{array}{c}\text { Manage } \\
\text {-ment } \\
\text { Support }\end{array}$ & $\begin{array}{l}\text { Sustainabi } \\
\text { lity Norms }\end{array}$ & Rewards & $\begin{array}{c}\text { Employee } \\
\text { Involve- } \\
\text { ment }\end{array}$ & $\begin{array}{l}\text { Shared } \\
\text { Vision }\end{array}$ & $\begin{array}{c}\text { Employee } \\
\text { Under- } \\
\text { standing }\end{array}$ & $\begin{array}{c}\text { Positive } \\
\text { Engage } \\
\text {-ment }\end{array}$ & $\begin{array}{c}\text { Suppor- } \\
\text { tive } \\
\text { Attitude }\end{array}$ \\
\hline $\begin{array}{l}\text { Management } \\
\text { Support }\end{array}$ & $(.88)$ & & & & & & & \\
\hline $\begin{array}{l}\text { Sustainability } \\
\text { Norms }\end{array}$ & $.27 * * *$ & $(.91)$ & & & & & & \\
\hline Rewards & $.53 * * *$ & $.33 * * *$ & $(.89)$ & & & & & \\
\hline $\begin{array}{l}\text { Employee } \\
\text { Involvement }\end{array}$ & $.50 * * *$ & $.25 * * *$ & $.38 * * *$ & $(.82)$ & & & & \\
\hline Shared Vision & $.59 * * *$ & $.42 * * *$ & $.57 * * *$ & $.56 * * *$ & $(.90)$ & & & \\
\hline $\begin{array}{l}\text { Personal } \\
\text { Undrstanding }\end{array}$ & .00 & .10 & $-.14 *$ & .09 & .04 & $(.73)$ & & \\
\hline $\begin{array}{l}\text { Positive } \\
\text { Engagement }\end{array}$ & .06 & $.20 * *$ & $.15^{*}$ & $.33 * * *$ & $.17 * *$ & $.21 * * *$ & $(.92)$ & \\
\hline $\begin{array}{l}\text { Supportive } \\
\text { Attitude }\end{array}$ & -.09 & $.15^{*}$ & .01 & $.16^{* *}$ & -.00 & $.22 * * *$ & $.59 * * *$ & $(.88)$ \\
\hline
\end{tabular}


Table 12:

Discriminate Validity and Criterion Validity Correlations

\begin{tabular}{|c|c|c|c|c|c|}
\hline Scale & $\begin{array}{c}\text { Role } \\
\text { Overload }\end{array}$ & $\begin{array}{l}\text { Decision } \\
\text { Latitude }\end{array}$ & $\begin{array}{c}\text { Role } \\
\text { Expectation }\end{array}$ & $\begin{array}{c}\text { Role } \\
\text { Behavior }\end{array}$ & $\begin{array}{c}\text { Environmental } \\
\text { Stewardship }\end{array}$ \\
\hline $\begin{array}{l}\text { Management } \\
\text { Support }\end{array}$ & .05 & $.21 * * *$ & $.15^{*}$ & $.18 * *$ & -.03 \\
\hline $\begin{array}{l}\text { Sustainability } \\
\text { Norms }\end{array}$ & -.05 & .07 & $.24 * * *$ & $.31 * * *$ & .06 \\
\hline Rewards & -.04 & $.21 * * *$ & $.20 * *$ & .12 & .10 \\
\hline $\begin{array}{l}\text { Employee } \\
\text { Involvement }\end{array}$ & $.12 *$ & $.13^{*}$ & $.19 * *$ & $.44 * * *$ & $.19 * *$ \\
\hline Shared Vision & .01 & .10 & $.29 * * *$ & $.29 * * *$ & .08 \\
\hline $\begin{array}{l}\text { Personal } \\
\text { Understanding }\end{array}$ & .05 & .02 & .03 & $.25 * * *$ & $.23 * *$ \\
\hline $\begin{array}{l}\text { Positive } \\
\text { Engagement }\end{array}$ & -.10 & .03 & .07 & $.52 * * *$ & $.44 * * *$ \\
\hline $\begin{array}{l}\text { Supportive } \\
\text { Attitude }\end{array}$ & -.07 & .01 & .00 & $.34 * * *$ & $.41 * * *$ \\
\hline Role Overload & $(.89)$ & -.063 & -- & -- & -- \\
\hline $\begin{array}{l}\text { Decision } \\
\text { Latitude }\end{array}$ & & $(.83)$ & -- & -- & -- \\
\hline $\begin{array}{l}\text { Role } \\
\text { Expectation }\end{array}$ & & & $(.95)$ & $.27 * * *$ & .02 \\
\hline Role Behavior & & & & $(.92)$ & $.35 * * *$ \\
\hline $\begin{array}{l}\text { Environmental } \\
\text { Stewardship }\end{array}$ & & & & & $(.60)$ \\
\hline
\end{tabular}


Table 13:

Organizational profile of SCS measures

\begin{tabular}{|c|c|c|c|c|}
\hline Themes & Measure & Mean & Median & $\begin{array}{l}\text { Standard } \\
\text { Deviation } \\
\end{array}$ \\
\hline \multirow{5}{*}{$\begin{array}{l}\text { Sustainability } \\
\text { Climate } \\
\text { Measures }\end{array}$} & $\begin{array}{l}\text { Administrative } \\
\text { Support }\end{array}$ & 3.09 & 3.13 & 0.78 \\
\hline & $\begin{array}{l}\text { Sustainability } \\
\text { Norms }\end{array}$ & 3.28 & 3.25 & 0.81 \\
\hline & Rewards & 2.58 & 2.67 & 0.75 \\
\hline & $\begin{array}{l}\text { Employee } \\
\text { Involvement }\end{array}$ & 3.05 & 3.00 & 0.81 \\
\hline & Shared Vision & 2.37 & 2.25 & 0.78 \\
\hline \multirow{3}{*}{$\begin{array}{l}\text { Sustainability } \\
\text { Beliefs }\end{array}$} & $\begin{array}{l}\text { Personal } \\
\text { Understanding }\end{array}$ & 3.76 & 4.00 & 0.83 \\
\hline & $\begin{array}{l}\text { Positive } \\
\text { Engagement }\end{array}$ & 3.65 & 3.75 & 0.82 \\
\hline & $\begin{array}{l}\text { Supportive } \\
\text { Attitude }\end{array}$ & 4.21 & 4.33 & 0.59 \\
\hline \multirow{4}{*}{$\begin{array}{l}\text { Quality of } \\
\text { Work life } \\
\text { Indicators }\end{array}$} & $\begin{array}{l}\text { Sense of } \\
\text { Community }\end{array}$ & 3.36 & 3.5 & 0.82 \\
\hline & Work Overload & 3.14 & 3.25 & 0.94 \\
\hline & $\begin{array}{l}\text { Decision- } \\
\text { Latitude }\end{array}$ & 3.64 & 3.80 & 0.75 \\
\hline & $\begin{array}{l}\text { Job } \\
\text { Satisfaction } \\
\end{array}$ & 3.22 & 3.40 & 0.76 \\
\hline \multirow{4}{*}{$\begin{array}{l}\text { Important } \\
\text { Outcomes }\end{array}$} & $\begin{array}{l}\text { Community } \\
\text { Engagement }\end{array}$ & 3.12 & 3.00 & 0.91 \\
\hline & $\begin{array}{l}\text { Sustainability } \\
\text { Role Expctatns }\end{array}$ & 2.79 & 2.75 & 1.09 \\
\hline & $\begin{array}{l}\text { Sustainability } \\
\text { Role Behaviors }\end{array}$ & 2.71 & 2.75 & 0.78 \\
\hline & $\begin{array}{l}\text { Environmental } \\
\text { Stewardship }\end{array}$ & 3.86 & 3.86 & 0.53 \\
\hline
\end{tabular}

Note: All scores based on measures coded from 1-5 (see Scale Key of Table 6 for scale qualifiers) 
Table 14:

Correlations between Sustainability Climate Measures and Environmental Stewardship items.

\begin{tabular}{lccccc}
\hline Measure & $\begin{array}{c}\text { Administra- } \\
\text { tive Support }\end{array}$ & $\begin{array}{c}\text { Sustainability } \\
\text { Norms }\end{array}$ & Rewards & $\begin{array}{c}\text { Employee } \\
\text { Involvement }\end{array}$ & $\begin{array}{c}\text { Shared } \\
\text { Vision }\end{array}$ \\
\hline ES_1 & -.09 & .02 & -.10 & .04 & -.03 \\
\hline ES_2 & -.10 & -.09 & -.06 & -.03 & -.01 \\
\hline$E S \_3$ & $.13^{*}$ & $.14^{*}$ & .06 & $.27^{* *}$ & $.13^{*}$ \\
\hline$E S \_4$ & $.13^{*}$ & $.16^{*}$ & .02 & $.30^{* *}$ & $.14^{*}$ \\
\hline$E S \_5$ & -.03 & $.13^{*}$ & .11 & .09 & .08 \\
\hline$E S \_6$ & -.06 & .10 & .05 & $.14^{*}$ & .10 \\
\hline$E S \_7$ & -.05 & -.09 & -.03 & .08 & -.03
\end{tabular}

** Correlation is significant at the 0.01 level (2-tailed).

* Correlation is significant at the 0.05 level (2-tailed). 
Table 15:

Hierarchical regression analysis of sustainability climate factors on SRE, controlling for demographics.

\begin{tabular}{|c|c|c|c|c|c|c|c|c|}
\hline \multirow[b]{2}{*}{ Variable } & \multicolumn{8}{|c|}{ Sustainability Role Expectations } \\
\hline & $R^{2}$ & $\Delta R^{2}$ & $F$ & $d f$ & $\Delta F$ & $\beta$ & $t$ & $p$ \\
\hline Step 1 & .00 & .00 & .28 & 3,232 & .28 & & & .84 \\
\hline Tenure & & & & & & .05 & .72 & .47 \\
\hline Gender & & & & & & .04 & .55 & .58 \\
\hline $\begin{array}{l}\text { Academic vs. } \\
\text { Non-academic }\end{array}$ & & & & & & -.01 & -.09 & .93 \\
\hline Step 2 & .11 & .11 & 3.59 & 5,227 & 5.56 & & & .001 \\
\hline $\begin{array}{l}\text { Management } \\
\text { support }\end{array}$ & & & & & & -.02 & -.21 & .83 \\
\hline $\begin{array}{l}\text { Sustainability } \\
\text { norms }\end{array}$ & & & & & & .16 & 2.29 & .02 \\
\hline Rewards & & & & & & .03 & .32 & .75 \\
\hline $\begin{array}{l}\text { Employee } \\
\text { involvement }\end{array}$ & & & & & & .05 & .56 & .58 \\
\hline Shared vision & & & & & & .19 & 2.06 & .04 \\
\hline
\end{tabular}


Table 16:

Hierarchical regression analysis of sustainability climate factors on SRB, controlling for demographics.

\begin{tabular}{|c|c|c|c|c|c|c|c|c|}
\hline \multirow[b]{2}{*}{ Variable } & \multicolumn{8}{|c|}{ Sustainability Role Behaviors } \\
\hline & $R^{2}$ & $\Delta R^{2}$ & $F$ & $d f$ & $\Delta F$ & $\beta$ & $t$ & $p$ \\
\hline Step 1 & .01 & .01 & .47 & 3,235 & .47 & & & .70 \\
\hline Tenure & & & & & & .07 & 1.06 & .29 \\
\hline Gender & & & & & & .03 & .39 & .70 \\
\hline $\begin{array}{l}\text { Academic vs. } \\
\text { Non-academic }\end{array}$ & & & & & & -.02 & -.27 & .79 \\
\hline Step 2 & .28 & .28 & 11.25 & 5,230 & 17.61 & & & $<.001$ \\
\hline $\begin{array}{l}\text { Management } \\
\text { support }\end{array}$ & & & & & & -.08 & -1.03 & .30 \\
\hline $\begin{array}{l}\text { Sustainability } \\
\text { norms }\end{array}$ & & & & & & .29 & 4.58 & $<.001$ \\
\hline Rewards & & & & & & -.14 & -1.90 & .06 \\
\hline $\begin{array}{l}\text { Employee } \\
\text { involvement }\end{array}$ & & & & & & .43 & 5.99 & $<.001$ \\
\hline Shared vision & & & & & & .06 & .74 & .46 \\
\hline
\end{tabular}


Table 17:

Hierarchical regression analysis of sustainability beliefs factors on SRB, controlling for demographics.

\begin{tabular}{|c|c|c|c|c|c|c|c|c|}
\hline \multirow[b]{2}{*}{ Variable } & \multicolumn{8}{|c|}{ Sustainability Role Behaviors } \\
\hline & $R^{2}$ & $\Delta R^{2}$ & $F$ & $d f$ & $\Delta F$ & $\beta$ & $t$ & $p$ \\
\hline Step 1 & .01 & .01 & .42 & 3,233 & .42 & & & .74 \\
\hline Tenure & & & & & & .07 & 1.1 & .27 \\
\hline Gender & & & & & & .01 & .14 & .89 \\
\hline $\begin{array}{l}\text { Academic vs. } \\
\text { Non-academic }\end{array}$ & & & & & & -.01 & -.07 & .95 \\
\hline Step 2 & .31 & .30 & 16.86 & 3.230 & 33.11 & & & $<.001$ \\
\hline $\begin{array}{l}\text { Personal } \\
\text { understanding }\end{array}$ & & & & & & .16 & 2.85 & .005 \\
\hline $\begin{array}{l}\text { Positive } \\
\text { engagement }\end{array}$ & & & & & & .45 & 6.42 & $<.001$ \\
\hline $\begin{array}{l}\text { Supportive } \\
\text { attitude }\end{array}$ & & & & & & .06 & .86 & .39 \\
\hline
\end{tabular}


Table 18:

Hierarchical regression analysis of sustainability beliefs factors on ES, controlling for demographics.

\begin{tabular}{|c|c|c|c|c|c|c|c|c|}
\hline \multirow[b]{2}{*}{ Variable } & \multicolumn{8}{|c|}{ Environmental Stewardship } \\
\hline & $R^{2}$ & $\Delta R^{2}$ & $F$ & $d f$ & $\Delta F$ & $\beta$ & $t$ & $p$ \\
\hline Step 1 & .03 & .03 & 2.26 & 3,233 & 2.26 & & & .08 \\
\hline Tenure & & & & & & -.10 & -1.5 & .13 \\
\hline Gender & & & & & & -.14 & -2.1 & .04 \\
\hline $\begin{array}{l}\text { Academic vs. } \\
\text { Non-academic }\end{array}$ & & & & & & .01 & .20 & .85 \\
\hline Step 2 & .26 & .23 & 13.49 & 3.230 & 24.05 & & & $<.001$ \\
\hline $\begin{array}{l}\text { Personal } \\
\text { understanding }\end{array}$ & & & & & & .12 & 2.07 & .04 \\
\hline $\begin{array}{l}\text { Positive } \\
\text { engagement }\end{array}$ & & & & & & .32 & 4.4 & .000 \\
\hline $\begin{array}{l}\text { Supportive } \\
\text { attitude }\end{array}$ & & & & & & .17 & 2.24 & .03 \\
\hline
\end{tabular}


Table 19:

Hierarchical regression analysis of sustainability climate and sustainability beliefs factors on SRB, controlling for demographics.

\begin{tabular}{|c|c|c|c|c|c|c|c|c|}
\hline \multirow[b]{2}{*}{ Variable } & \multicolumn{8}{|c|}{ Sustainability Role Behaviors } \\
\hline & $R^{2}$ & $\Delta R^{2}$ & $F$ & $d f$ & $\Delta F$ & $\beta$ & $t$ & $p$ \\
\hline Step 1 & .01 & .01 & .42 & 3,235 & .42 & & & .74 \\
\hline Tenure & & & & & & .07 & 1.07 & .29 \\
\hline Gender & & & & & & .01 & .18 & .86 \\
\hline $\begin{array}{l}\text { Academic vs. } \\
\text { Non-academic }\end{array}$ & & & & & & -.01 & -.12 & .91 \\
\hline Step 2 & .43 & .42 & 15.20 & 8,224 & 20.64 & & & $<.001$ \\
\hline $\begin{array}{l}\text { Management } \\
\text { support }\end{array}$ & & & & & & -.04 & -.57 & .57 \\
\hline $\begin{array}{l}\text { Sustainability } \\
\text { norms }\end{array}$ & & & & & & .22 & 3.73 & $<.001$ \\
\hline Rewards & & & & & & -.11 & -1.58 & .12 \\
\hline $\begin{array}{l}\text { Employee } \\
\text { involvement }\end{array}$ & & & & & & .27 & 4.07 & $<.001$ \\
\hline Shared vision & & & & & & .07 & .89 & .37 \\
\hline $\begin{array}{l}\text { Personal } \\
\text { understanding }\end{array}$ & & & & & & .13 & 2.49 & .01 \\
\hline $\begin{array}{l}\text { Positive } \\
\text { engagement }\end{array}$ & & & & & & .33 & 4.86 & $<.001$ \\
\hline $\begin{array}{l}\text { Supportive } \\
\text { attitude }\end{array}$ & & & & & & .06 & .82 & .41 \\
\hline
\end{tabular}




\section{REFERENCES}

Ajzen, I., \& Fishbein, M. (1972). Attitudes and normative beliefs as factors influencing behavioral intentions. Journal of Personality and Social Psychology, 21, 1-9.

Ajzen, I. (1991). The theory of planned behavior. Organizational Behavior and Human Decision Processes, 50, 179-211.

Ajzen, I. (1988). Attitudes, personality and behavior. Milton Keynes, UK: Open University Press.

Bansal, P. \& Roth, K. (2000). Why companies go green: A model of ecological responsiveness. Academy of Management Journal, 43, 717-736.

Barling, J., Loughlin, C., Kelloway, E. K. (2002). Development and test of a model linking safety-specific transformational leadership and occupational safety. Journal of Applied Psychology, 87(3), 488-496.

Barney, J.B. (1991). Firm resources and sustained competitive advantage. Journal of Management, 17(1), 99-120.

Basile, G. \& Rosenblum, J (2000). Walk this way. Forum for Applied Research and Public Policy, 15, 29-34.

Bass, B.M. (1985). Leadership and Performance Beyond Expectations. New York: Free Press.

Beattie, A, \& Ehrlich, P. (2001). Wild Solutions: How biodiversity is money in the bank. New Haven and London: Yale University Press.

Berger, P., \& Luckmann, T. (1966). The Social Construction of Reality. New York: Penguin.

Boldero, J. (1995). The prediction of household recycling of newspapers: The role of attitudes, intentions, and situational factors. Journal of Applied Social Psychology, 25(5), 440-462.

Brower, M., Leon, W (1999). The consumer's guide to effective environmental choices: Practical advice from the Union of Concerned Scientists. Three Rivers Press: New York. 
Bruce, W.M., \& Blackburn, J.W. (1992). Balancing Job Satisfaction and Performance: A guide for human resource professionals. Westport Connectivut: Quorum Books.

Bullock, R.J. (1984). Improving Job Satisfaction. New York: Pergamon Press.

Cammann, C., Fichman, M., Jenkins, G. D., \& Klesh, J. (1983). Michigan organizational assessment questionnaire. In S.E. Seashore, E. E. Lawler, P.H. Mirvis, \& C. Camman (Eds.), Assessing organizational change: A guide to methods, measures, and practices (pp. 71-138). New York: Wiley.

Cantell, R.B. (1966). The scree test for the number of factors. Multivariate Behavioral Research, 1, 245-276.

Castle, D. (2003). Interview with Hall, D. Conducted Spring 2003.

Colligan, Michael J; Cohen, Alexander (2004). The role of training in promoting workplace safety and health. [Chapter] Barling, Julian (Ed); Frone, Michael R. (Ed). (2004). The Psychology of Workplace Safety. (pp. 223-248). Washington, DC, US: American Psychological Association.

Cortina, J. M. (1993) What is coefficient alpha? An examination of theory and applications. Journal of Applied Psychology, 78 (1), 98-104.

Dedobbeleer, N., \& Beland, F. (1991). A safety climate measure for construction sites. Journal of Safety Research, 22, 97-103.

Denison, D. (1996). What is the difference between organizational culture and climate? A native's point of view on a decade of paradigm wars. Academy of Management Review, 21 (3), 619-654.

Dess, G. G. \& Picken, J. C. (2000). Changing roles: Leadership in the 21 st century. Organizational Dynamics. 28(3), 18-34.

DeVellis, R. F. (1991). Scale development: Theory and application. Applied Social Research Methods Series, 26. London: Sage Publications.

Doppelt, B. (2003). Leading Change Toward Sustainability: A change management guide for business, government, and civil society. Sheffield, UK: Greenleaf Publishing.

Drexler, J.A. (1977). Organizational climate: Its homogeneity within organizations. Journal of Applied Psychology, 62, 38-42. 
Easton, G. S., \& Jarrell S. L.(1998). The effects of total quality management on corporate performance: An empirical investigation. Journal of Business, 71, 253-307.

Ehrlich, P. R., Jianguo, L (2002). Some roots of terrorism. Population \& Environment, 24(2), 183-192.

Eldredge, N. (1998). Life in the Balance: Humanity and the biodiversity crisis. Princeton, NJ: Princeton University Press.

Epstein, P. (1999). Global warming: Health and disease. World Wildlife Fund.

Epstein, P., Diaz, H., Elias, S., Grabherr, G., Graham, N., Martens, W., Thompson, E.M., and Susskind, J. (1998). Biological and physical signs of climate change: focus on mosquito borne diseases. Bulletin of the American Meteorological Society, 79, 409-417.

Feldman, J., \& Lynch, J. (1988). Self-generated validity and other effects of measurement on belief, attitude, intention, and behavior. Journal of Applied Psychology, 3, 421-435.

Festinger, L. (1957). A theory of cognitive dissonance. Stanford, CA: Stanford University Press.

Fishbein, M., Chan, D., O’Reilly, K., Schnell, D., Wood, R., Beeker, C., Cohn, D. (1992). Attitudinal and normative factors as determinants of gay men's intentions to perform AIDs-related sexual behaviors: A multi-site analysis. Journal of Applied Social Psychology, 22(13), 999-1011.

Ford, K. J., MacCallum, R. C, Tait, M. (1986). The application of exploratory factor analysis in applied psychology: A critical review and analysis. Personnel Psychology, 39(2), 291-314.

Goldberger, A.L. (1996). Non-linear dynamics for clinicians: chaos theory, fractals, and complexity at the bedside. The Lancet, 347, 1312-1314.

Goldberger, A.L., Rigney, D. R. West, B.J. (1990). Chaos and fractals in human physiology. Science America, 262, 42-29.

Goudie, a. (1990). The Human Impact on the Natural Environment, $3^{\text {rd }}$ Ed. The MIT Press: Cambridge, Mass.

Hall, D.E. (2003). Assessing the sustainability climate of PSU students: A pilot study. Unpublished manuscript, Portland State University. 
Halme, M. (2002). Corporate environmental paradigms in shift: Learning during the course of action at UPM-Kymmene. Journal of Management Studies, 39(8), 1087-1109.

Hardin, G (1968). The tragedy of the commons. Science, 162, 1243-1248.

Hart, S.L. (1995). A natural-resource-based view of the firm. Academy of Management Review, 20(4), 986-1014.

Hawken, P. (1993) The Ecology of Commerce: A declaration of sustainability. New York: Harper Books.

Hinkin, T. R. (1998). A brief tutorial on the development for use in survey questionnaires. Organizational Research Methods, 104-121.

Hofmann, D. A., \& Stetzer, A. (1996). A cross-level investigation of factors influencing unsafe behaviors and accidents. Personnel Psychology, 49, 307339.

Howe, J. G. (1977). Group climate: An exploratory analysis of construct validity. Organizational Behavior and Human Performance, 19, 106-125.

Hughes, TP; Baird, AH; Bellwood, DR; Card, M; Connolly, SR; Folke, C; Grosberg, R; Hoegh-Guldberg, O; Jackson, JBC; Kleypas, J; Lough, JM; Marshall, P; Nystroem, M; Palumbi, SR; Pandolfi, JM; Rosen, B; Roughgarden, J (2003). Climate change, human impacts, and the resilience of coral reefs. Science, 301, (5635), 929-933.

Iadacola, P. \& Shupe, A. (1998). Violence, Inequality, and Human Freedom. New York: General Hall Publishers.

Intergovernmental Panel on Climate Change, Working Group II (2001). Climate Change 2001: Impacts, adaptation, and vulnerability. MacCarthy, J.J. et al., eds. Cambridge University Press, Cambridge, UK.

Johnston. H. R. (1976). A new conceptualization of source of organizational climate. Administrative Science Quarterly, 21, 95-103.

Joyce, W. F. \& Slocum, J.W., Jr. (1990). Strategic Context and Organizational Climate, In B. Schneider (Ed), Organizational Climate and Culture, (pp. 130-151). San Francisco: Jossey-Bass Publishers. 
Joyce, W. F. \& Slocum, J. W., Jr. (1984). Collective climate: Agreement as a basis for defining aggregate climates in organizations. Academy of Management Journal, 27, 721-742.

Karasek, R. A. (1979). Job demands, job decision latitude, and mental strain: Implications for job redesign. Administrative Science Quarterly, 24, 285308.

Karasek R. A., Theorell T. (1990). Healthy Work. New York: Basic Books

Katz, D., \& Khan, R. L. (1978). The social psychology of organizations ( ${ }^{\text {nd }}$ Ed). New York, Wiley.

Korten, D. (2001). When Corporations Rule the World. San Francisco, CA: Berrett-Koehler Publishers.

Kotter (1995). Leading change: Why transformation efforts fail. Harvard Business Review, 1-20.

Lam, S., \& Schaubroeck, J. (2000). A field experiment testing frontline opinion leaders as change agents. Journal of Applied Psychology, 85(6), 987-995.

Landsbergis, P. A., Schnall, P. L., Belkic, K. L., Baker, D., Schwartz, J. E., \& Pickering, T. G., (2002). The workplace and cardiovascular disease: Relevance and potential role for occupational health psychology. In Quick, J. C. \& Tetrcik, L. E., Handbook of Occupational Health Psychology, (pp. 265-287). Washington, DC: American Psychological Association.

Large, J. (2004) The costs of a violent society. Seattle Times, April 15 ${ }^{\text {th }}, 2004$.

Lewin, K., Lippitt, R., White, R. K. (1939). Patterns of aggressive behavior in experimentally created "social climates." Journal of Social Psychology, 10, 271-299.

Lewin, K. (1951). Field theory in social science. New York: Harper \& Row.

Lipsitz, L.A. Goldberger, A.L., (1992). Loss of complexity and aging: Potential applications of fractals and chaos theory to senescence. The Journal of the American Medical Association, 267, 1806-1809.

Malmqvist, B; Rundle, S (2002) Threats to the running water ecosystems of the world. Environmental Conservation 29 (2), 134-153. 
Manstead, A. S. R. (1996). Attitudes and behavior. Applied Social Psychology, 329.

Margolis, J. D., \& Walsh, J. P. (2001) People and Profits: The search for a link between a company's social and financial performance. Mahwah, N.J.: Lawrence Erlbaum Associates.

Marcus, S. E. (2004). Strategic decision making in organizations that value financial, social, and environmental sustainability. Unpublished doctoral dissertation, Portland State University.

Maslow, A.H. (1954). Motivation and Personality. New York: Harper \& Brothers.

Maslow, A.H. (1970). Motivations and Personality (2 ${ }^{\text {nd }}$ ed.). New York: Harper \& Row.

Mead, G. (1934). Mind, self, and society. Chicago: University of Chicago Press.

Meadows, D.H. (1997). Ways to intervene in a system. Whole Earth Review, Winter 1997.

Moran, E. \& Volkwein, J. (1992). The cultural approach to the formation of organizational climate. Human Relations, 45 (1), 19-47.

Myers (1979), The Sinking Arc: A new look at the problem of disappearing species. Oxford: Pergamon Press.

Nairne, J. (2003). Psychology: The adaptive mind ( ${ }^{\text {rd }}$ Ed.), Belmont, CA: Wadsworth.

Natural Step, The (2001). Workshop: Implementing sustainability using the Natural Step framework. Portland, OR, August, 2001.

Neal, A., Griffin, M. A., \& Hart, P. M. (2000). The impact of organizational climate on safety climate and individual behavior. Safety Science, 34, 99-109.

Neal, A. \& Griffin, M. A. (2004). Safety climate and safety at work. [Chapter] J. Barling, M. R. Frone, (Eds). The Psychology of Workplace Safety. (pp. 1534). Washington, DC, US: American Psychological Association.

Northwest Environment Watch (2002). This place on earth 2002: Measuring what matters. Seattle, WA: NEW. 
Oregon Natural Resource Council (2002). Bush unveils plan to boost logging Oregon's public forests. www.onrc.org/press/044.bushplan.html

Paine, L.S. (2003). Value Shift: Why companies must merge social and financial imperatives to achieve superior performance. New York: McGraw-Hill.

Parker, S. K., Axtell, C. M., \& Turner, N. (2001). Designing a safer workplace: Importance of job autonomy, communication quality, and supportive supervisors. Journal of Occupational Health Psychology, 6, 3, 211-228.

Paulhus, D. L. (1984). Two-component models of socially desirable responding. Journal of Personality and Social Psychology, 46, 598-609.

Powell, G. N. \& Butterfield, D. A. (1978). The case for subsystem climates in organizations. Academy of Management Review, 3, 151-157.

Putnam, R. D. (2000). Bowling Alone: The collapse and revival of American community. New York: Simon \& Schuster.

Quinn, D. (1992). Ishmael. New York: Bantam-Turner Books.

Reese, W. E. (1996) Revisiting carrying capacity: Area-based indicators of sustainability. Population and Environment, 17, 225-239. http://dieoff.org/page110.htm

Robert, K.-H. (1997). A compass for sustainable development. International Journal of Sustainable Development and World Ecology, 4, 79-92.

Robinson, E. (2004). A decade of compromise: Timber towns struggle under forest plan. The Columbian.

www.columbian.com/04132004/front_pa/134852.html

Rodgers, R., Hunter, J.E., Rogers, D. L. (1993). Influence of top-management commitment on management program success. Journal of Applied Psychology, 78(1), 151-155.

Rodgers, R., Hunter, J.E. (1991). Impact of management by objectives on organizational productivity. Journal of Applied Psychology, 76, 322-336.

Rogers, E. M. (1995). Diffusion of innovations. New York: Free Press.

Rosenblum, J. (1999-2000). A deeper look at the system conditions. The Natural Step Newsletter, 1, 8-11. 
Ruckelshaus, William (1989). Toward a sustainable world. Scientific American, $261,166-174$.

Russell, D. W. (2002). In search of underlying dimensions: The use (and abuse) of factor analysis in Personality and Social Psychology Bulletin, 28(12), 16291646.

Russo, M.V., Fouts, P.A. (1997). A resource-based perspective on corporate environmental performance and profitability. Academy of Managerment Journal, 40(3), 534-559.

Schein, E. (1992). Organizational Culture and Leadership. San Francisco, JosseyBass Publishers.

Schnaiberg, A. (1980). The Environment: From surplus to scarcity. New York: Oxford University Press.

Schnall, P., Belkic, K., Landsbergis, P., \& Baker, D. (2000). The Workplace and Cardiovascular Disease. Hanley \& Belfus, Inc., Occup Med 15(1).

Schneider, B. (1975) Organizational climate: Individual preferences and organizational realities. Journal of Applied Psychology, 56, 211-217.

Schneider, B (1990). The climate for service: An application of the climate construct. In B. Schneider (Ed), Organizational Climate and Culture, (pp. 383-412). San Francisco: Jossey-Bass Publishers.

Schneider, B., Bowen, D.E., Ehrhart, M. G. \& Holcombe, K. M. (2000). The climate for service: Evolution of a construct. In N. M. Ashkanasy, C. P. Wilderom, M. F. Peterson (Eds.), Handbook of organizational culture and climate (pp. 21-36). Thousand Oaks, CA: Sage.

Senge, (1990). The Fifth Discipline: The art and practice of a learning organization. A conversation with Peter Senge. July $19^{\text {th }}, 1990$, Grafton, Vermont. Edited by Colleen Lannon Kim.

Senge, P.M. \& Carstedt, G. (2001). Innovating our way to the next industrial revolution. MIT Sloan Management Review, Winter2001, 24-38.

Shapiro, I., \& Greenstein, R. (1999). The widening income gulf. Center on Budget and Policy Priorities. http://www.cbpp.org/9-4-99tax-rep.htm

Shuman, M. (1998). Going local: creating self-reliant communities in a global age. New York: Free Press. 
Simard, M, \& Marchand, A. (1997). Workgroups' propensity to comply with safety rules: The influence of micro-macro organisational factors. Ergonomics, 40, 2, 172-188.

Skinner, B.F. (1938). The behavior of organisms; an experimental analysis. New York, London, D. Appleton-Century Company.

SOER Science Panel (2000). Oregon State of the environment report: Statewide summary (prepared for the Oregon Progress Board by the SOER Science Panel, Paul G. Riser, Chair. September 2000.

Spielberger, C. D., Vagg, P. R., \& Wasala, C. F. (2003). Occupational stress: Job pressures and lack of support. In Quick, J. C. \& Tetrick, L. E., Handbook of Occupational Health Psychology (pp. 201-219). Washington, DC: American Psychological Association.

Spreitzer, G. M. (1995). An empirical test of a comprehensive model of intrapersonal empowerment in the workplace. American Journal of Community Psychology, 23(5), 601-629.

Strandberg, C.H (1971). Water pollution. In G. H. Smith (ed.), Conservation of Natural Resources (4 ${ }^{\text {th }}$ Edn.), New York: Wiley, 189-219.

Tagiuri, R, Litwin, G. H. (Eds.) (1968). Organizational climate: explorations of a concept. Boston, Division of Research, Graduate School of Business Administration, Harvard University.

Theorell, T (2002). To be able to exert control over one's own situation: A necessary condition for coping with stressors. In Quick, J. C. \& Tetrcik, L. E., Handbook of Occupational Health Psychology (pp. 201-219). Washington, DC: American Psychological Association.

Thompson, K.R., Luthans, f. (1990). Organizational culture: A behavioral perspective. Ch. 9, pp. 319-344. Organizational Climate and Culture, Schneider, B. (Ed), Jossey-Bass Publishers: San Francisco.

Tjosvold, T, \& Tsoa, Y. (1989). Productive organizational collaboration: The role of values and cooperation. Journal of Organizational Behavior, 10, 189195.

Travis, JMJ (2003) Climate change and habitat destruction: a deadly anthropogenic cocktail. Proceedings of the Royal Society of London, Series B : Biological Sciences, Vol 270, no. 1514, 467-473. 
United Nations Development Programme (1998). Human Development Report: Consumption for human development. New York: Oxford University Press.

United Nations Development Programme (1994). Human Development Report: New dimensions of human security. New York: Oxford University Press.

Upham, P. (2000). An assessment of the Natural Step theory of sustainability. Journal of Cleaner Production, 8, 445- 454.

Upham, P. (2000). Scientific consensus on sustainability: The case of the Natural Step. Sustainable Development. 8: 180-190.

Vredenburgh, A. G. (2002). Organizational safety: Which management practices are most effective in reducing employee injury rates? Journal of Safety Research, 33, 2, 259-276.

Wackernagel, M., \& Rees, W. (1995). Our Ecological Footprint: Reducing Human Impact on the Earth. Gabriola Island, B.C.: New Society Publishers.

Warr P, Cook J, Wall T. (1979). Scales for the measurement of some work attitudes and aspects of psychological well-being. Journal of Occupational Psychology, 52, 129-148.

Wessells, M. (2002). The psychology of terrorism: Programs and practices in response and prevention. In C. E. Stout (Ed.) Psychological dimensions to war and peace, Vol. 4. (pp. 57-73). Westport, CT, US: Praeger Publishers/Greenwood Publishing Group, Inc.

Weyman, A., Clarke, D, D, \& Cox, T. (2003). Developing a factor model of coal miners' attributions on risk-taking at work. Work \& Stress, 17, 4, 306-320.

White, K. A. (2002). Improving attitude-behavior correspondence through exposure to normative support from a salient in-group. Basic \& Applied Social Psychology, 24 (2), 91-119.

Wolff, E. N (2000). Recent trends in wealth ownership, 1983-1998. Jerome Levy Economics Institute. http://www.levy.org/docs/wrkpap/papers/300.html

Wollman, N. (2002) Description of the National Index of Violence and Harm. Manchester College Peace Studies Institute. http://www.manchester.edu/Academic/Programs/Departments/Peace_Studie s/VI/ descr00e.pdf 
World Commission on Environment and Development (1987). Our common future: Report of the world commission on environment and development. United Nations Environment Program. April 14, 1987

World Wildlife Fund (2004). Living planet report. Eds., Jonathan Loh \& Mathis Wackernagel. October, 2004.

Zohar, D. (1980). Safety climate in the industrial organization: Theoretical and applied implications. Journal of Applied Psychology, 65, 96-102.

Zohar, D. (2000). A group-level model of safety climate: Testing the effect of group climate on microaccidents in manufacturing jobs. Journal of Applied Psychology, 85, 587-596.

Zohar, D. (2003). Safety climate: Conceptual and measurement issues. In Quick, J. C., Tetrick, L. E. (Eds). Handbook of occupational health psychology (pp.123-142).American Psychological Association, Washington, DC.

Zwick, M. (2004). Elements and Relations: Aspects of scientific metaphysics. Unpublished manuscript, Portland State University. 


\section{APPENDICES}

Appendix A: Direct e-mail invitation

To: Non-instructional faculty \& Classified Staff

From: Jay Kenton<kentonj@pdx.edu>

Reply to: David Hall<deh@pdx.edu>

Subject line: Sustainability Survey

Dear Colleagues,

As you may be aware, Portland State is dedicating efforts towards exploring sustainability (to be clarified in the survey) in the academic curriculum, and applying the concept to the operations of the University.

You are invited, as an employee of the University, to participate in a study that seeks your perspective on the subject of sustainability. The survey also asks questions about your work life, such as your levels of job satisfaction and work load as important measures of social sustainability. The development and evaluation of the survey is the Master's Thesis work of a graduate student.

We would greatly appreciate if you're able to volunteer your time (about 20 minutes) to fill out the survey, which has received Human Subjects Review Committee approval. The results of the survey will be made publicly available during the Spring term. Announcement of the availability of the results will be made through Currently, and the University's web-site dedicated to sustainability (www.sustain.pdx.edu).

To participate, link to the survey here:

http://survey.oit.pdx.edu/ss/wsb.dll/deh/SCS_non_instr_faculty.htm

Thanks, and best to all of you!

Sincerely,

Jay Kenton

Vice President for Finance and Administration 


\section{Appendix B: Currently posting}

Earlier this week all classified staff, non-instructional faculty and University administrators received an e-mail from Vice President, Jay Kenton, regarding an invitation to participate in a web-based survey. Employees of Facilities and Planning are being provided the same opportunity through hard-copy versions. Dubbed the Sustainability Climate Survey (SCS), the survey explores the subject of sustainability at PSU through the eyes of the University's employees. The questions are designed to assess whether or not an organization is effectively creating a work environment that promotes and facilitates thinking and decisionmaking along the lines of sustainability. The SCS also asks questions regarding work-life, such as work load and job satisfaction as important measures of social sustainability.

The development and analysis of the SCS is Thesis project of David Hall, a student in the Industrial/Organizational Psychology program. Hall's work is supported by Michele Crim, who was hired to help implement sustainability into the University's operations. Similar versions of the SCS likely will be distributed again in coming years to track progress of integrating the concept of sustainability throughout the University.

The study has received Human Subjects approval, and the results will be made publicly available. Data collection will continue for only a short period of time. Questions regarding the content and nature of the SCS are welcomed; simply write to David Hall (eh@ pdx.edu).

To take the survey, follow the appropriate link (note: employees of Facilities and Planning, please DO NOT take the web-based version of the survey, hard-copies will be made available to you.):

$\sim$ Non-instructional faculty: http://survey.oit.pdx.edu/ss/wsb.dll/deh/SCS non instr faculty.htm

Classified staff: http://survey.oit.pdx.edu/ss/wsb.dll/deh/SCS staff.htm Administrators: http://survey.oit.pdx.edu/ss/wsb.dll/deh/SCS administrators.htm 
Appendix C: Facilities \& Planning intro letter

\section{PORTLAND STATE UNIVERSITY}

Facilities \& Planning

617 SW Montgomery

P.O. Box 751

Portland, Oregon 97207-0751

PHONE: 503-725-3738

FAX: 503-725-4329

WEB: www.pp.pdx.edu

Dear Colleagues,

As you may be aware, Portland State is dedicating efforts towards exploring sustainability (to be clarified in the survey) in the academic curriculum, and applying the concept to the operations of the University.

You are invited, as an employee of the University, to participate in a study that seeks your perspective on the subject of sustainability. The survey also asks questions about your work life, such as your levels of job satisfaction and work load as important measures of social sustainability. The development and evaluation of the survey is the Master's Thesis work of a graduate student.

We would greatly appreciate if you're able to volunteer your time (about 20 minutes) to fill out the survey, which has received Human Subjects Review Committee approval. The results of the survey will be made publicly available during the Spring term. Announcement of the availability of the results will be made through Currently, and the University's web-site dedicated to sustainability (www.sustain.pdx.edu).

Thanks, and best to all of you!

Sincerely,

Mike Irish

Director of Facilities and Planning 
Appendix D: Letter of informed consent

Dear Research Participant,

You are invited to participate in a study that seeks your perspective as an employee of the University on the subject of sustainability (to be explained in the survey). The survey also asks questions about your work life, such as experienced levels of work load and job satisfaction. Should you choose to participate, candid responses are greatly appreciated.

The purpose of this survey is twofold. First, to gain an understanding of how effectively PSU is creating an atmosphere that promotes and facilitates thinking and actions guided by the concept of sustainability. Second, the development and analysis of the survey is the Master's Thesis for a student in Industrial/Organizational Psychology.

Your participation is voluntary. Your responses are confidential, and no individuals outside of those conducting the research will view the completed surveys. Presentation of the results will not contain any information that could be used to identify you as a participant or your individual responses. If you decide not to participate in this study it will not affect your university status, or relationship with anyone in the campus community. If you choose to participate, the survey should take roughly $\mathbf{2 0}$ minutes to complete. You may withdraw your consent by exiting the survey at any time.

You may speak to the researchers conducting this study, who will answer any questions about the study and what you are being asked to do. The study is being conducted by David Hall (725-3963, deh@pdx.edu), under the guidance of Bob Sinclair, Ph.D. (725-3965, sinclair@ pdx.edu), and Michele Crim, Sustainability Coordinator of Operations (crmm@pdx.edu, 725-8945).

If you have concerns or problems regarding your participation in this study, or your rights as a research participant, please contact the Human Subjects Research Review Committee, Office of Research and Sponsored Projects, 111 Cramer Hall, Portland State University, 725-4288. You may also contact the researchers.

Sincerely,

David E. Hall

Department of Psychology

deh@pdx.edu

725-3963 
Appendix E: The Sustainability Climate Survey

Thanks for participating! Please be candid, and enjoy!

$$
* * * * * * * * *
$$

1) What division of Facilities and Planning are you in? (Check the appropriate box)
Administrative / Office Support
Architecture
Electrical
$\square$ Environmental Health \& Safety
Landscaping
Maintenance / Carpentry
Security / Stores
Shipping / Mail / Warehouse
Systems
Other

2) Employed:

Full-time

Part-time

3) Length of employment at PSU:

$0-1$ years

1-5 years

5-10 years

10-20 years

more than 20 years

4) Gender:

$\square$ Female

$\square$ Male 


\section{Please read the following introduction to "sustainability":}

Interest in sustainability follows from the recognition that many activities of human society are at odds with basic laws of nature and social organization. It's assumed that if these actions continue they will lead to environmental changes and/or social conflict that will jeopardize the health of human society and the natural environment.

The sustainability movement then is the effort to change our way of living such that we are able to continue to meet our needs without compromising the ability of future generations to meet their needs.

To achieve this we must consider the three dimensions of economy, society and natural environment as interconnected. The health of each is dependent on the health of the other two. In practice, sustainability is the union of these dimensions.

For example, a sustainable community (or region or society) is one with a vibrant economy that serves community and social well-being through opportunity for people to satisfy their needs without degrading the natural environment's ability to support life (e.g. provide healthy food, clean air, clean water).

Once you've had a chance to read the above paragraphs, please mark a " $V$ " or " $X$ " in the box that best represents your level of agreement with the following statements:

\begin{tabular}{|c|c|c|c|c|c|c|}
\hline & & $\begin{array}{l}\text { Strongly } \\
\text { Disagree }\end{array}$ & Disagree & Neutral & Agree & $\begin{array}{c}\text { Strongly } \\
\text { Agree }\end{array}$ \\
\hline 5 & $\begin{array}{l}\text { The above paragraphs are } \\
\text { my first introduction to the } \\
\text { idea of sustainability. }\end{array}$ & & & & & \\
\hline 6 & $\begin{array}{l}\text { I still have very little } \\
\text { understanding of this idea } \\
\text { of sustainability. }\end{array}$ & & & & & \\
\hline 7 & $\begin{array}{l}\text { My understanding of } \\
\text { sustainability goes well } \\
\text { beyond this introduction. }\end{array}$ & & & & & \\
\hline 8 & $\begin{array}{l}\text { This idea of sustainability is } \\
\text { relevant to my job at PSU. }\end{array}$ & & & & & \\
\hline 9 & $\begin{array}{l}\text { I agree with the above } \\
\text { description of } \\
\text { sustainability. }\end{array}$ & & & & & \\
\hline
\end{tabular}


10) If you disagree with the above description of sustainability, we'd value your comments:

11) If you have additional thoughts about what sustainability means, we'd love to hear them:

Below are paired items, and a third option of "unsure." For each set, please select the one that is most consistent with the concept of sustainability. If you are not sure, please select "unsure."

12) Select one:

Renewable resources

Non-renewable resources

Unsure

13) Select one:

Linear

Cyclical

Unsure

14) Select one:

19) Select one:

Gap between rich and poor

$\square$ Social equity

Unsure
17) Select one:

"Take-make-waste" production

"Borrow-use-return" production

Unsure

18) Select one:

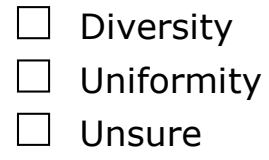

Wealth

Quality of Life

Unsure

15) Select one:

20) Select one:

Interdependence

Consumption

$\square$ Independence

$\square$ Unsure

$\square$ Conservation

$\square$ Unsure 
16) Select one:

$\square$ Isolation

Community

Unsure
21) Select one:

Economical

Inefficient

Unsure

Please select the response that best represents your level of agreement with the following statements:

\begin{tabular}{|c|c|c|c|c|c|c|}
\hline & & Strongly & Disagree & Neutral & Agree & $\begin{array}{c}\text { Strongly } \\
\text { Aaree }\end{array}$ \\
\hline 22 & $\begin{array}{l}\text { PSU's administration has } \\
\text { done a good job of } \\
\text { communicating that } \\
\text { sustainability is a } \\
\text { University priority. }\end{array}$ & & & & & \\
\hline 23 & $\begin{array}{l}\text { PSU's administration } \\
\text { takes the subject of } \\
\text { sustainability very } \\
\text { seriously. }\end{array}$ & & & & & \\
\hline 24 & $\begin{array}{l}\text { PSU's administration has } \\
\text { clearly demonstrated } \\
\text { support for efforts } \\
\text { towards sustainability. }\end{array}$ & & & & & \\
\hline 25 & $\begin{array}{l}\text { I believe that PSU's } \\
\text { administration sincerely } \\
\text { supports efforts towards } \\
\text { sustainability. }\end{array}$ & & & & & \\
\hline 26 & $\begin{array}{l}\text { My coworkers take the } \\
\text { subject of sustainability } \\
\text { very seriously. }\end{array}$ & & & & & \\
\hline 27 & $\begin{array}{l}\text { My coworkers feel a } \\
\text { compelling need to adopt } \\
\text { sustainability practices } \\
\text { and thinking. }\end{array}$ & & & & & \\
\hline 28 & $\begin{array}{l}\text { My coworkers are truly } \\
\text { concerned about issues } \\
\text { of social justice AND the } \\
\text { health of the } \\
\text { environment. }\end{array}$ & & & & & \\
\hline
\end{tabular}




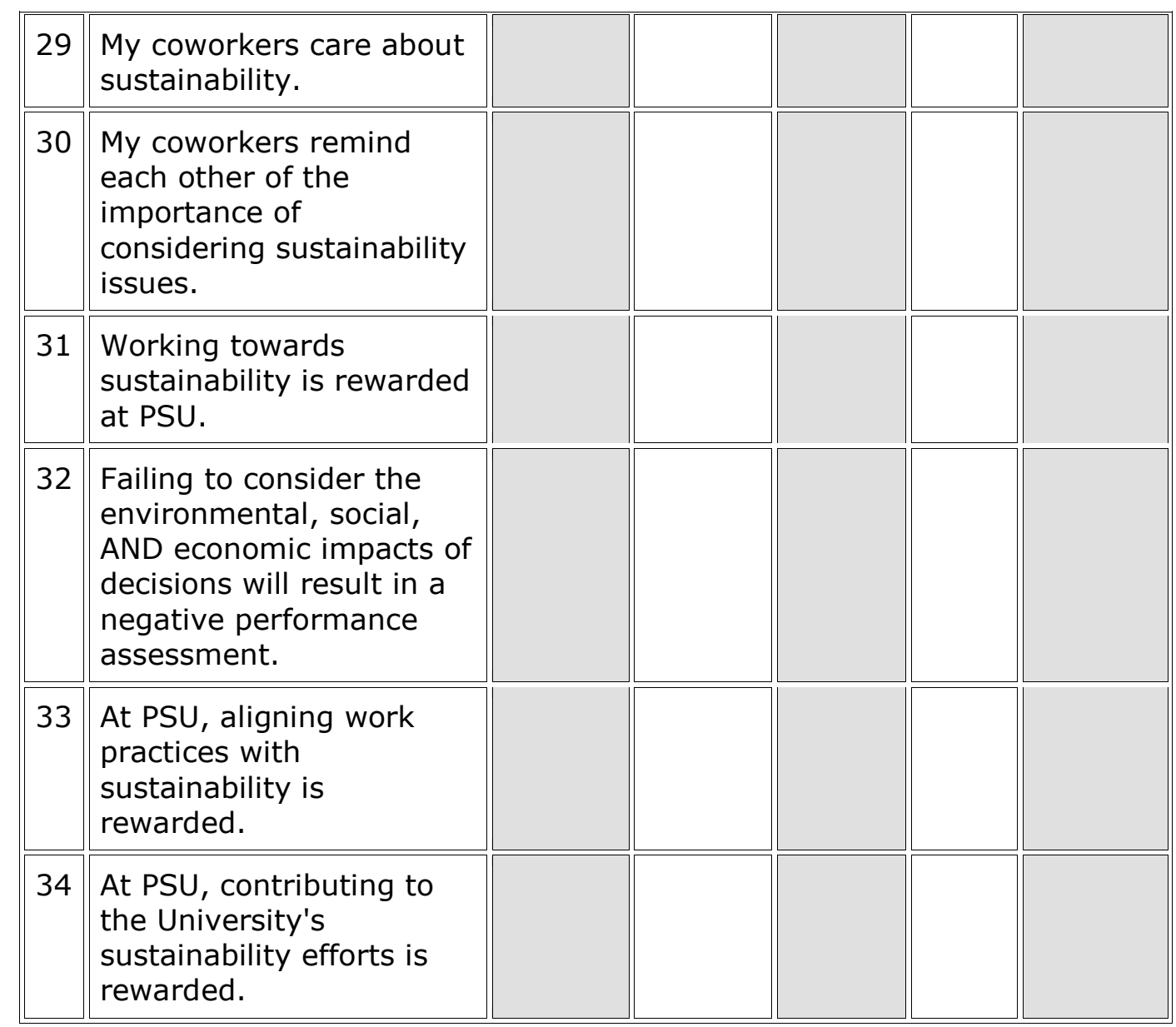

Your agreement:

\begin{tabular}{|c|c|c|c|c|c|c|}
\hline & & $\begin{array}{l}\text { Strongly } \\
\text { Disagree }\end{array}$ & Disagree & Neutral & Agree & $\begin{array}{c}\text { Strongly } \\
\text { Agree }\end{array}$ \\
\hline 35 & $\begin{array}{l}\text { PSU has made } \\
\text { information about } \\
\text { sustainability available } \\
\text { to me. }\end{array}$ & & & & & \\
\hline 36 & $\begin{array}{l}\text { I have been involved in } \\
\text { PSU's sustainability } \\
\text { efforts. }\end{array}$ & & & & & \\
\hline 37 & $\begin{array}{l}\text { I feel encouraged to } \\
\text { share my ideas related } \\
\text { to PSU's sustainability } \\
\text { efforts. }\end{array}$ & & & & & \\
\hline 38 & I have had the & & & & & \\
\hline
\end{tabular}


Sustainability Climate Survey 162

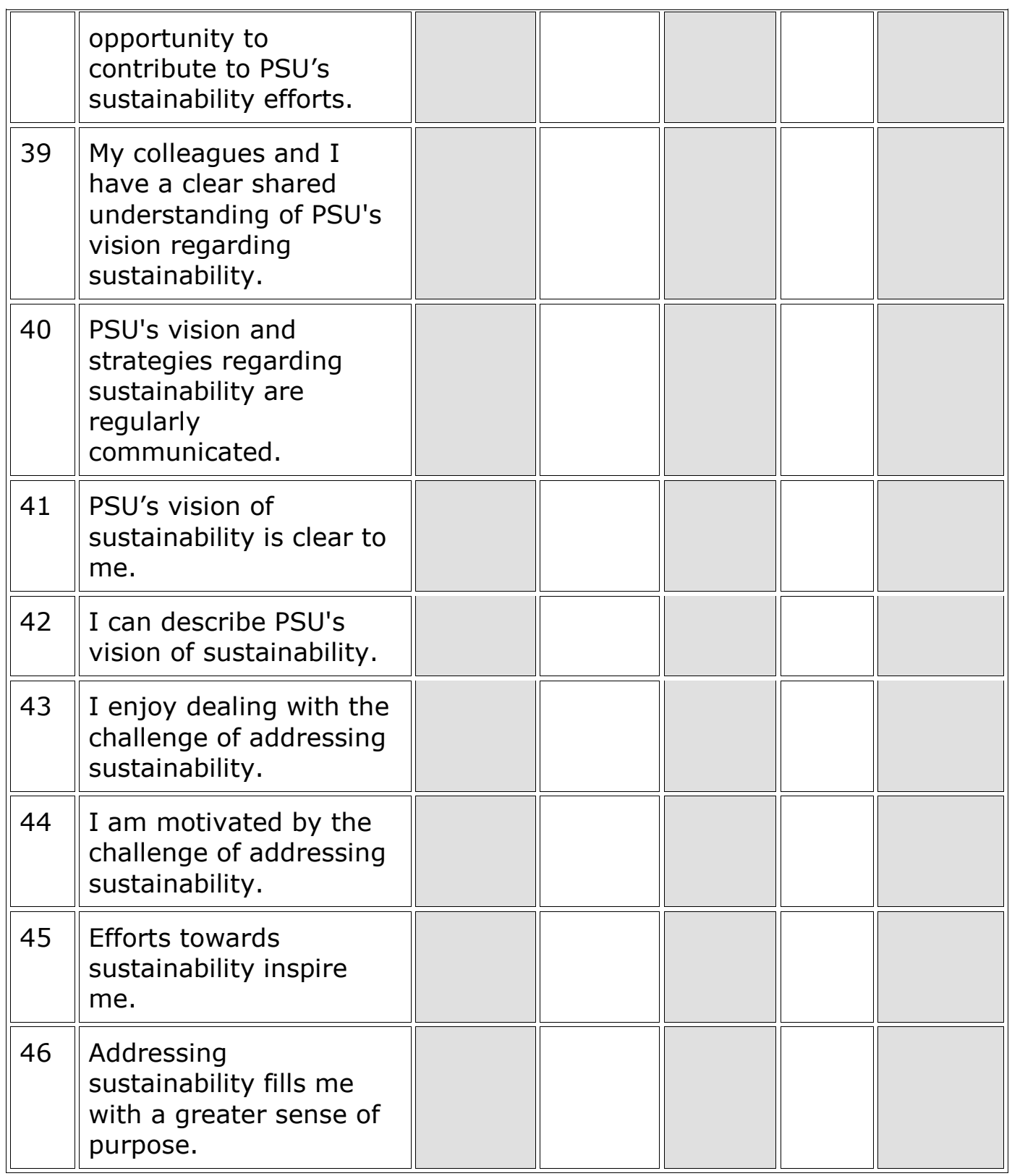


Your agreement:

\begin{tabular}{|c|c|c|c|c|c|c|}
\hline & & $\begin{array}{l}\text { Strongly } \\
\text { Disagree }\end{array}$ & Disagree & Neutral & Agree & $\begin{array}{c}\text { Strongly } \\
\text { Agree }\end{array}$ \\
\hline 47 & $\begin{array}{l}\text { Our decisions and } \\
\text { actions today hold } \\
\text { significant } \\
\text { consequences for future } \\
\text { generations. }\end{array}$ & & & & & \\
\hline 48 & $\begin{array}{l}\text { It is our responsibility } \\
\text { as a public institution to } \\
\text { strive towards } \\
\text { sustainability. }\end{array}$ & & & & & \\
\hline 49 & $\begin{array}{l}\text { Addressing } \\
\text { sustainability is } \\
\text { essential to the long- } \\
\text { term existence of } \\
\text { human society. }\end{array}$ & & & & & \\
\hline 50 & $\begin{array}{l}\text { Addressing } \\
\text { sustainability is } \\
\text { essential to the long- } \\
\text { term existence of PSU. }\end{array}$ & & & & & \\
\hline 51 & $\begin{array}{l}\text { Many aspects of today's } \\
\text { society are } \\
\text { unsustainable. }\end{array}$ & & & & & \\
\hline 52 & $\begin{array}{l}\text { Societal problems are } \\
\text { exaggerated. }\end{array}$ & & & & & \\
\hline 53 & $\begin{array}{l}\text { Environmental problems } \\
\text { are exaggerated. }\end{array}$ & & & & & \\
\hline 54 & $\begin{array}{l}\text { There is nothing to } \\
\text { worry about, technology } \\
\text { always has and always } \\
\text { will solve the problems } \\
\text { threatening the } \\
\text { environment. }\end{array}$ & & & & & \\
\hline 55 & $\begin{array}{l}\text { There are more } \\
\text { important issues than } \\
\text { sustainability to which } \\
\text { PSU should devote } \\
\text { attention. }\end{array}$ & & & & & \\
\hline
\end{tabular}


Your agreement:

\begin{tabular}{|c|c|c|c|c|c|c|}
\hline & & $\begin{array}{l}\text { Strongly } \\
\text { Disagree }\end{array}$ & Disagree & Neutral & Agree & $\begin{array}{c}\text { Strongly } \\
\text { Agree }\end{array}$ \\
\hline 56 & $\begin{array}{l}\text { There is a strong sense } \\
\text { of community at PSU. }\end{array}$ & & & & & \\
\hline 57 & $\begin{array}{l}\text { People at PSU are } \\
\text { courteous and respectful } \\
\text { of one another. }\end{array}$ & & & & & \\
\hline 58 & $\begin{array}{l}\text { People look out for the } \\
\text { welfare of one another } \\
\text { at PSU. }\end{array}$ & & & & & \\
\hline 59 & $\begin{array}{l}\text { People at PSU work } \\
\text { together to solve } \\
\text { problems }\end{array}$ & & & & & \\
\hline 60 & $\begin{array}{l}\text { I have so much work to } \\
\text { do, I cannot do } \\
\text { everything well. }\end{array}$ & & & & & \\
\hline 61 & $\begin{array}{l}\text { I never seem to have } \\
\text { enough time to get } \\
\text { everything done. }\end{array}$ & & & & & \\
\hline 62 & $\begin{array}{l}\text { My job leaves me with } \\
\text { little time to get things } \\
\text { done. }\end{array}$ & & & & & \\
\hline 63 & $\begin{array}{l}\text { I have a hard time } \\
\text { meeting the demands of } \\
\text { my job. }\end{array}$ & & & & & \\
\hline 64 & $\begin{array}{l}\text { I have a lot of say about } \\
\text { what happens on my } \\
\text { job. }\end{array}$ & & & & & \\
\hline 65 & $\begin{array}{l}\text { My job allows me to } \\
\text { make a lot of decisions } \\
\text { on my own. }\end{array}$ & & & & & \\
\hline 66 & $\begin{array}{l}\text { I get to do a variety of } \\
\text { different things on my } \\
\text { job. }\end{array}$ & & & & & \\
\hline 67 & $\begin{array}{l}\text { My job allows me to be } \\
\text { creative. }\end{array}$ & & & & & \\
\hline
\end{tabular}


68 I have an opportunity to develop my abilities.

Your level of satisfaction with:

\begin{tabular}{|c|c|c|c|c|c|c|}
\hline & & $\begin{array}{l}\text { Very dis- } \\
\text { satisfied }\end{array}$ & $\begin{array}{c}\text { Dis- } \\
\text { satisfied }\end{array}$ & $\begin{array}{c}\text { Un- } \\
\text { decided }\end{array}$ & Satisfied & $\begin{array}{c}\text { Very } \\
\text { satisfied }\end{array}$ \\
\hline 69 & $\begin{array}{l}\text { physical working } \\
\text { conditions. }\end{array}$ & & & & & \\
\hline 70 & $\begin{array}{l}\text { recognition you get } \\
\text { for good work. }\end{array}$ & & & & & \\
\hline 71 & your compensation. & & & & & \\
\hline 72 & $\begin{array}{l}\text { your opportunity to } \\
\text { use your abilities. }\end{array}$ & & & & & \\
\hline 73 & $\begin{array}{l}\text { Overall satisfaction } \\
\text { with your job. }\end{array}$ & & & & & \\
\hline
\end{tabular}


We would like to know whether you feel certain activities are an expected part of your responsibilities, or if you consider them above and beyond what is expected of you.

Please select 1 of the 5 options:

\begin{tabular}{|c|c|c|c|c|c|c|}
\hline & & $\begin{array}{l}\text { (1) } \\
\text { Definitely } \\
\text { expected } \\
\text { part of } \\
\text { my job }\end{array}$ & (2) & $\begin{array}{l}\text { (3) } \\
\text { Somewhat } \\
\text { beyond } \\
\text { expect- } \\
\text { ations }\end{array}$ & (4) & $\begin{array}{l}(5) \\
\text { Definitely } \\
\text { above \& } \\
\text { beyond } \\
\text { expect- } \\
\text { ations }\end{array}$ \\
\hline 74 & $\begin{array}{l}\text { Making suggestions about } \\
\text { how to integrate } \\
\text { sustainability into policies } \\
\text { and procedures. }\end{array}$ & & & & & \\
\hline 75 & $\begin{array}{l}\text { Raising concerns about } \\
\text { sustainability issues } \\
\text { during meetings. }\end{array}$ & & & & & \\
\hline 76 & $\begin{array}{l}\text { Improving my knowledge } \\
\text { and understanding of } \\
\text { sustainability. }\end{array}$ & & & & & \\
\hline 77 & $\begin{array}{l}\text { Reminding coworkers to } \\
\text { consider issues of } \\
\text { sustainability. }\end{array}$ & & & & & \\
\hline 78 & $\begin{array}{l}\text { Helping my coworkers to } \\
\text { learn about issues of } \\
\text { sustainability. }\end{array}$ & & & & & \\
\hline 79 & $\begin{array}{l}\text { Making decisions with } \\
\text { consideration of the } \\
\text { environmental, social } \\
\text { AND economic } \\
\text { implications. }\end{array}$ & & & & & \\
\hline 80 & $\begin{array}{l}\text { Aligning my work } \\
\text { practices with the concept } \\
\text { of sustainability. }\end{array}$ & & & & & \\
\hline 81 & $\begin{array}{l}\text { Integrating the concept of } \\
\text { sustainability into my } \\
\text { work practices. }\end{array}$ & & & & & \\
\hline
\end{tabular}


In the following section we would like to know the frequency you actually engage in the following actions as an employee of Facilities and Planning.

\begin{tabular}{|c|c|c|c|c|c|c|}
\hline & Never & Rarely & $\begin{array}{c}\text { Some- } \\
\text { times }\end{array}$ & Often & $\begin{array}{l}\text { Very } \\
\text { often }\end{array}$ \\
\hline 82 & $\begin{array}{l}\text { I make suggestions about } \\
\text { how to integrate } \\
\text { sustainability into policies } \\
\text { and procedures. }\end{array}$ & & & & & \\
\hline 83 & $\begin{array}{l}\text { I raise concerns about } \\
\text { sustainability issues during } \\
\text { planning meetings. }\end{array}$ & & & & & \\
\hline 84 & $\begin{array}{l}\text { I work to improve my } \\
\text { knowledge and } \\
\text { understanding of } \\
\text { sustainability. }\end{array}$ & & & & & \\
\hline 85 & $\begin{array}{l}\text { I remind coworkers to } \\
\text { consider issues of } \\
\text { sustainability. }\end{array}$ & & & & & \\
\hline 86 & $\begin{array}{l}\text { I help my coworkers to learn } \\
\text { about issues of } \\
\text { sustainability. }\end{array}$ & & & & & \\
\hline 87 & $\begin{array}{l}\text { I make decisions with } \\
\text { consideration of the } \\
\text { environmental, social AND } \\
\text { economic implications. }\end{array}$ & & & & & \\
\hline 88 & $\begin{array}{l}\text { I align my work practices } \\
\text { with the concept of } \\
\text { sustainability. }\end{array}$ & & & & & \\
\hline 89 & $\begin{array}{l}\text { I integrate the concept of } \\
\text { sustainability into my work } \\
\text { practices. }\end{array}$ & & & & & \\
\hline
\end{tabular}


Sustainability Climate Survey 168

\begin{tabular}{|c|c|c|c|c|c|c|}
\hline & & Never & Rarely & $\begin{array}{l}\text { Some- } \\
\text { times }\end{array}$ & Usually & Always \\
\hline 90 & $\begin{array}{l}\text { I am very conservative in my } \\
\text { use of resources and supplies } \\
\text { at work. }\end{array}$ & & & & & \\
\hline 91 & $\begin{array}{l}\text { I take public transportation, } \\
\text { walk, bicycle, or car pool to } \\
\text { work. }\end{array}$ & & & & & \\
\hline 92 & $\begin{array}{l}\text { At work I recycle paper } \\
\text { products }\end{array}$ & & & & & \\
\hline 93 & $\begin{array}{l}\text { At work I ensure I recycle all } \\
\text { other recyclable materials. }\end{array}$ & & & & & \\
\hline 94 & $\begin{array}{l}\text { I seek reused or recycled } \\
\text { products for work related } \\
\text { purchases. }\end{array}$ & & & & & \\
\hline 95 & $\begin{array}{l}\text { At work I eat organic and/or } \\
\text { locally grown foods. }\end{array}$ & & & & & \\
\hline 96 & $\begin{array}{l}\text { I use a non-disposable } \\
\text { beverage container at work. }\end{array}$ & & & & & \\
\hline
\end{tabular}

Please rate the frequency to which the following statements apply to you:

In general:

\begin{tabular}{|c|c|c|c|c|c|c|}
\hline & & Never & Rarely & $\begin{array}{l}\text { Some- } \\
\text { times }\end{array}$ & Often & $\begin{array}{l}\text { Very } \\
\text { often }\end{array}$ \\
\hline 97 & $\begin{array}{l}\text { I put time and effort into } \\
\text { promoting social causes. }\end{array}$ & & & & & \\
\hline 98 & $\begin{array}{l}\text { I'm an active member of my } \\
\text { community. }\end{array}$ & & & & & \\
\hline 99 & $\begin{array}{l}\text { I'm actively involved in } \\
\text { addressing social issues. }\end{array}$ & & & & & \\
\hline 100 & $\begin{array}{l}\text { I participate in community } \\
\text { service. }\end{array}$ & & & & & \\
\hline
\end{tabular}


101) What would help you to contribute to PSU's sustainability efforts? (Select all that apply)

More information about the concepts and meaning of sustainability

A clearer sense of PSU's vision for sustainability

More opportunity for involvement

Stronger leadership towards sustainability

Increased collaboration with other functions/departments in the university

More time in the day

$\square$ Rewards, incentives, and/or acknowledgement for making contributions towards sustainability.

Other (please specify):

(Feel free to use the back of this sheet as additional space for your comments)

102) What do you see as the greatest barriers to implementing sustainability into PSU's campus operations?

103) What do you see as some of the best opportunities for PSU to contribute to the advancement of the sustainability movement?

104) Please share any other thoughts or concerns you have about sustainability at PSU:

105) Please share any thoughts you may have about the nature of this survey:

Thanks so much for your thoughtful participation! 
Special thanks to the following folks for their assistance in making the survey possible:

Michele Crim, Bob Sinclair, Donald Truxillo, Dave Burgess and the Office of Institutional Research and Planning, Carrie Medina, SWARM, Cathleen Davidson, Will Garrick and his team of support staff, Kathryn Kirkland, Jay Kenton and Mike Irish for their support, and each one of you who took the time to participate and share your perspective. Thank You!

Appreciation also for your hard work and effort in maintaining the University's operations, we'd be a wreck without you.

Warmest wishes to all!

\section{PLEASE RETURN COMPLETED SURVEYS TO:}

\section{The envelope by the chalk board next to the break room The envelope at the front desk of Facilities and Planning OR Via campus mail: PSY, Dave Hall}


Ajzen, I., \& Fishbein, M. (1972). Attitudes and normative beliefs as factors influencing behavioral intentions. Journal of Personality and Social Psychology, 21, 1-9.

Ajzen, I. (1991). The theory of planned behavior. Organizational Behavior and Human Decision Processes, 50, 179-211.

Ajzen, I. (1988). Attitudes, personality and behavior. Milton Keynes, UK: Open University Press.

Bansal, P. \& Roth, K. (2000). Why companies go green: A model of ecological responsiveness. Academy of Management Journal, 43, 717-736.

Barling, J., Loughlin, C., Kelloway, E. K. (2002). Development and test of a model linking safety-specific transformational leadership and occupational safety. Journal of Applied Psychology, 87(3), 488-496.

Barney, J.B. (1991). Firm resources and sustained competitive advantage. Journal of Management, 17(1), 99-120.

Basile, G. \& Rosenblum, J (2000). Walk this way. Forum for Applied Research and Public Policy, 15, 29-34.

Bass, B.M. (1985). Leadership and Performance Beyond Expectations. New York: Free Press.

Beattie, A, \& Ehrlich, P. (2001). Wild Solutions: How biodiversity is money in the bank. New Haven and London: Yale University Press.

Berger, P., \& Luckmann, T. (1966). The Social Construction of Reality. New York: Penguin.

Boldero, J. (1995). The prediction of household recycling of newspapers: The role of attitudes, intentions, and situational factors. Journal of Applied Social Psychology, 25(5), 440-462.

Brower, M., Leon, W (1999). The consumer's guide to effective environmental choices: Practical advice from the Union of Concerned Scientists. Three Rivers Press: New York.

Bruce, W.M., \& Blackburn, J.W. (1992). Balancing Job Satisfaction and Performance: A guide for human resource professionals. Westport Connectivut: Quorum Books.

Bullock, R.J. (1984). Improving Job Satisfaction. New York: Pergamon Press.

Cammann, C., Fichman, M., Jenkins, G. D., \& Klesh, J. (1983). Michigan organizational assessment questionnaire. In S.E. Seashore, E. E. Lawler, P.H. Mirvis, \& C. 
Camman (Eds.), Assessing organizational change: A guide to methods, measures, and practices (pp. 71-138). New York: Wiley.

Cantell, R.B. (1966). The scree test for the number of factors. Multivariate Behavioral Research, 1, 245-276.

Castle, D. (2003). Interview with Hall, D. Conducted Spring 2003.

Colligan, Michael J; Cohen, Alexander (2004). The role of training in promoting workplace safety and health. [Chapter] Barling, Julian (Ed); Frone, Michael R. (Ed). (2004). The Psychology of Workplace Safety. (pp. 223-248). Washington, DC, US: American Psychological Association.

Cortina, J. M. (1993) What is coefficient alpha? An examination of theory and applications. Journal of Applied Psychology, 78 (1), 98-104.

Dedobbeleer, N., \& Beland, F. (1991). A safety climate measure for construction sites. Journal of Safety Research, 22, 97-103.

Denison, D. (1996). What is the difference between organizational culture and climate? A native's point of view on a decade of paradigm wars. Academy of Management Review, 21 (3), 619-654.

Dess, G. G. \& Picken, J. C. (2000). Changing roles: Leadership in the 21 st century. Organizational Dynamics. 28(3), 18-34.

DeVellis, R. F. (1991). Scale development: Theory and application. Applied Social Research Methods Series, 26. London: Sage Publications.

Doppelt, B. (2003). Leading Change Toward Sustainability: A change management guide for business, government, and civil society. Sheffield, UK: Greenleaf Publishing.

Drexler, J.A. (1977). Organizational climate: Its homogeneity within organizations. Journal of Applied Psychology, 62, 38-42.

Easton, G. S., \& Jarrell S. L.(1998). The effects of total quality management on corporate performance: An empirical investigation. Journal of Business, 71, 253-307.

Ehrlich, P. R., Jianguo, L (2002). Some roots of terrorism. Population \& Environment, 24(2), 183-192.

Eldredge, N. (1998). Life in the Balance: Humanity and the biodiversity crisis. Princeton, NJ: Princeton University Press.

Epstein, P. (1999). Global warming: Health and disease. World Wildlife Fund. 
Epstein, P., Diaz, H., Elias, S., Grabherr, G., Graham, N., Martens, W., Thompson, E.M., and Susskind, J. (1998). Biological and physical signs of climate change: focus on mosquito borne diseases. Bulletin of the American Meteorological Society, 79, 409-417.

Feldman, J., \& Lynch, J. (1988). Self-generated validity and other effects of measurement on belief, attitude, intention, and behavior. Journal of Applied Psychology, 3, $421-435$.

Festinger, L. (1957). A theory of cognitive dissonance. Stanford, CA: Stanford University Press.

Fishbein, M., Chan, D., O’Reilly, K., Schnell, D., Wood, R., Beeker, C., Cohn, D. (1992). Attitudinal and normative factors as determinants of gay men's intentions to perform AIDs-related sexual behaviors: A multi-site analysis. Journal of Applied Social Psychology, 22(13), 999-1011.

Ford, K. J., MacCallum, R. C, Tait, M. (1986). The application of exploratory factor analysis in applied psychology: A critical review and analysis. Personnel Psychology, 39(2), 291-314.

Goldberger, A.L. (1996). Non-linear dynamics for clinicians: chaos theory, fractals, and complexity at the bedside. The Lancet, 347, 1312-1314.

Goldberger, A.L., Rigney, D. R. West, B.J. (1990). Chaos and fractals in human physiology. Science America, 262, 42-29.

Goudie, a. (1990). The Human Impact on the Natural Environment, $3^{\text {rd }}$ Ed. The MIT Press: Cambridge, Mass.

Hall, D.E. (2003). Assessing the sustainability climate of PSU students: A pilot study. Unpublished manuscript, Portland State University.

Halme, M. (2002). Corporate environmental paradigms in shift: Learning during the course of action at UPM-Kymmene. Journal of Management Studies, 39(8), 1087-1109.

Hardin, G (1968). The tragedy of the commons. Science, 162, 1243-1248.

Hart, S.L. (1995). A natural-resource-based view of the firm. Academy of Management Review, 20(4), 986-1014.

Hawken, P. (1993) The Ecology of Commerce: A declaration of sustainability. New York: Harper Books. 
Hinkin, T. R. (1998). A brief tutorial on the development for use in survey questionnaires. Organizational Research Methods, 104-121.

Hofmann, D. A., \& Stetzer, A. (1996). A cross-level investigation of factors influencing unsafe behaviors and accidents. Personnel Psychology, 49, 307-339.

Howe, J. G. (1977). Group climate: An exploratory analysis of construct validity. Organizational Behavior and Human Performance, 19, 106-125.

Hughes, TP; Baird, AH; Bellwood, DR; Card, M; Connolly, SR; Folke, C; Grosberg, R; Hoegh-Guldberg, O; Jackson, JBC; Kleypas, J; Lough, JM; Marshall, P; Nystroem, M; Palumbi, SR; Pandolfi, JM; Rosen, B; Roughgarden, J (2003). Climate change, human impacts, and the resilience of coral reefs. Science, 301, (5635), 929-933.

Iadacola, P. \& Shupe, A. (1998). Violence, Inequality, and Human Freedom. New York: General Hall Publishers.

Intergovernmental Panel on Climate Change, Working Group II (2001). Climate Change 2001: Impacts, adaptation, and vulnerability. MacCarthy, J.J. et al., eds. Cambridge University Press, Cambridge, UK.

Johnston. H. R. (1976). A new conceptualization of source of organizational climate. Administrative Science Quarterly, 21, 95-103.

Joyce, W. F. \& Slocum, J.W., Jr. (1990). Strategic Context and Organizational Climate, In B. Schneider (Ed), Organizational Climate and Culture, (pp. 130-151). San Francisco: Jossey-Bass Publishers.

Joyce, W. F. \& Slocum, J. W., Jr. (1984). Collective climate: Agreement as a basis for defining aggregate climates in organizations. Academy of Management Journal, 27, 721-742.

Karasek, R. A. (1979). Job demands, job decision latitude, and mental strain: Implications for job redesign. Administrative Science Quarterly, 24, 285-308.

Karasek R. A., Theorell T. (1990). Healthy Work. New York: Basic Books

Katz, D., \& Khan, R. L. (1978). The social psychology of organizations (2 ${ }^{\text {nd }}$ Ed). New York, Wiley.

Korten, D. (2001). When Corporations Rule the World. San Francisco, CA: BerrettKoehler Publishers.

Kotter (1995). Leading change: Why transformation efforts fail. Harvard Business Review, 1-20. 
Lam, S., \& Schaubroeck, J. (2000). A field experiment testing frontline opinion leaders as change agents. Journal of Applied Psychology, 85(6), 987-995.

Landsbergis, P. A., Schnall, P. L., Belkic, K. L., Baker, D., Schwartz, J. E., \& Pickering, T. G., (2002). The workplace and cardiovascular disease: Relevance and potential role for occupational health psychology. In Quick, J. C. \& Tetrcik, L. E., Handbook of Occupational Health Psychology, (pp. 265-287). Washington, DC: American Psychological Association.

Large, J. (2004) The costs of a violent society. Seattle Times, April 15 ${ }^{\text {th }}, 2004$.

Lewin, K., Lippitt, R., White, R. K. (1939). Patterns of aggressive behavior in experimentally created "social climates." Journal of Social Psychology, 10, 271299.

Lewin, K. (1951). Field theory in social science. New York: Harper \& Row.

Lipsitz, L.A. Goldberger, A.L., (1992). Loss of complexity and aging: Potential applications of fractals and chaos theory to senescence. The Journal of the American Medical Association, 267, 1806-1809.

Malmqvist, B; Rundle, S (2002) Threats to the running water ecosystems of the world. Environmental Conservation 29 (2), 134-153.

Manstead, A. S. R. (1996). Attitudes and behavior. Applied Social Psychology, 3-29.

Margolis, J. D., \& Walsh, J. P. (2001) People and Profits: The search for a link between a company's social and financial performance. Mahwah, N.J.: Lawrence Erlbaum Associates.

Marcus, S. E. (2004). Strategic decision making in organizations that value financial, social, and environmental sustainability. Unpublished doctoral dissertation, Portland State University.

Maslow, A.H. (1954). Motivation and Personality. New York: Harper \& Brothers.

Maslow, A.H. (1970). Motivations and Personality (2 ${ }^{\text {nd }}$ ed.). New York: Harper \& Row.

Mead, G. (1934). Mind, self, and society. Chicago: University of Chicago Press.

Meadows, D.H. (1997). Ways to intervene in a system. Whole Earth Review, Winter 1997.

Moran, E. \& Volkwein, J. (1992). The cultural approach to the formation of organizational climate. Human Relations, 45 (1), 19-47. 
Myers (1979), The Sinking Arc: A new look at the problem of disappearing species. Oxford: Pergamon Press.

Nairne, J. (2003). Psychology: The adaptive mind ( $3^{\text {rd }}$ Ed.), Belmont, CA: Wadsworth.

Natural Step, The (2001). Workshop: Implementing sustainability using the Natural Step framework. Portland, OR, August, 2001.

Neal, A., Griffin, M. A., \& Hart, P. M. (2000). The impact of organizational climate on safety climate and individual behavior. Safety Science, 34, 99-109.

Neal, A. \& Griffin, M. A. (2004). Safety climate and safety at work. [Chapter] J. Barling, M. R. Frone, (Eds). The Psychology of Workplace Safety. (pp. 15-34). Washington, DC, US: American Psychological Association.

Northwest Environment Watch (2002). This place on earth 2002: Measuring what matters. Seattle, WA: NEW.

Oregon Natural Resource Council (2002). Bush unveils plan to boost logging Oregon's public forests. www.onrc.org/press/044.bushplan.html

Paine, L.S. (2003). Value Shift: Why companies must merge social and financial imperatives to achieve superior performance. New York: McGraw-Hill.

Parker, S. K., Axtell, C. M., \& Turner, N. (2001). Designing a safer workplace: Importance of job autonomy, communication quality, and supportive supervisors. Journal of Occupational Health Psychology, 6, 3, 211-228.

Paulhus, D. L. (1984). Two-component models of socially desirable responding. Journal of Personality and Social Psychology, 46, 598-609.

Powell, G. N. \& Butterfield, D. A. (1978). The case for subsystem climates in organizations. Academy of Management Review, 3, 151-157.

Putnam, R. D. (2000). Bowling Alone: The collapse and revival of American community. New York: Simon \& Schuster.

Quinn, D. (1992). Ishmael. New York: Bantam-Turner Books.

Reese, W. E. (1996) Revisiting carrying capacity: Area-based indicators of sustainability. Population and Environment, 17, 225-239. http://dieoff.org/page110.htm

Robert, K.-H. (1997). A compass for sustainable development. International Journal of Sustainable Development and World Ecology, 4, 79-92. 
Robinson, E. (2004). A decade of compromise: Timber towns struggle under forest plan. The Columbian. www.columbian.com/04132004/front_pa/134852.html

Rodgers, R., Hunter, J.E., Rogers, D. L. (1993). Influence of top-management commitment on management program success. Journal of Applied Psychology, 78(1), 151-155.

Rodgers, R., Hunter, J.E. (1991). Impact of management by objectives on organizational productivity. Journal of Applied Psychology, 76, 322-336.

Rogers, E. M. (1995). Diffusion of innovations. New York: Free Press.

Rosenblum, J. (1999-2000). A deeper look at the system conditions. The Natural Step Newsletter, 1, 8-11.

Ruckelshaus, William (1989). Toward a sustainable world. Scientific American, 261, 166-174.

Russell, D. W. (2002). In search of underlying dimensions: The use (and abuse) of factor analysis in Personality and Social Psychology Bulletin, 28(12), 1629-1646.

Russo, M.V., Fouts, P.A. (1997). A resource-based perspective on corporate environmental performance and profitability. Academy of Managerment Journal, 40(3), 534-559.

Schein, E. (1992). Organizational Culture and Leadership. San Francisco, Jossey-Bass Publishers.

Schnaiberg, A. (1980). The Environment: From surplus to scarcity. New York: Oxford University Press.

Schnall, P., Belkic, K., Landsbergis, P., \& Baker, D. (2000). The Workplace and Cardiovascular Disease. Hanley \& Belfus, Inc., Occup Med 15(1).

Schneider, B. (1975) Organizational climate: Individual preferences and organizational realities. Journal of Applied Psychology, 56, 211-217.

Schneider, B (1990). The climate for service: An application of the climate construct. In B. Schneider (Ed), Organizational Climate and Culture, (pp. 383-412). San Francisco: Jossey-Bass Publishers.

Schneider, B., Bowen, D.E., Ehrhart, M. G. \& Holcombe, K. M. (2000). The climate for service: Evolution of a construct. In N. M. Ashkanasy, C. P. Wilderom, M. F. Peterson (Eds.), Handbook of organizational culture and climate (pp. 21-36). Thousand Oaks, CA: Sage. 
Senge, (1990). The Fifth Discipline: The art and practice of a learning organization. A conversation with Peter Senge. July $19^{\text {th }}, 1990$, Grafton, Vermont. Edited by Colleen Lannon Kim.

Senge, P.M. \& Carstedt, G. (2001). Innovating our way to the next industrial revolution. MIT Sloan Management Review, Winter2001, 24-38.

Shapiro, I., \& Greenstein, R. (1999). The widening income gulf. Center on Budget and Policy Priorities. http://www.cbpp.org/9-4-99tax-rep.htm

Shuman, M. (1998). Going local: creating self-reliant communities in a global age. New York: Free Press.

Simard, M, \& Marchand, A. (1997). Workgroups' propensity to comply with safety rules: The influence of micro-macro organisational factors. Ergonomics, 40, 2, 172-188.

Skinner, B.F. (1938). The behavior of organisms; an experimental analysis. New York, London, D. Appleton-Century Company.

SOER Science Panel (2000). Oregon State of the environment report: Statewide summary (prepared for the Oregon Progress Board by the SOER Science Panel, Paul G. Riser, Chair. September 2000.

Spielberger, C. D., Vagg, P. R., \& Wasala, C. F. (2003). Occupational stress: Job pressures and lack of support. In Quick, J. C. \& Tetrick, L. E., Handbook of Occupational Health Psychology (pp. 201-219). Washington, DC: American Psychological Association.

Spreitzer, G. M. (1995). An empirical test of a comprehensive model of intrapersonal empowerment in the workplace. American Journal of Community Psychology, 23(5), 601-629.

Strandberg, C.H (1971). Water pollution. In G. H. Smith (ed.), Conservation of Natural Resources (4 ${ }^{\text {th }}$ Edn.), New York: Wiley, 189-219.

Tagiuri, R, Litwin, G. H. (Eds.) (1968). Organizational climate: explorations of a concept. Boston, Division of Research, Graduate School of Business Administration, Harvard University.

Theorell, T (2002). To be able to exert control over one's own situation: A necessary condition for coping with stressors. In Quick, J. C. \& Tetrcik, L. E., Handbook of Occupational Health Psychology (pp. 201-219). Washington, DC: American Psychological Association. 
Thompson, K.R., Luthans, f. (1990). Organizational culture: A behavioral perspective. Ch. 9, pp. 319-344. Organizational Climate and Culture, Schneider, B. (Ed), Jossey-Bass Publishers: San Francisco.

Tjosvold, T, \& Tsoa, Y. (1989). Productive organizational collaboration: The role of values and cooperation. Journal of Organizational Behavior, 10, 189-195.

Travis, JMJ (2003) Climate change and habitat destruction: a deadly anthropogenic cocktail. Proceedings of the Royal Society of London, Series B : Biological Sciences, Vol 270, no. 1514, 467-473.

United Nations Development Programme (1998). Human Development Report: Consumption for human development. New York: Oxford University Press.

United Nations Development Programme (1994). Human Development Report: New dimensions of human security. New York: Oxford University Press.

Upham, P. (2000). An assessment of the Natural Step theory of sustainability. Journal of Cleaner Production, 8, 445- 454.

Upham, P. (2000). Scientific consensus on sustainability: The case of the Natural Step. Sustainable Development. 8: 180-190.

Vredenburgh, A. G. (2002). Organizational safety: Which management practices are most effective in reducing employee injury rates? Journal of Safety Research, 33, 2, 259-276.

Wackernagel, M., \& Rees, W. (1995). Our Ecological Footprint: Reducing Human Impact on the Earth. Gabriola Island, B.C.: New Society Publishers.

Warr P, Cook J, Wall T. (1979). Scales for the measurement of some work attitudes and aspects of psychological well-being. Journal of Occupational Psychology, 52, 129-148.

Wessells, M. (2002). The psychology of terrorism: Programs and practices in response and prevention. In C. E. Stout (Ed.) Psychological dimensions to war and peace, Vol. 4. (pp. 57-73). Westport, CT, US: Praeger Publishers/Greenwood Publishing Group, Inc.

Weyman, A., Clarke, D, D, \& Cox, T. (2003). Developing a factor model of coal miners' attributions on risk-taking at work. Work \& Stress, 17, 4, 306-320.

White, K. A. (2002). Improving attitude-behavior correspondence through exposure to normative support from a salient in-group. Basic \& Applied Social Psychology, 24 (2), 91-119. 
Wolff, E. N (2000). Recent trends in wealth ownership, 1983-1998. Jerome Levy Economics Institute. http://www.levy.org/docs/wrkpap/papers/300.html

Wollman, N. (2002) Description of the National Index of Violence and Harm. Manchester College Peace Studies Institute. http://www.manchester.edu/Academic/Programs/Departments/Peace_Studies/VI/ descr00e.pdf

World Commission on Environment and Development (1987). Our common future: Report of the world commission on environment and development. United Nations Environment Program. April 14, 1987

World Wildlife Fund (2004). Living planet report. Eds., Jonathan Loh \& Mathis Wackernagel. October, 2004.

Zohar, D. (1980). Safety climate in the industrial organization: Theoretical and applied implications. Journal of Applied Psychology, 65, 96-102.

Zohar, D. (2000). A group-level model of safety climate: Testing the effect of group climate on microaccidents in manufacturing jobs. Journal of Applied Psychology, $85,587-596$.

Zohar, D. (2003). Safety climate: Conceptual and measurement issues. In Quick, J. C., Tetrick, L. E. (Eds). Handbook of occupational health psychology (pp.123142).American Psychological Association, Washington, DC.

Zwick, M. (2004). Elements and Relations: Aspects of scientific metaphysics. Unpublished manuscript, Portland State University. 